Page 1 of 2

$\begin{aligned} & \text { 2. ECN Category } \\ & \text { (mark one) } \\ & \text { Supplemental } \\ & \text { Direct Revision } \\ & \text { Change ECN } \\ & \text { Temporary } \\ & \text { Standby } \\ & \text { Supersedure } \\ & \text { Cancel/Void }\end{aligned}$ []

[]
12a. Modification Work
Yes (fill out Blk.
$12 b$ )
(NA Blks. 12b,
12c, 12d)

13a. Description of Change Complete revision.
3. Originator's Name, Organization, MSIN, and Telephone No.

Dave L. Banning, Requirements

Planning and Support, R2-12, $372-2728$

6. Project Title/No./Work Order No.

Data Quality Objectives for

Tank Farm Waste Compatibility

Program

9. Document Numbers Changed by this ECN (includes sheet no. and rev.)

HNF-SD-WM-DQ0-001, Rev. 2-A

\begin{tabular}{|l|l|}
\hline $\begin{array}{l}\text { 4. USQ Required? } \\
{[] \text { Yes }[X] \text { No }}\end{array}$ & $\begin{array}{l}\text { 5. Date } \\
07 / 01 / 99\end{array}$ \\
N/A & E, Q \\
\hline $\begin{array}{r}\text { 7. Bldg./Sys./Fac. No. } \\
\text { 8. Approval Designator } \\
\text { ECNS: } 623160, \\
635490,644158\end{array}$ & N/A Related ECN No(s). \\
\hline
\end{tabular}

635490,644158

12b. Work Package $12 \mathrm{c}$. Modification Work Complete

12d. Restored to Originat CondiNo.

$\mathrm{N} / \mathrm{A}$

$N / A$

tion (Temp. or Standby ECN only) $\mathrm{N} / \mathrm{A}$

Design Authority/Cog. Engineer Signature \& Date

13b. Design Baseline Document?

Design Authority/Cog. Engineer Signature \& Date

[X] No

14a. Justification (mark one)

Criteria Change [X] Design Improvement [] Environmental [] Facility Deactivation

As-Found

[]

Facilitate const []

Const. Error/Omission []

Design Error/Omission

[]

14b. Justification Details

Total revision was needed to document changes in analytical requirements for waste transfers. 

ECN-654984

\begin{tabular}{|c|c|c|c|c|c|}
\hline $\begin{array}{l}\text { 16. Design } \\
\text { Verification } \\
\text { Required }\end{array}$ & \multicolumn{4}{|c|}{ 17. Cost Impact } & 18. Schedule Impact \\
\hline [] Yes & Additional & $\$$ & Additional & $\$$ & Improvement \\
\hline$[X]$ No & Savings & $\$$ & Savings & $\$$ & Delay \\
\hline
\end{tabular}

19. Change Impact Review: Indicate the related documents (other than the engineering documents identified on side 1 ) that will be affected by the change described in Block 13. Enter the affected document number in Block 20. SDD/DD

Functional Design Criteria

[] Seismic/Stress Analysis

Operating Specification

[]

Stress/Design Report

[] Interface Control Drawing

Criticality Specification

[]

Conceptual Design Report

[]

Equipment Spec.

[]

Const. Spec.

Procurement Spec.

Vendor Information

OM Manual

[]

[]

[]

OM Manual

FSAR/SAR

Safety Equipment List

[]

[]

Radiation Work Permit

Environmental Impact Statement

[]

[]

[]

Environmental Report

[]

Environmental Permit

[]

[]
[]
[]$]$
[]
[]
[]
[]
[]
[]
[]
[]
[]
[]
[]
[]
[]

Tank Calibration Manual

Health Physics Procedure

Spares Multiple Unit Listing

Calibration Procedure

Installation Procedure

Maintenance Procedure

Engineering Procedure

Operating Instruction

Operating Procedure

Operational Safety Requirement

IEFD Drawing

Cell Arrangement Drawing

Essential Material Specification

Fac. Proc. Samp. Schedule

Inspection Plan

Inventory Adjustment Request

Test Procedures/Specification

Component Index

ASME Coded item

Human Factor Consideration

Computer Software

Electric Circuit Schedule

ICRS Procedure

Process Control Manual/Plan

Process Flow Chart

Purchase Requisition

20. Other Affected Documents: (NOTE: Documents (isted below will not be revised by this ECN.) Signatures below indicate that the signing organization has been notified of other affected documents listed below. Document Number/Revision Document Number/Revision

Document Number Revision N/A 


\section{Data Quality Objectives for Tank Farms Waste Compatibility Program}

Dave L. Banning

Lockheed Martin Hanford, Corp., Richland, WA 99352

U.S. Department of Energy Contract DE-AC06-96RL13200

$\begin{array}{lll}\text { EDT/ECN: } & \text { ECN }-654984 & \text { UC: } 2070 \\ \text { Org Code: } & 74 B 10 & \text { CACN/COA: 106635/EI00 } \\ \text { B\&R Code: } & \text { EW } 3120074 & \text { Total Pages: } 124\end{array}$

Key Words: Data Quality Objectives, DQO, DQOS, Tank Farm, Waste Compatibility, Compatibility, Compatibility Program

Abstract: N/A

TRADEMARK DISCLAIMER. Reference herein to any specific commercial product, process, or service by trade name, trademark, manufacturer, or otherwise, does not necessarily constitute or imply its endorsement, recommendation, or favoring by the United States Government or any agency thereof or its contractors or subcontractors.

Printed in the United States of America. To obtain copies of this document, contact: Document Control Services, P.O. Box 950, Mailstop H6-08, Richland WA 99352, Phone (509) 372-2420; Fax (509) 376-4989.

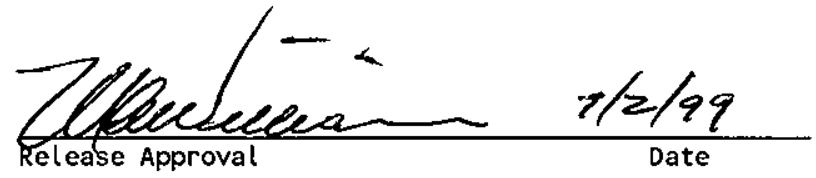

Approved for Public Release 
(2) Title

Data Quality Objectives for Tank Farms Waste Compatibility Program

CHANGE CONTROL RECORO

\begin{tabular}{|c|c|}
\hline Revision & (4) Description of Change - Replace, Add, and Delete Pages \\
\hline 0 & (7) EDT -605330 \\
\hline 1 & Total Revision per ECN-623160 \\
\hline 2 & Incorporate per ECN-635490 \\
\hline $2 a R S$ & Incorporate per ECN-644158 \\
\hline
\end{tabular}

3 RS Incorporate per ECin-654984.

Authorized for Release

\begin{tabular}{l|ll} 
(5) Cog. Engr. & (6) Cog. Mgr. Date \\
\hline
\end{tabular}

\begin{tabular}{l|l}
\hline NA & NA \\
\hline
\end{tabular}

K.D. Fowler W.B. Barton

C.H. Mulkey D.J. Carrell

K.D. Fowler N.W. Kigch

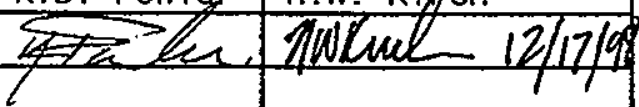

D.L.Banning J.W. Hunt pzBaning 2 (L) $72 / 99$ 


\title{
Data Quality Objectives for Tank Farms Waste Compatibility Program
}

\author{
Charles H. Mulkey
}

Lockheed Martin Hanford Corporation

Mitzi Miller

Larry Jackson

Environmental Quality Management

Date Published

June 1999

Prepared for the U. S. Department of Energy

Assistant Secretary for Environmental Management

Project Hanford Management Contractor for the

U.S. Department of Energy under Contract DE-AC06-96RL13200

Approved for Public Release; Further Dissemination Unlimited 
HNF-SD-WM-DQO-001 Rev. 3

This page intentionally left blank. 
HNF-SD-WM-DQO-001 Rev. 3

\section{EXECUTIVE SUMMARY}

There are 177 waste storage tanks containing over $210,000 \mathrm{~m}^{3}$ (55 million gal) of mixed waste at the Hanford Site. The River Protection Project (RPP) has adopted the data quality objective (DQO) process used by the U.S. Environmental Protection Agency (EPA) (EPA 1994a) and implemented by RPP internal procedure (Banning 1999a) to identify the information and data needed to address safety issues.

This DQO document is based on several documents that provide the technical basis for inputs and decision/action levels used to develop the decision rules that evaluate the transfer of wastes. This DQO process supports various documents, such as sampling and analysis plans, doubleshell tank (DST) waste analysis plans, and tank characterization plans.

This document identifies the type, quality, and quantity of data needed to determine whether transfer of supernatant can be performed safely. The requirements in this document are designed to prevent the mixing of incompatible waste as defined in Washington Administrative Code (WAC) 173-303-040. Waste transfers which meet the requirements contained in this document and the Double-Shell Tank Waste Analysis Plan (Mulkey 1998) are considered to be compatible, and prevent the mixing of incompatible waste.

The scope of this DQO process includes transfers of:

- liquid with $<5 \%$ solids by volume,

- salt well liquids, 
- evaporator slurry with a specific gravity $(\mathrm{SpG})$ of $\leq 1.41$, and

- dilute aqueous waste streams.

The transfer of waste that does not meet the definition of liquid and/or which does not meet the criteria contained in this document will be evaluated on a case-by-case basis and is not part of the scope of this DQO process. Historical information was used to include saltwell liquids and evaporator slurry with $\mathrm{SpG} \leq 1.41$ as part of the scope of this DQO. These two types of liquids/slurry are part of the authorization basis; therefore, these are included in the scope of this DQO.

Only safety issues were considered in this DQO process. Operational parameters are dealt with in operating specifications and other documents. Section 10 provides a summary of sampling and analysis requirements. 


\section{CONTENTS}

$1.0 \quad$ INTRODUCTION AND SCOPE

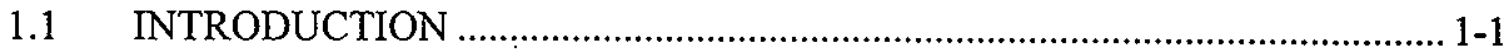

1.2 SCOPE

1.3 ORGANIZATION OF THE DQO …………......................................... 1-2

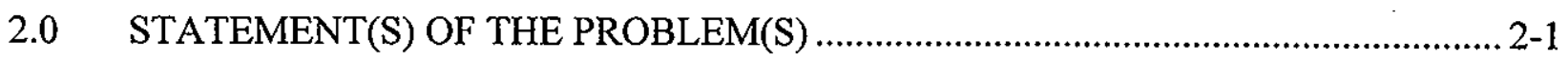

2.1 BACKGROUND ……......................................................................... 2-1

2.2 PROBLEM STATEMENT ........................................................................ 2-1

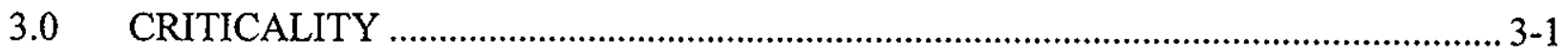

$3.1 \quad$ INTRODUCTION …….........................................................................

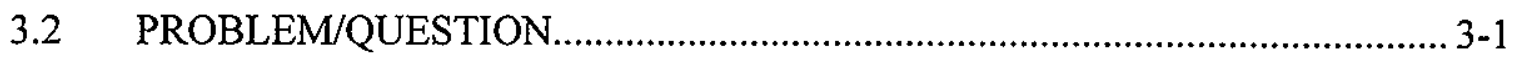

3.3 BOUNDARIES .................................................................................... 3-2

3.4 DATA QUALITY OBJECTIVE DECISION LOGIC AND BASIS FOR

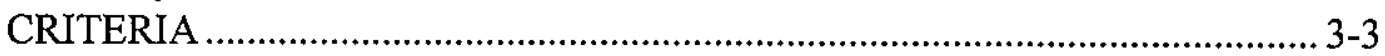

3.4.1 Transfers Between SST, DSTs, and DCRT …….............................. 3-3

3.4.2 Transfers from the DST System to the 242-A Evaporator........................ 3-3

3.4.3 Waste Transfers from Generators Facilities Outside the DST System Into the DST System .................................................................. 3-4

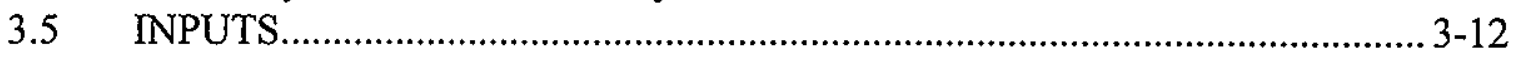

3.6 UNCERTAINTY OR CHANCE OF MAKING INCORRECT

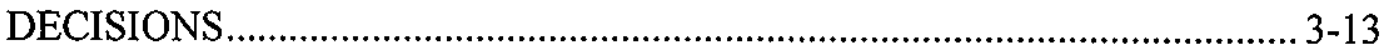

3.7 SAMPLING DESIGN ........................................................................ 3-14

3.7.1 Transfers from Generators to DST System........................................... 3-14

3.7.2 Transfers from the DST System to the 242-A Evaporator...................... 3-16

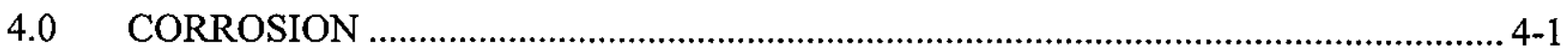

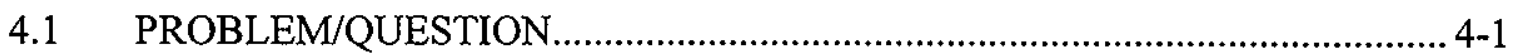

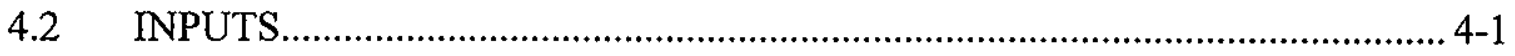

4.2.1 Tank Composition................................................................................. 4-1

4.2.2 Input Basis for Hydroxide, Nitrite, Nitrate ............................................ 4-2

4.2.3 Basis for Temperature and Hydroxide Criteria.......................................... 4-3

4.2.4 Evaluation of Pipe Flushing.................................................................... 4-3

4.2.5 Definition of Caustic Depletion and Deficient ........................................ 4-3

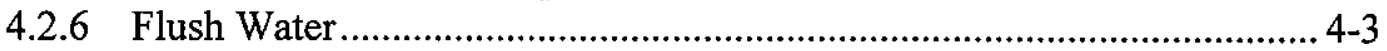

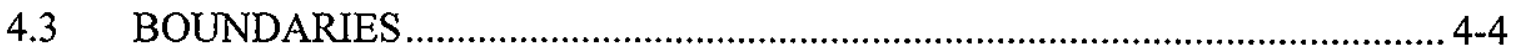

4.4 DECISION RULES/LOGIC .....................................................................

4.4.1 Corrosion Specifications Stated as Decision Rules .................................. 4-4

4.4.2 Transfers from Generators to DSTs ...................................................... 4-5

4.4.3 DST to DST Transfers ....................................................................... 4-9

4.4.4 Double-contained Receiver Tanks ........................................................... 4-9 
4.4.5 242-A Evaporator to DSTs .................................................................. 4-10

4.4.6 Piping Systems................................................................................... 4-10

4.4.7 204-AR Transfer Station .................................................................. 4-10

4.4.8 Catch Tanks Within DST System ....................................................... 4-10

4.5 UNCERTAINTY OR CHANCE OF MAKING INCORRECT DECISION .... 4-10

4.5.1 Consequences of an Incorrect Decision .............................................. 4-11

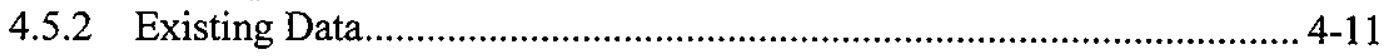

4.5.3 Assessment of the Decision Error ........................................................ 4-12

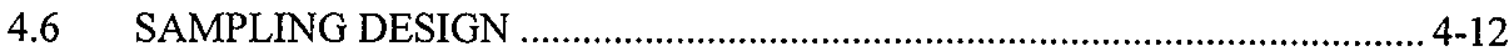

4.6.1 Transfers From DST-to-DST and SST-to-DST .................................... 4-12

4.6.2 Number and Location of Samples Generator-to-DST Transfers ........... 4-18

4.6.3 Double-contained Receiver Tanks ........................................................ 4-19

4.6.4 Transfers Between the 242-A Evaporator and the DST System............ 4-19

4.7 DATA ASSESSMENT ............................................................................. 4-19

$5.0 \quad$ ORGANIC AND ENERGETIC REACTION ……...................................................

$5.1 \quad$ PROBLEMS/QUESTIONS ....................................................................... 5-1

5.1.1 Background for Organic Complexants ………….................................... 5-1

5.1.2 Background for Organic Solvents..................................................... 5-2

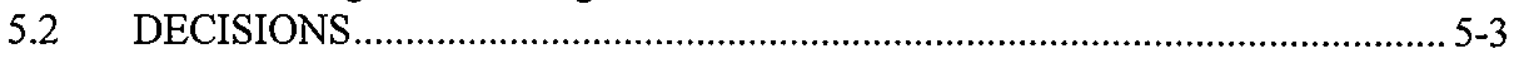

$5.3 \quad$ INPUT AND BOUNDARIES ………………........................................... 5-3

5.3.1 DSTs, DCRT and Catch Tank Bulk Runaway Screening Criteria .......... 5-4

5.3.2 Single-shell Tanks.............................................................................. 5-5

5.3.3 Piping Between DST and SST Systems ……....................................... 5-6

5.3.4 242-A Evaporator Slurry to DST ........................................................ 5-6

5.3.5 Basis for Total Organic Carbon Action Level ......................................... 5-6

5.4 DECISION RULE ................................................................................. 5-7

5.4.1 For all Transfers Made Before OSD and DST Waste Acceptance Plan (Mulkey 1998) Updates ................................................................. 5-7

5.4.2 SST to DST, 242-A Evaporator Slurry to DST, Generator to DST Transfers For Transfers Before OSD and DST Waste Acceptance Plan (Mulkey 1998) Updates ................................................................ 5-7

5.4.3 Decision Logic After OSD and DST Waste Acceptance Plan (Mulkey 1998) Updates .................................................................. 5-8

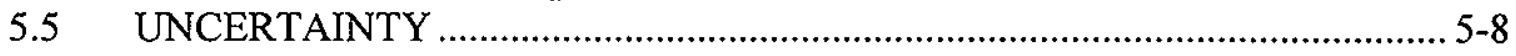

5.6 SAMPLING DESIGN ............................................................................. 5-9

5.6.1 Number and Location of Samples SSTs and DSTs, 242-A

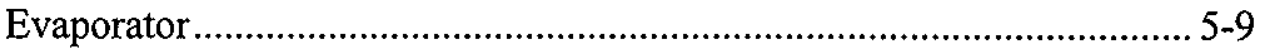

5.6.2 Number and Location of Samples for Generator-to-DST Transfers...... 5-10

5.6.3 Analytes and QC ............................................................................ 5-10

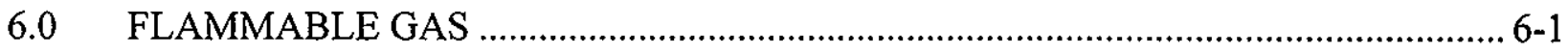

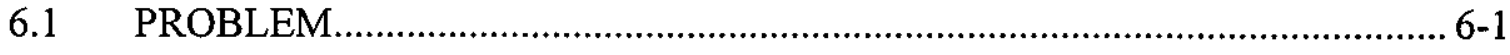




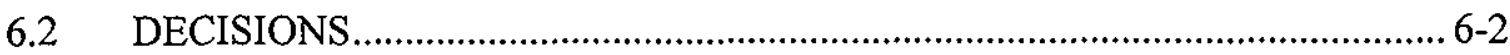

6.2.1 Will Transfer Cause Flammable Gas Release and Retention in the Sending or the Receiving Tank in Excess of $25 \%$ of the Lower

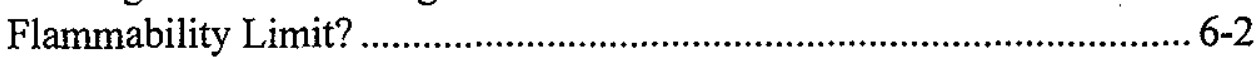

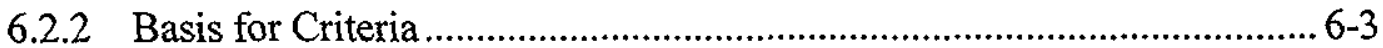

6.2.3 Basis of Specific Gravity Specification ..................................................... 6-7

6.2.4 Retention and Release of Flammable Gas in Pipes ................................ 6-7

6.2.5 Basis for Assessment of Time to Lower Flammable Limit ....................... 6-7

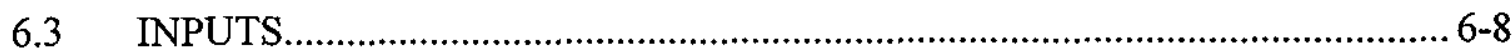

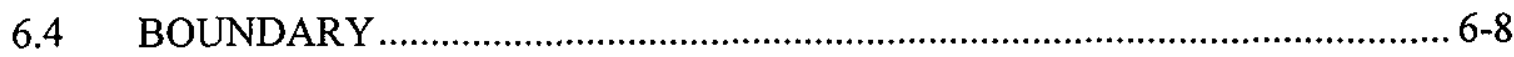

6.5 DECISION RULE ……………............................................................ 6-9

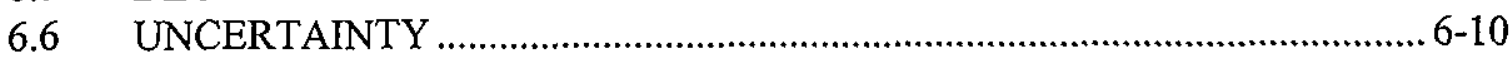

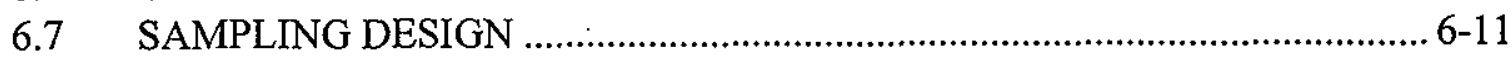

6.7.1 Number and Location of Samples from SSTs and DSTs ..................... 6-11

6.7.2 Number and Location of Samples for the Generators............................. 6-11

6.7.3 Number and Location of Samples for the 242-A Evaporator ................. 6-12

6.7.4 Catch Tanks Within the DST System ................................................. 6-12

6.7.5 Analytes and Quality Control ............................................................ 6-12

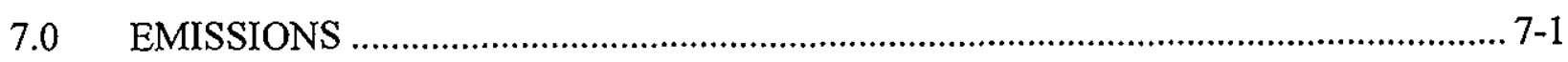

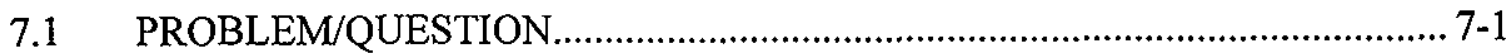

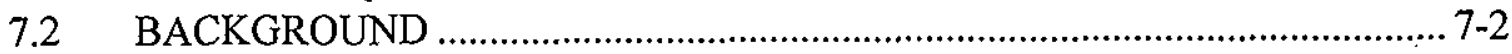

7.2.1 Facility Safety Analysis Report, Basis for Interim Operations, and Safety Analysis ..................................................................................... 7-2

7.2.2 Existing Data................................................................................ 7-4

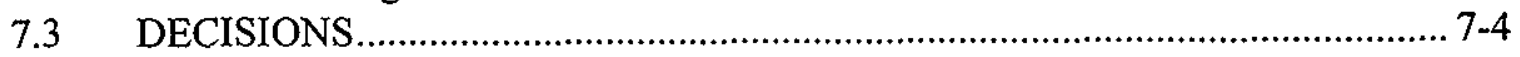

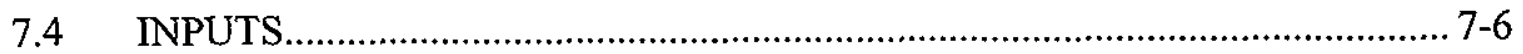

7.4.1 Potential Action Levels..................................................................... 7-7

7.4.2 Evaluation of Gas Evolution Mechanisms........................................... 7-8

7.4.3 Emission Release Mechanisms ......................................................... 7-9

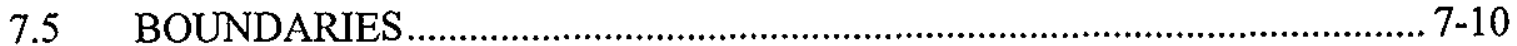

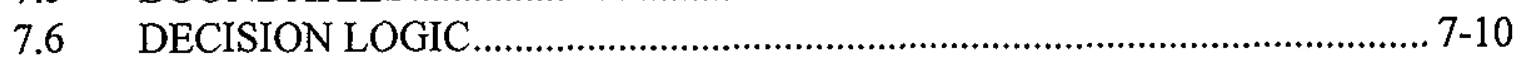

7.7 UNCERTAINTY ................................................................................... 7-11

7.8 SAMPLING AND ANALYSIS DESIGN ……............................................ 7-11

8.0 DETERMINATION OF BASELINE CHARACTERISTICS OF DST RECEIVING SALT WELL PUMPING WASTES ………………................................................... 8-1

9.0 EXCEPTIONS TO THE WASTE SAMPLING AND ANALYTICAL REQUIREMENTS

10.0 SUMMARY OF SAMPLING AND ANALYSIS DESIGN ……............................... 10-1

10.1 INTRODUCTION ................................................................................. 10-1

10.2 GENERAL CHEMICAL COMPATIBILITY CRITERIA ……....................... 10-1 
11.0 ROLE OF WASTE COMPATIBILITY REQUIREMENTS FOR WASTE TRANSFERS CONDUCTED AS PART OF RETRIEVAL/DISPOSAL EFFORTS

12.0 REFERENCES

\section{APPENDICES}

A. SIGNED AGREEMENT BETWEEN DOE AND ECOLOGY A-1

B. EXISTING DATA SUMMARY B-1

\section{FIGURES}

Figure 3-1. Criticality Decision Logic For Transfers From Generators Outside RPP to the DST System

Figure 3-2. Laboratory Detection Limit Decision Logic ................................................... 3-18

Figure 4-1. Decision Logic for Generator to DST Transfer ................................................... 4-6

Figure 4-2. Decision Logic for DST-to-DST or SST-to-DST Transfer ................................. 4-8

Figure 4-3. DST Grab Sampling Decision Logic ........................................................... 4-14

Figure 5-1. Decision for 242-A Evaporator ...................................................................

Figure 5-2. Decision Logic for DST Transfers, SST to DST Transfers, Generator Transfers

Figure 5-3. DST/SST Grab Sample Logic ..................................................................... 5-14

Figure 6-1. Plot of dL/dP Versus Waste Depth * Waste SpG for All DSTs .......................... 6-6

Figure 8-1. Salt Well Receiver Double-Shell Tank Grab Sampling Decision Logic .............. 8-2

\section{TABLES}

Table 3-1. Minimum Neutron Absorber/Plutonium Subcritical Mass Ratio ......................... 3-10

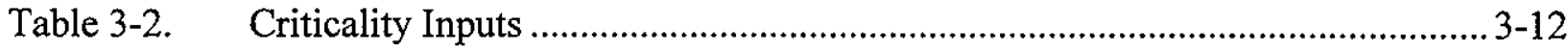

Table 3-3. Consequences of Incorrect Decisions …............................................................ 3-13 
Table 3-4. RDL and QC Criteria for Generator Criticality Evaluation............................... 3-16

Table 4-1. Recommended Detection Limits and Analytical Quality Control..................... 4-18

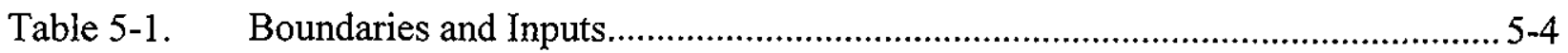

Table 5-2. Summary of Organic Sample Design/Action Limits ...........................................5-9

Table 5-3. Recommended Detection Limits and Analytical QC........................................ 5-11

Table 6-1. Recommended Detection Limits and Analytical Quality Control ..................... 6-12

Table 7-1. Toxic Contaminants and Corresponding Safety Levels and Tank

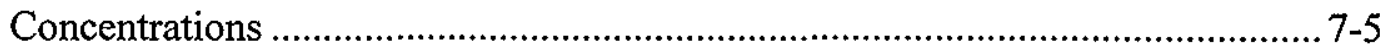

Table 7-2. Analytes That Exceed Limit of Concern in Tank Headspace ................................ 7-6

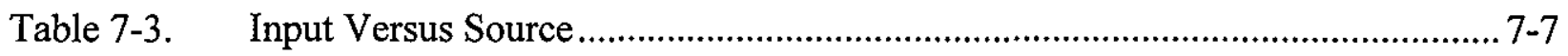

Table 7-4. Level, Exposure Time, and Protective Actions for Ammonia ………………….... 7-8

Table 10-1. Summary of Criteria for SST to DST Transfers ............................................ 10-1

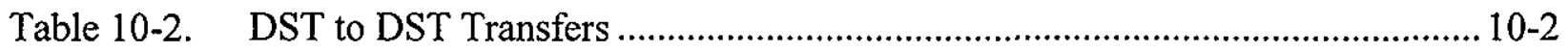

Table 10-3. 242-A Evaporator to DST Transfers ................................................................ 10-2

Table 10-4. DST to 242-A Evaporator Transfers .................................................................. 10-3

Table 10-5. Generator to DST Transfers......................................................................... 10-3

Table 10-6. Catch Tanks Receiving Spills or With Insufficient Process Knowledge............ 10-4 
HNF-SD-WM-DQO-001, Rev. 3

This page intentionally left blank. 


\section{ACRONYMS}

$\begin{array}{ll}\text { AEA } & \text { alpha energy analysis } \\ \text { BIO } & \text { Basis for Interim Operations } \\ \text { CFR } & \text { Code of Federal Regulations } \\ \text { CPS } & \text { Criticality Prevention Specification } \\ \text { DCRT } & \text { double-contained receiver tank } \\ \text { dL/dP } & \text { differential of length versus pressure } \\ \text { DOE } & \text { U.S. Department of Energy } \\ \text { DSC } & \text { differential scanning calorimetry } \\ \text { DST } & \text { double-shill tank } \\ \text { DQO } & \text { data quality objective } \\ \text { Ecology } & \text { Washington State Department of Ecology } \\ \text { EDTA } & \text { Ethylenediaminetetraacetic acid } \\ \text { EPA } & \text { U.S. Environmental Protection Agency } \\ \text { ERPGs } & \text { Emergency Response Planning Guidelines } \\ \text { FG } & \text { flammable gas } \\ \text { FSAR } & \text { Facility Safety Analysis Report } \\ \text { GRE } & \text { gas release event } \\ \text { HEDTA } & \text { Hydroxyethylethylenediaminetriacetic acid } \\ \text { HEPA } & \text { high-efficiency particulate air (filter) } \\ \text { IC } & \text { ion chromatography } \\ \text { ICP/AES } & \text { inductively coupled plasma/atomic emission spectroscopy } \\ \text { IDLH } & \text { immediate danger to life and health } \\ \text { LCS } & \text { laboratory control sample } \\ \text { LEL } & \text { lower explosive limit } \\ \text { LFL } & \text { lower flammability limit } \\ \text { LL } & \text { liquid level } \\ \text { MS } & \text { matrix spike } \\ \text { N/A } & \text { not applicable } \\ \text { ND } & \text { not determined } \\ \text { NL } & \text { not listed } \\ \text { NIOSH } & \text { National Institute of Occupational Safety and Health } \\ \text { OSD } & \text { Operating Specification Document } \\ \text { OSHA } & \text { Occupational Health and Safety Administration } \\ \text { PEL } & \text { permissible exposure limit } \\ \text { PEL-TWA } & \text { permissible exposure limit-time weighted average } \\ \text { QC } & \text { quality control } \\ \text { RPD } & \text { relative percent difference } \\ \text { RPP } & \text { River Protection Project } \\ \text { RSD } & \text { relative standard deviation } \\ \text { SARR } & \text { Safety Analysis Requirements Report } \\ & \end{array}$


SCC stress corrosion cracking

$\mathrm{SpG}$

SRS

SST

specific gravity

TBP

Savannah River Site

TGA

single-shell tank

tributyl phosphate

TLV

thermogravimetric analysis

TOC

threshold limit value

TWINS

total organic carbon

TWRS

wt $\%$

Tank Waste Information Network System

$\mathrm{X}$

Tank Waste Remediation System

weight percent

$\mathrm{X} / \mathrm{Pu}$

neutron absorber

WAC

neutron absorber-to-plutonium mass ratio

Washington Administrative Code 


\subsection{INTRODUCTION AND SCOPE}

\subsection{INTRODUCTION}

There are 177 waste storage tanks containing over $210,000 \mathrm{~m}^{3}$ (55 million gal) of mixed waste at the Hanford Site. The River Protection Project (RPP) has adopted the data quality objective (DQO) process used by the U.S. Environmental Protection Agency (EPA) (EPA 1994a) and implemented by RPP internal procedure (Banning 1999a) to identify the information and data needed to address safety issues.

This DQO document is based on several documents that provide the technical basis for inputs and decision/action levels used to develop the decision rules that evaluate the transfer of wastes. A number of these documents are presently in the process of being revised. This document will need to be revised if there are changes to the technical criteria in these supporting documents. This DQO process supports various documents, such as sampling and analysis plans and doubleshell tank (DST) waste analysis plans.

This document identifies the type, quality, and quantity of data needed to determine whether transfer of supernatant can be performed safely. The requirements in this document are designed to prevent the mixing of incompatible waste as defined in Washington Administrative Code (WAC) 173-303-040. Waste transfers which meet the requirements contained in this document and the Double-Shell Tank Waste Analysis Plan (Mulkey 1998) are considered to be compatible, and prevent the mixing of incompatible waste.

\subsection{SCOPE}

The scope of this DQO process includes transfers of:

- liquid with $<5 \%$ solids by volume,

- $\quad$ salt well liquids,

- 242-A Evaporator slurry with a specific gravity ( $\mathrm{SpG})$ of $\leq 1.41$, and

- dilute aqueous waste streams.

The transfer of waste that does not meet the definition of liquid and/or which does not meet the criteria contained in this document will be evaluated on a case-by-case basis and is not part of the scope of this DQO process. Historical information was used to include saltwell liquids and 242-A Evaporator slurry with $\mathrm{SpG} \leq 1.41$ as part of the scope of this DQO. These two types of liquids/slurry are part of the authorization basis; therefore, these are included in the scope of this DQO. 
Only safety issues were considered in this DQO process. Operational parameters are dealt with in operating specifications and other documents.

No waste transfers are allowed into single-shell tanks (SSTs); therefore, no requirements for transfer of supernatant to SSTs are considered in this document. Transfers within the DST system, from other waste generators, and the 242-A Evaporator into DSTs are included in this DQO process.

One step of the EPA DQO (EPA 1994a) process is the evaluation of uncertainty or decision error. Per the EPA DQO process guidance, in order to assess decision error, one must clearly determine the consequences of making an incorrect decision and the magnitude of the consequences. The consequences of making incorrect decisions are used to assess the concentrations requiring the greatest accuracy and precision. It must be clearly understood that discussions related to uncertainty in this document are not to be used as justification for not meeting the criteria.

\subsection{ORGANIZATION OF THE DQO}

Section 2.0 states the problems on which this DQO is based. Sections 3.0 through 7.0 describe the five major safety issues that must be addressed to assure safe transfers of wastes between tanks. These issues are:

- Criticality

- Corrosion

- Organic and energetic reaction

- Flammable gas (FG)

- Emissions

Section 8.0 discusses the special case of determining the baseline conditions in the DST that will receive the wastes pumped from saltwell pumping operations. Section 9.0 addresses special waste streams that may be added to the receiving tank without prior analysis. Section 10.0 provides a summary of sampling and analysis design as it supports this program. Section 11.0 describes the relationship between retrieval/disposal transfer operations conducted as part of the privatization program and the waste compatibility program. 


\subsection{STATEMENT(S) OF THE PROBLEM(S)}

\subsection{BACKGROUND}

Revision 1 of this document included safety and operational issues. Revision 2 and this revision (Revision 3) of the compatibility DQO process includes only the safety issues. Operational issues are covered in operating specifications, procedures, and other documents. The transfer of waste into the DST system typically involves the commingling of two or more waste streams. Mixing two or more types of waste may cause physical and chemical reactions, some of which could result in safety issues. The goal of this DQO process is to predict and prevent transfers of waste that generate safety hazards.

\section{$2.2 \quad$ PROBLEM STATEMENT}

The purpose of the compatibility DQO process is to establish the information and data needed to support the transfer of waste in a safe manner and to prevent the creation of safety problems. The major question to be addressed is:

Can the waste transfer proceed without resulting in any unsafe conditions or conditions that preclude future disposal/retrieval?

Specific safety hazards are to be based on one or more of the following criteria, taken from waste management regulations (WAC 173-303-395(1)(b), 40 Code of Federal Regulations (CFR) 265.17, and 40 CFR 264.17). A safety hazard will:

- Generate extreme heat or pressure, fire or explosion, or violent reaction;

- Produce uncontrolled toxic mists, fumes, dusts, or gases in sufficient quantities to threaten human health;

- Produce uncontrolled flammable fumes or gases in sufficient quantities to pose a risk of fire or explosions;

- Damage the structural integrity of the device or facility containing the waste; and/or

- Through other like means, threaten human health or the environment. 
During initial meetings to generate Revision 2 of this document, the decision makers from the U.S. Department of Energy (DOE), the Office of River Protection and Washington State Department of Ecology (Ecology), agreed on a list of safety-related questions that is the focus of this DQO process. Appendix A provides a copy of the signed agreement. The questions are related to the following safety issues:

- Retrieval/disposal

- Criticality

- Corrosion

- Organics/energetics

- FG generation

- Chemical reactions generating emissions or uncontrolled reactions. 


\subsection{CRITICALITY}

\subsection{INTRODUCTION}

The seven-step EPA DQO (EPA 1994a) process was used. For clarity and brevity, the order of information presented for criticality has been altered. The DQO steps are presented in the order used in the text of this section with the traditional EPA DQO step sequence number in parentheses.

- Problem/Question (Step 1)

- General Boundaries (Step 4)

- Decision Logic, Action Levels, and Basis for the Action Levels or Decision Criteria (Steps 2 and 5)

- Inputs (Step 3)

- Consequences of Making an Incorrect Decision (Step 6 Uncertainty)

- Sampling and Analysis Design (Step 7).

\subsection{PROBLEM/QUESTION}

The decision makers presented the following question related to criticality conditions during transfer of waste in Tank Farms. The logic addresses the solution to the question:

Will the concentration of fissile material in the resulting or receiving tank(s) be sufficient to cause a criticality hazard?

Addressing this problem will ensure that operations in the Tank Farms will be subcritical.

\section{Background}

The following four predominant factors affect criticality:

- Concentration of the fissile material in the supernatant and in the solids

- The ratio of the fissionable material to neutron absorbers

- Geometry and neutron moderation

- Chemistry, particularly pH. 
The concentration of the fissionable material is affected by the solubility of the plutonium and the neutron absorbers at a given $\mathrm{pH}$. Fissionable material is expressed as plutonium equivalents and includes plutonium-239 and uranium-233/235. All references to plutonium concentration are calculated as plutonium equivalents. Plutonium-240 is nonfissile in a thermal neutron environment and is a neutron absorber; therefore, if plutonium 239/240 are reported simultaneously, assuming the material is all plutonium 239 is conservative. Americium-241 is not included because it cannot become critical in an over-moderated system. The quantity of water and other hydrogen containing compounds in tank waste is greater than the required amount for optimum moderation; therefore, the waste is "over-moderated."

The DOE and the U.S. Nuclear Regulatory Commission require the use of the doublecontingency principle. The controls for Tank Farms that satisfy the double-contingency principle as described in Criticality Safety of Double Shell Waste Storage Tanks (Rogers 1994). Credit was not taken for over moderation and large tank size even though these are contingencies that would reduce the potential for criticality. The double-contingency principle is as follows:

"Process designs shall incorporate sufficient factors of safety to require at least two unlikely, independent, and concurrent changes in process conditions before a criticality accident is possible. Protection shall be provided by either: (a) the control of two independent process parameters (which is the preferred approach, if practical), or (b) a system of multiple (at least two) controls on a single parameter. The number of controls required upon a single controlled process parameter shall be based upon control reliability and any features that mitigate the consequences of control failure. In all cases, no single credible event or failure shall result in the potential for a criticality accident." (DOE Order 420.1 [DOE 1997].)

\subsection{BOUNDARIES}

Current operations apply to three types of transfers: (1) transfers of the current contents from existing DST, SST, and double-contained receiver tank (DRCT) inventory, (2) transfers from outside the tank system and (3) transfers to the 242-A Evaporator. Transfers from outside sources include material received from generators that are not part of RPP.

Transfers of existing inventory within the SSTs, DSTs and double-contained receiver tanks (DCRTs) require no new analytical information with regard to the criticality criteria because all tanks are currently classified as safe with regard to criticality. A team of senior technical personnel reviewed the technical basis for the nuclear criticality safety of waste stored in Hanford Site underground tanks. The team concluded that, under current plutonium inventories and operating conditions, a nuclear criticality accident is incredible in any of the Hanford Site SSTs, 
DSTs or DCRTs (Bratzel et al, 1996). These facilities are currently managed as Limited Control Facilities as described in Cox et al. (1997), Chapter 5.7, Rev. 1A. The technical basis for the management of tanks under this procedure is found in a series of criticality safety evaluation documents. They are:

- Criticality Safety of Double Shell Waste Storage Tanks (Rogers 1994)

- Tank Farm Nuclear Criticality Review (Bratzel et al. 1996)

These evaluations and the existing procedures for operating Limited Control Facilities are sufficient to permit transfers of existing inventory without further analytical data. Therefore, this DQO does not apply to transfers of existing inventory between tanks in the SST and DST systems.

\subsection{DATA QUALITY OBJECTIVE DECISION LOGIC AND BASIS FOR CRITERIA}

\subsubsection{Transfers Between SST, DSTs, and DCRT}

Requirements on $\mathrm{pH}$, plutonium concentration and the subcritical mass ratio of neutron absorbers to plutonium applied to discharges from a waste generating facility outside the RPP system do not apply to transfers made between Tank Farm facilities or transfers from the 242-A Evaporator facility campaign. Transfers from the DST system to the 242-A Evaporator are discussed below.

The technical basis for this is outlined in Bratzel et al. (1996). The following information is from the aforementioned document and summarizes the findings of the technical experts.

A team of senior technical personnel, whose expertise covered all relevant aspects of fissile materials chemistry and physics, reviewed the technical basis for the nuclear criticality safety of waste stored in underground tanks at the Hanford Site. This report documents significant technical bases and findings of the senior review team. The team concluded that, under plutonium inventories and operating conditions, a nuclear criticality accident is incredible in any of the Hanford Site SSTs, DSTs, or DCRTs (Bratzel et al. 1996).

\subsubsection{Transfers from the DST System to the 242-A Evaporator}

Decision: Is the concentration of plutonium in the 242-A Evaporator feed less than $0.005 \mathrm{~g} / \mathrm{L}$ $(0.019 \mathrm{~g} / \mathrm{gal}) ?$

All of the waste streams that were sent to the Hanford Site underground waste tanks contained only small amounts of plutonium. Furthermore, the concentrations of various neutron absorbers in the waste streams were consistently high. A team of senior technical personnel has reviewed 
the technical basis for the nuclear criticality safety of waste stored in Hanford underground tanks. The team concluded that, under current plutonium inventories and operating conditions, a nuclear criticality accident is incredible in any Hanford Site SST, DST or DCRT (Bratzel et al. 1996).

The DST system is classified as a "Limited Control" facility (HNF-PRO-334 [PHMC 1997a]). This classification is based on the DST system containing a fissile material inventory in excess of 177 grams (one third of a minimum critical mass) and an evaluation which demonstrates that a criticality is prevented by the form and distribution of the fissile material. Wastes are discharged from generating facilities with a low concentration of plutonium and a high ratio of solids as necessary to ensure a high degree of subcriticality. The alkalinity of waste streams is maintained high to ensure insolubility of plutonium and waste solids.

Before acceptance into the DST system, each waste stream is assessed for compatability with the waste in the receiving tank. The $\mathrm{pH}$, plutonium concentration and the absorber-to-plutonium ratio (as required) are evaluated against criticality prevention limits (LMHC 1998). Compliance with the Criticality Prevention Specification (CPS) assures that the form and distribution of fissile material in the receiving tank is consistent with the basis for the facility classification.

Plutonium that will be discharged to the DST system will have been subjected to acid dissolution followed by caustic coprecipitation with heavy metal neutron absorbers. As a result of the processing, the plutonium and neutron absorbers formed agglomerates with subcritical mass ratios. For waste from the Plutonium Finishing Plant, iron was added to the waste to ensure dilution of plutonium in the solids.

Submicron particle size is an important result of the acid dilution and caustic precipitation process. The small particle size limits segregation of plutonium in the DST system caused by differences in settling velocities.

The composition of each waste stream entering the DST system is documented on a Waste Stream Profile Sheet as required by the DST Waste Analysis Plan (HNF-SD-WM-EV-053 [Mulkey 1998]). The bounding values from the Waste Stream Profile Sheet are used to assess waste compatibility. Prior to discharge into the DST system, new and revised Waste Stream Profile Sheets from non-Tank Farm waste generators are reviewed by Nuclear Safety and Licensing. The review is necessary to ensure that the decomposition of the waste steam is/remains in compliance with the boundaries of the evaluation established in the Criticality Safety Evaluation Report (Rogers 1994).

\subsubsection{Waste Transfers from Generators Facilities Outside the DST System Into the DST System}


Figure 3-1 presents the decision logic discussed for transfers into the DST system. Each decision is discussed along with the subsequent actions to be taken and the basis of the decision.

\section{Decision 1: Is the plutonium equivalent $\leq 0.001 \mathrm{~g} / \mathrm{L}$ ?}

The plutonium equivalent is averaged over the entire volume of the transferred waste batch. If the plutonium is $\leq 0.001 \mathrm{~g} / \mathrm{L}$ averaged over the entire volume of batch and the $\mathrm{pH}$ is $\geq 8$, the transfer is allowed. The limit of $0.001 \mathrm{~g} / \mathrm{L}$ acts as a screening limit; below this limit absorber to plutonium ratios analysis is not required per the logic of Section 3.4.3.1.

3.4.3.1 Basis of Decision Criteria. The basis for the criteria is found in the Criticality Prevention Specifications for Tank Farms (PHMC 1997d), and is explained in the following paragraphs. The basis for the limit is focused on the control of the concentration of the plutonium equivalent in the tank geometry, historical data/process knowledge, and solubility of plutonium and the absorbers at a $\mathrm{pH} \geq 8$. When the plutonium equivalent is below $0.001 \mathrm{~g} / \mathrm{L}$, a criticality event cannot occur. Material, such as water from runoff, are well below the $0.001 \mathrm{~g} / \mathrm{L}$ and cannot become critical.

The subcritical concentration limit in dry, conservative, waste model solids as established in An Analytical Model for Evaluating Subcritical Limits for Waste in Hanford Site Storage Tanks (Rogers 1993) is $2.6 \mathrm{~g} \mathrm{Pu} / \mathrm{L}$ of solids. The generators of waste lack the instrumentation to measure the quantity of solids in waste transferred to Tank Farms. Therefore, limits on plutonium in transferred waste batches must ensure that the plutonium concentration in the tank does not exceed $2.6 \mathrm{~g} \mathrm{Pu} / \mathrm{L}$ of solids, and assessment of compliance must be obtainable. HNF procedures (HNF-PRO-334, -537, and 540) (PHMC 1997a, 1997b and 1997d), require that "When mass control is used and maintained only by administrative controls, the fraction of critical mass set as the operational limit will be $\leq 0.45$, unless double batching is not credible." Double batching is a safety factor that assumes that the total mass transferred or processed is double the amount actually allowed.

Therefore, the concentration of plutonium at any location in a tank must be controlled to $<1.17 \mathrm{~g} \mathrm{Pu} / \mathrm{L}$ of solids. The historical transfer requirement for plutonium is $0.013 \mathrm{~g} \mathrm{Pu} / \mathrm{L}$ of the mixture of solids and liquids and the highest concentration of plutonium found in a sample analysis is $0.35 \mathrm{~g} \mathrm{Pu} / \mathrm{L}$ of tank solids, so the maximum concentration increase has been defined as $0.35 / 0.013=27$ times the actual amount found in the tank. Therefore, if the plutonium concentration in the tank waste increases by the nominal amount of 27 times, the concentration of plutonium in transferred batches should be controlled to $1.17 / 27=0.04 \mathrm{~g} \mathrm{Pu} / \mathrm{L}$ of solid/liquid mixture. The basis for interim operation (BIO) supports the use of $0.04 \mathrm{~g} \mathrm{Pu} / \mathrm{L}$; however the CPS requires $0.033 \mathrm{~g} \mathrm{Pu} / \mathrm{L}$. Because the CPS is more conservative, $0.033 \mathrm{~g} \mathrm{Pu} / \mathrm{L}$, this limit is used in this document. When the CPS is updated, $0.04 \mathrm{~g} \mathrm{Pu} / \mathrm{L}$ will be the allowed limit (CPSPHMC 1997d). 
$\frac{\text { Highest Pu equivalent found tank }}{\text { Historical requirement for Pu equivalent }}=\frac{0.35 \mathrm{gPu} / \mathrm{L}}{0.013 \mathrm{gPu} / \mathrm{L}}=27$ 
Figure 3-1. Criticality Decision Logic For Transfers From Generators Outside RPP to the DST System

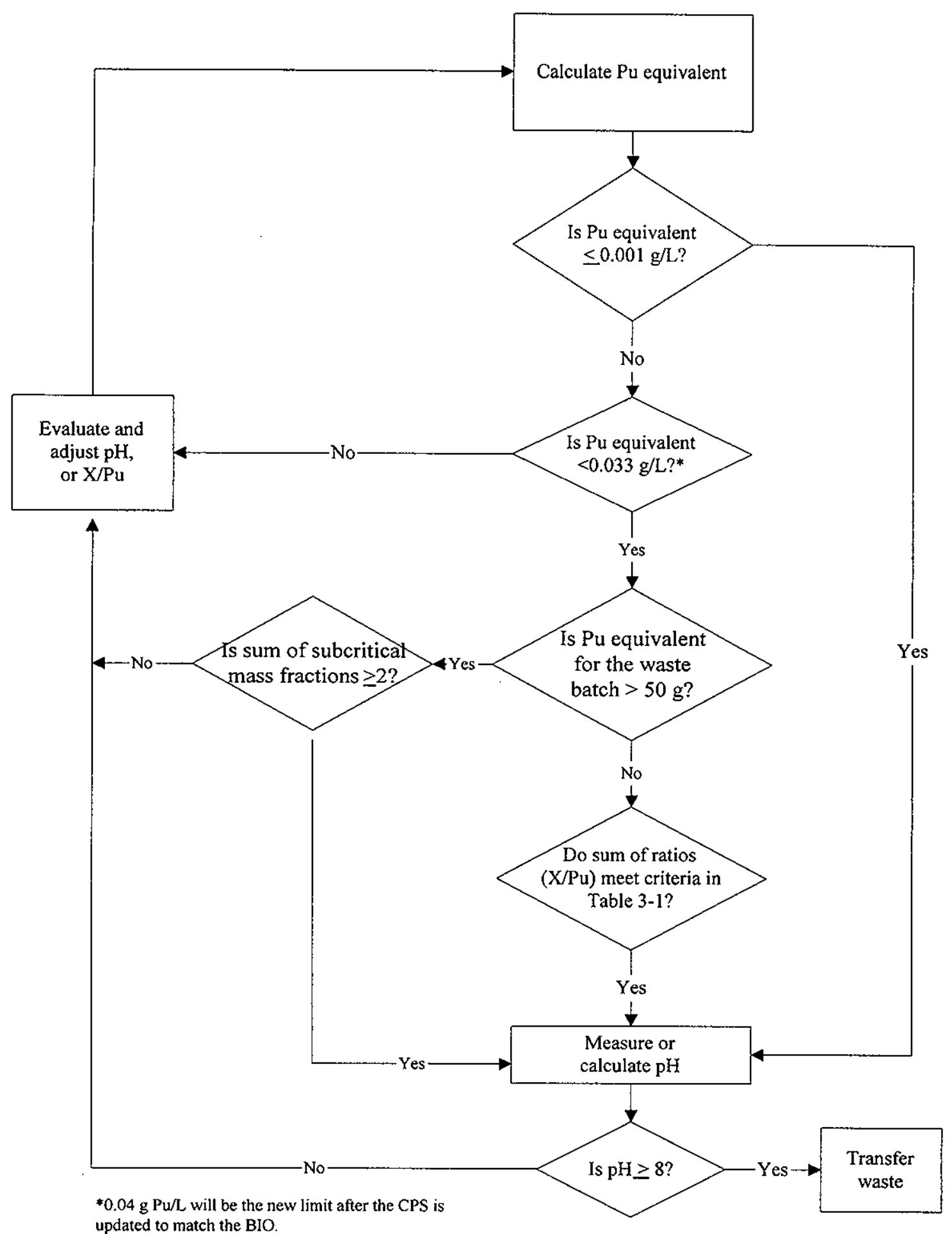


The $0.001 \mathrm{~g} \mathrm{Pu} / \mathrm{L}$ is $59 \%$ less than the upper bound solubility for plutonium in an alkaline salt solution of $0.0017 \mathrm{~g} \mathrm{Pu} / \mathrm{L}$. Any alkaline solution that has $>0.0017 \mathrm{~g} \mathrm{Pu} / \mathrm{L}$ will precipitate the plutonium and compliance with the $\mathrm{X} / \mathrm{Pu}$ ratios shown in Table 3-1 will ensure the plutonium is intimately associated with neutron absorbers. Any alkaline solution with $<0.0017 \mathrm{~g} \mathrm{Pu} / \mathrm{L}$ may easily retain the plutonium as dissolved material and the addition of metals will not provide a dilution. The value of $0.001 \mathrm{~g} \mathrm{Pu} / \mathrm{L}$ is an arbitrary value that is less than the solubility limit. The value of $0.001 \mathrm{~g} \mathrm{Pu} / \mathrm{L}$ is used in combination with the $\mathrm{pH}$ to quickly identify liquids that do not require additional analyses.

$$
\frac{\text { Concentration limit at any point inside the tank }}{27}=0.04 \mathrm{~g} \mathrm{Pu} / \mathrm{L} \text { equivalent }
$$

The concentration of the plutonium is $\mathrm{pH}$-dependent. The solubility in the liquid phase will decrease as the $\mathrm{pH}$ increases, causing more plutonium to precipitate. The solubility in the liquid will increase if the $\mathrm{pH}$ decreases. Because metal absorbers are a precipitate in alkaline solutions, their addition will not decrease the dissolved plutonium concentration, which is $<0.001 \mathrm{~g} \mathrm{Pu} / \mathrm{L}$. Therefore, requiring subcritical mass ratios of absorber to dissolved plutonium in solution is not physically possible.

3.4.3.2 Consequence of Making an Incorrect Decision. The evaluation of the consequence of making an incorrect decision is to assist in establishing the accuracy and precision needed for the analysis. Fewer significant consequences do not mean that the limit is not applicable or that the limit is not required. The $0.001 \mathrm{~g} \mathrm{Pu} / \mathrm{L}$ is based both on the solubility limit and on the adjustment of the $\mathrm{pH}$. Additionally, the actual limit is $0.04 \mathrm{~g} / \mathrm{L}$ plutonium equivalent, which is 40 times higher than the screening limit of $0.001 \mathrm{~g} \mathrm{Pu} / \mathrm{L}$. The consequence of making an incorrect decision at these low concentrations or $\mathrm{pH}$, is not likely to create a criticality event.

\section{Decision 2: Is the plutonium equivalent $<0.033 \mathrm{~g} / \mathrm{L}(0.125 \mathrm{~g} / \mathrm{gal})$ ?}

The plutonium concentration is averaged over the entire volume of the transferred waste batch. If the concentration is $\leq 0.033 \mathrm{~g} / \mathrm{L}(0.125 \mathrm{~g} / \mathrm{gal})$, the $\mathrm{pH}$ is $\geq 8$, and one of the absorber-toplutonium subcritical mass ratios are within the limits in Table $3-1$, the waste can be safely transferred. If the concentration is $>0.033 \mathrm{~g} / \mathrm{L}(0.125 \mathrm{~g} / \mathrm{gal})$, the concentration of the plutonium equivalent must be decreased to provide assurance that one of the ratios of plutonium-to-neutron absorbers is above the ratio in Table 3-1.

3.4.3.3 Basis for Decision Criteria. The basis is discussed in Section 3.4.3.1.

3.4.3.4 Consequence of Making an Incorrect Decision. The evaluation of the consequence of making an incorrect decision is to assist in the evaluation of the accuracy and precision needed for the analysis. Fewer significant consequences do not mean that the limit is not applicable or 
that the limit is not required. The plutonium concentration limit is based on several conservative assumptions.

First, the subcritical limit plutonium concentration of $2.6 \mathrm{~g} \mathrm{Pu} / \mathrm{L}$ of solids is based on the waste composition used to calculate the value containing the highest concentration of poor neutron absorbers and reflectors, and the lowest concentration of adequate neutron absorbers from 28 waste tank samples. A measure of nuclear reactivity is the infinite multiplication factor called k-infinity. As k-infinity approaches one (the critical mass concentration), geometry and optimum moderation are approached. The evaluation of k-infinity takes into account the effect of water as a moderator. The water content of the waste composition was added as an independent variable in the conservative waste model. The most reactive composition of the model is the point where the water goes to zero. The subcritical plutonium concentration limit is determined when the $\mathrm{k}$-infinity $=0.95$ with a $95 \%$ confidence interval (CI). The intent of the model is to provide confidence that the concentration of the plutonium equivalent is well below criticality limits.

Second, part of the basis for the limit is $0.35 \mathrm{~g} \mathrm{Pu} / \mathrm{L}$, which is the highest value for any sample of solid waste in the tanks. Thousands of samples have been taken. Using the highest sample suggests that the nominal concentrating factor is actually $<27$. Therefore, the limit of $0.04 \mathrm{~g}$ $\mathrm{Pu} / \mathrm{L}$ includes a minimum safety factor of 27 . The $0.033 \mathrm{~g} \mathrm{Pu} / \mathrm{L}$ in the CPS is more conservative than the $0.04 \mathrm{~g} \mathrm{Pu} / \mathrm{L}$.

As a violation of the limit becomes more significant, the consequences to an external generator are of concern because a criticality is more likely in the confinement of the generator's holdup tank than in the waste tank where the solids can spread out and dilute the plutonium. The consequences for Tank Farms become a concern only after many batches of high concentration plutonium waste are received.

3.4.3.5 Boundaries. All transfers from sources outside the Tank Farm system must comply with the $0.033 \mathrm{~g} \mathrm{Pu} / \mathrm{L}$ transfer limits. Compliance of transfers from the generators external to tanks farms must be based on sampling and analysis, and data supplied as part of the waste acceptance form package submitted for approval by Tank Farms to show that waste meets waste acceptance criteria.

\section{Decisions 3a, b, and c:}

a) Is the neutron absorber (X) to $\mathrm{X} / \mathrm{Pu}$ of the combined wastes in the tank after waste transfer greater than or at least one of the minimum subcritical ratios shown in Table 3-1?

b) Does the plutonium equivalent content of a single waste batch exceed $50 \mathrm{~g}$ ?

c) If so, is the sum of the component subcritical mass fractions greater than or equal to two? 
The sum is calculated by the following equation:

$$
\text { Sum of }\left[\left(\mathrm{X}_{\mathrm{i}} / \mathrm{Pu}\right)_{\text {actual }} /\left(\mathrm{X}_{\mathrm{i}} / \mathrm{Pu}\right)_{\text {subcritical }}\right] \geq 2
$$

where:

$$
\mathrm{X}=\text { total uranium, chromium, iron, manganese and nickel. }
$$

This condition is not required if the plutonium concentration is $\leq 0.001 \mathrm{~g} \mathrm{Pu} / \mathrm{L}$ in the transferred waste.

Table 3-1. Minimum Neutron Absorber/Plutonium

Subcritical Mass Ratio

\begin{tabular}{|l|c|}
\hline \multicolumn{1}{|c|}{$\begin{array}{c}\text { Neutron Absorber } \\
(\mathbf{X})\end{array}$} & $\begin{array}{c}\text { Minimum Neutron Absorber/Plutonium } \\
\text { Subcritical Mass Ratio } \\
(\mathbf{X} / \mathbf{P u})\end{array}$ \\
\hline Total uranium (U) & 770 \\
\hline Iron (Fe) & 160 \\
\hline Manganese (Mn) & 32 \\
\hline Nickel (Ni) & 105 \\
\hline Chromium (Cr) & 135 \\
\hline
\end{tabular}

3.4.3.6 Basis for Decision. The above measurements apply to the supernate. The $\mathrm{pH}$ requirements result in precipitation of the plutonium into the solids. Based on this fact, the evaluation of the neutron absorber/plutonium subcritical mass ratio was based on the solids. The subcritical limit for the plutonium concentration was determined to be $2.6 \mathrm{~g} \mathrm{Pu} / \mathrm{L}$ of solid waste in the DST tanks. Taken by itself, the solid material, which provides for the dilution of plutonium to $2.6 \mathrm{~g} \mathrm{Pu} / \mathrm{L}$, can be any solid material. There are solid materials in nature that could be used to calculate a subcritical limit for the plutonium concentration, which is $<2.6 \mathrm{~g} \mathrm{Pu} / \mathrm{L}$. The subcritical ratios are a ratio of the mass of the absorber to plutonium, such that for any given quantity or volume, the waste is inherently subcritical when the ratio is exceeded. Full compliance will ensure the plutonium is diluted with solids containing sufficient neutron absorption to remain subcritical (Bratzel et al. 1996).

3.4.3.7 Consequence of Making an Incorrect Decision. Consequences are used to assess the concentration levels that require the greatest accuracy. Only one of the subcritical mass ratios needs to be satisfied to ensure that the waste is subcritical. The mixing of plutonium with the solids currently in the waste tanks will also ensure some dilution. The subcritical mass ratios are only necessary when the concentration of plutonium exceeds $2.6 \mathrm{~g} \mathrm{Pu} / \mathrm{L}$ of solids, because plutonium concentrations $<2.6 \mathrm{~g} \mathrm{Pu} / \mathrm{L}$ are subcritical, regardless of the quantity or geometry. 
Theoretically, if plutonium is the only constituent of a waste batch, the precipitated plutonium will settle into a flat slab at the bottom of the tank or on top of solids currently in the tank. Because the waste tanks are very large, the flat, plutonium-rich slab will be very thin, which is a critically safe geometry. Criticality safety is a concern when enough batches of only plutonium are transferred such that the slab is at least $18 \mathrm{~cm}$ (7 in.) deep and approaches the "minimum critical" areal density of $240 \mathrm{~g} \mathrm{Pu} / \mathrm{ft}^{2}$. The quantity of plutonium required to achieve the minimum critical areal density is $1,056 \mathrm{~kg}(2,328 \mathrm{lb})$, which is equal to the upper bound estimate of the total quantity of plutonium sent to all of the Tank Farms.

3.4.3.8 Boundaries. The only boundary that must fully comply with the decision is the waste generator, but only if the plutonium concentration of a waste batch exceeds $0.001 \mathrm{~g} \mathrm{Pu} / \mathrm{L}$. At or below this concentration of plutonium, the waste is subcritical regardless of the quantity or geometry.

The metals shown in Table 3-1 precipitate as oxyhydroxides in alkaline solutions similar to tank waste, so the addition of metals will not add to the dilution of plutonium that is suspended or dissolved in solution. Various supernatant constituents, like carbonates, organic, and inorganic complexants, may increase the suspension or solubility of plutonium in the solution, but will also increase the quantity of the other metal oxyhydroxides. The tracking of plutonium requires knowledge of the plutonium concentration in these supernatants. Based on discussions presented in Section 3.4.3.1 of this document, the extensive tracking of these other complexed metals is considered unnecessary because the concentration of plutonium cannot reach the subcritical plutonium concentration limit.

\section{Decision 4: Is the $\mathrm{pH} \geq 8$ ?}

Before the waste is sent, the $\mathrm{pH}$ may be adjusted and measured. For high ionic strength solutions $(\mathrm{pH}>12), \mathrm{pH}$ may be substantiated by hydroxide concentration according to the corrosion specification criteria as stated in Section 4.0 of this document.

3.4.3.9 Basis of Decision Criteria. The Facility Safety Analysis Report (FSAR), BIO, and Criticality Safety Evaluation Reports, which establish the minimum critical conditions of the waste in all tanks, begin with the premise that the plutonium is a precipitate in the alkaline salt solutions. The intent of this control is to ensure the plutonium resides primarily in the solid phase of the waste. In reality, all Tank Farms' criticality safety limits and controls are based on this initial condition. DOE Order 420.1 (DOE 1997) requires that a review of the program ensures that process operations have not been altered, such that the applicability of the evaluation has been compromised. The subcritical limit concentration of plutonium evaluated in dry, conservative waste model solids is $2.6 \mathrm{~g} \mathrm{Pu} / \mathrm{L}$ of solids, as opposed to a subcritical limit concentration in an idealized plutonium-water system of $7.2 \mathrm{~g} \mathrm{Pu} / \mathrm{L}$. The chemistry of plutonium in an alkaline salt solution is discussed further in Serne et al. (1996) and Whyatt et al. (1996). 
3.4.3.10 Consequence of Making an Incorrect Decision. The consequences are used to assess the appropriate levels of accuracy and precision needed for a given concentration range. The alkalinity of the waste is a secondary control since violation cannot, by itself, create a criticality hazard. The parameters necessary for a criticality include plutonium concentration and plutonium mass in a geometry, which is optimum for the given mass and concentration. A violation of the $\mathrm{pH}$ requirement will increase the solubility of plutonium in the supernatant, which has a higher minimum critical concentration, but it will not necessarily mobilize the plutonium into a condition favorable for criticality. Violation of $\mathrm{pH}$ is only one criterion affecting criticality. The concentration of neutron absorbers and geometry also affect criticality.

3.4.3.11 Boundaries. All boundary transfers from sources outside the Tank Farm system must comply with the $\mathrm{pH}$ requirement.

The 242-A Evaporator documents the forthcoming waste treatment campaign in a precampaign process evaluation plan. In this plan, the $\mathrm{pH}$ of the feed tank measured prior to processing the waste is documented and reviewed to assure it meets criticality criteria.

\subsection{INPUTS}

The following data and information inputs are required to address the previous decisions. Table 3-2 lists the decisions by the numbers corresponding to Section 3.4 and the associated inputs.

Table 3-2. Criticality Inputs

\begin{tabular}{|c|c|}
\hline Decision & Inputs \\
\hline \multicolumn{2}{|c|}{ Transfers from Generators Outside RPP to DST System } \\
\hline 1. Is plutonium equivalent $\leq 0.001 \mathrm{~g} / \mathrm{L}$ ? & ${ }^{239} \mathrm{Pu}$ or total plutonium, total $\mathrm{U}$ or ${ }^{233 / 235} \mathrm{U}$ \\
\hline 2. $\quad$ Is plutonium equivalent $\leq 0.033 \mathrm{~g} / \mathrm{L}$ ? & ${ }^{239} \mathrm{Pu}$ or total plutonium, total $\mathrm{U}$ or ${ }^{233 / 235} \mathrm{U}$ \\
\hline $\begin{array}{l}\text { 3a. Is the neutron absorber }(\mathrm{X}) \text { to } \mathrm{X} / \mathrm{Pu} \text { of the } \\
\text { combined wastes in the tank after waste transfer } \\
\text { greater than or at least one of the minimum } \\
\text { subcritical ratios shown in Table 3-1? }\end{array}$ & $\begin{array}{l}\text { Uranium, chromium }(\mathrm{Cr}) \text {, iron }(\mathrm{Fe}) \text {, manganese }(\mathrm{Mn}) \text {, } \\
\text { nickel }(\mathrm{Ni})\end{array}$ \\
\hline $\begin{array}{l}\text { 3b. Does the plutonium equivalent content of a single } \\
\text { waste batch exceed } 50 \mathrm{~g} \text { ? }\end{array}$ & \\
\hline $\begin{array}{l}\text { 3c. If so, is the sum of the component subcritical } \\
\text { mass fractions greater than or equal to two? }\end{array}$ & \\
\hline 4. $\quad$ Is $\mathrm{pH} \geq 8$ ? & $\mathrm{pH}$ \\
\hline \multicolumn{2}{|c|}{ Transfers to 242-A Evaporator } \\
\hline $\begin{array}{l}\text { Is the concentration of plutonium in the } 242-\mathrm{A} \\
\text { Evaporator feed less than } 0.005 \mathrm{~g} / \mathrm{L}(0.019 \mathrm{~g} / \mathrm{gal}) \text { ? }\end{array}$ & Total plutonium or ${ }^{239} \mathrm{Pu}$ \\
\hline
\end{tabular}


Plutonium Equivalent. Total uranium and plutonium or the specific isotopes consisting of plutonium-239, and uranium-233/235 are used in the calculation. Use of the total plutonium is conservative because this assumes more isotopes are fissionable than is actually the case. Some plutonium-240 is not fissionable. Based on isotopic abundance, uranium-233 would be undetectable; therefore, measurement is not needed. Hanford is no longer dissolving fuel. The fuel processed in the past was typically below $1 \%$ enrichment in uranium-235; therefore, total uranium analysis is sufficient to assess the criticality. The subcritical mass ratio of uranium to plutonium was calculated assuming the uranium has a natural enrichment of uranium-235 (0.72 weight percent [wt\%]); therefore, all uranium- 235 in excess of $0.72 \mathrm{wt} \%$ of total uranium is assumed to be equivalent to plutonium-239 on a gram-per-gram basis.

For the 242-A Evaporator analysis only, when the uranium isotopic analysis is unavailable, a uranium enrichment of $0.82 \mathrm{wt} \%$ may be used. This is based on the highest enriched fuel debris discharged to the Tank Farms from $\mathrm{K}$ Basins containing N-reactor fuel.

\subsection{UNCERTAINTY OR CHANCE OF MAKING INCORRECT DECISIONS}

The consequences of making incorrect decisions are used to assess the concentrations requiring the greatest accuracy and precision. The consequences of making incorrect decisions have been outlined previously in Section 3.4. A summary of these consequences is provided in Table 3-3. The baseline decision, or hypothesis, is based on the strategy of disproving the baseline or disproving the worst-case decision. The incorrect decisions indicate what is decided by the users of the data versus the actual situation. The action levels used in the decision logic in Figure 3-1 are based on very conservative assumptions established well below actual limits of criticality for the tanks. Based on this, uncertainties could be large and still create no significant consequence.

Table 3-3. Consequences of Incorrect Decisions (2 Sheets)

\begin{tabular}{|l|l|}
\hline \multicolumn{1}{|c|}{ Decision } & \multicolumn{1}{c|}{ Result of Incorrect Decision } \\
\hline \multicolumn{1}{|c|}{ Baseline Decision 1: plutonium equivalent $\geq \mathbf{0 . 0 0 1} \mathrm{g} / \mathrm{L}$} \\
\hline $\begin{array}{l}\text { Decide plutonium }<0.001 \mathrm{~g} / \mathrm{L}, \text { actual } \\
\text { plutonium } \geq 0.001 \mathrm{~g} / \mathrm{L}\end{array}$ & $\begin{array}{l}\text { The actual criteria are } 0.033 \mathrm{~g} / \mathrm{L} \text { plutonium equivalents; therefore, } \\
\text { consequences do not affect the outcome unless the actual concentration } \\
\text { is }>0.033 \mathrm{~g} \text { Pu/L. }\end{array}$ \\
\hline $\begin{array}{l}\text { Decide plutonium } \geq 0.001 \mathrm{~g} / \mathrm{L}, \text { actual } \\
\text { plutonium }<0.001 \mathrm{~g} / \mathrm{L}\end{array}$ & $\begin{array}{l}\text { No criticality problem. } \\
\text { The concentration of } 0.033 \mathrm{~g} \text { Pu/L is the controlling concentration. } \\
\text { Extra cost to measure ratios and monitor the material would be } \\
\text { incurred. }\end{array}$ \\
\hline
\end{tabular}


Table 3-3. Consequences of Incorrect Decisions (2 Sheets)

\begin{tabular}{|c|c|}
\hline Decision & Result of Incorrect Decision \\
\hline \multicolumn{2}{|c|}{ Baseline Decision 2: plutonium equivalent $\geq 0.033 \mathrm{~g} / \mathrm{L}$} \\
\hline $\begin{array}{l}\text { Decide plutonium equivalent } \\
<0.033 \mathrm{~g} / \mathrm{L} \text {, actual } \geq 0.033 \mathrm{~g} / \mathrm{L}^{*}\end{array}$ & $\begin{array}{l}\text { At least three layers of conservatism must fail in order for this single } \\
\text { decision to cause a problem. The } 0.033 \mathrm{~g} / \mathrm{L} \text { is based on } 2.6 \mathrm{~g} \mathrm{Pu} / \mathrm{L} \text { of } \\
\text { solids, which is very conservative. The ratio of absorbers versus } \\
\text { plutonium is a second check to assure sufficient neutron absorbers are } \\
\text { present. The plutonium equivalent limit used in calculations is the } \\
\text { highest value for any solid sample in the tanks. Residual solids } \\
\text { incoming from a generator have a larger space to spread out in the tank, } \\
\text { limiting spatial confinement problems. }\end{array}$ \\
\hline $\begin{array}{l}\text { Decide plutonium equivalent } \\
\geq 0.033 \mathrm{~g} / \mathrm{L} \text {, actual }<0.033 \mathrm{~g} / \mathrm{L}^{*}\end{array}$ & Waste resources and storage space. Not a criticality problem. \\
\hline \multicolumn{2}{|r|}{ Baseline Decisions 3a, 3b, and 3c } \\
\hline \multicolumn{2}{|c|}{ Decision 3 is based on the results of Decision 2; uncertainty of Decision 2 is sufficient to cover Decision 3.} \\
\hline \multicolumn{2}{|c|}{ Baseline Decision 4: $\mathbf{p H} \leq 8$} \\
\hline Decide $\mathrm{pH} \geq 8$, but actual $\mathrm{pH} \leq 8$ & $\begin{array}{l}\text { Increase the solubility of plutonium in the supernatant, but spatial and } \\
\text { other factors must also fail to meet requirements to present a criticality } \\
\text { problem. } \\
\text { A large safety factor is built into the plutonium equivalent } \\
\text { concentration; therefore, errors in measurement of plutonium } \\
\text { equivalent, pH, and spatial considerations must all occur to cause a } \\
\text { criticality problem. }\end{array}$ \\
\hline Decide $\mathrm{pH} \leq 8$, but actual $\mathrm{pH} \geq 8$ & $\begin{array}{l}\text { No criticality problem would occur, because more caustic would be } \\
\text { added until the pH measurement was above } 8 \text {. } \\
\text { Increased cost for management of the waste and addition of extra } \\
\text { caustic. }\end{array}$ \\
\hline
\end{tabular}

*When CPS is updated, $0.04 \mathrm{~g} \mathrm{Pu} / \mathrm{L}$ will be used and uncertainty evaluation will remain unchanged.

\subsection{SAMPLING DESIGN}

The sampling design is discussed for each type of liquid transfer from sources outside the Tank Farm system.

\subsubsection{Transfers from Generators to DST System}

3.7.1.1 Analytes. Samples must be collected by the generator to assure compliance with criticality controls before receipt of the waste. The data are sent to Tank Farm operations and 
compliance organizations supporting Tank Farms for review by each organization before transfer. The analytes of concern include fissionable isotopes such as total plutonium, uranium235 , and uranium-233. Based on isotopic abundance, uranium-233 is present in exceedingly low ratios; therefore, analysis for this isotope would be undetectable and is not needed. The subcritical mass ratio of uranium to plutonium was calculated assuming the uranium has a natural enrichment of uranium-235 (0.72 wt\%); therefore, all uranium- 235 in excess of $0.72 \mathrm{wt} \%$ of total uranium is assumed to be equivalent to plutonium-239 on a gram-per-gram basis.

3.7.1.2 Process for Data Collection for Generators. The following steps are used to collect and assess the sample data.

1. Generator samples waste for analytes discussed in Table 3-4.

2. Generator submits the data to DST operations for review.

3. DST operation obtains data on the receiving tank from the plutonium Inventory System database or collects samples from the receiving tank. If samples are collected, the analytes are selected according to Table 3-2 and the methods selected according to Table 3-4.

4. DST Engineering evaluates the final concentration of plutonium equivalent, $\mathrm{pH}$, and absorber ratios based on the logic in Figure 3-1 and generates a compatibility assessment.

5. The assessment is reviewed by another engineer and by RPP regulatory compliance.

Some generators repeatedly transfer the same waste stream to the DSTs. In this case, samples must be collected from the waste stream at least once per year.

3.7.1.3 Quality Control and Method Detection Limits. Table 3-4 lists the analytes, the analytical technique, and quality control (QC) acceptance criteria. The method detection limit (MDL) for plutonium is $1 \times 10^{-3} \mathrm{~g} / \mathrm{L}$, which is at the initial action level presented in Decision 1 . Because the most critical action level is $0.033 \mathrm{~g} \mathrm{Pu} / \mathrm{L}$, a detection limit at the first action level is not deemed a concern.

Quality control criteria are based on normal laboratory operating parameters for the analytical techniques in the Hanford Analytical Services Quality Assurance Requirements Documents (DOE-RL 1998). Laboratory QC samples include matrix spikes (MSs), tracers for plutonium analyses, laboratory control samples (LCS), and laboratory duplicates. Each one of these is defined in the footnotes of Table 3-4. Criteria are also listed in the same table. The laboratory analyzes the QC samples in the batches with the actual samples and reviews the data for compliance with the criteria during analysis and before reporting the results. 
Because the ratio of plutonium versus the absorbers means that two detection limits must be considered simultaneously, detection limits cannot be established at a fixed point. In order to prevent the laboratory from running multiple dilutions on highly radioactive material and, in order to provide usable data for making the assessment of the ratios, the ratio is calculated by the laboratory project manager according to Figure 3-2. Figure 3-2 is ONLY used by the laboratory to assess detection limits, it is not used by the project for final evaluation of the waste to be transferred. If the detection limit is too high and does not allow calculation of an accurate ratio, another analysis at an appropriate dilution must be performed. In order to obtain usable responses for a particular metal, multiple analyses at various levels of dilution may be required. The metals have been prioritized in the order most likely to be present. The order of ratio evaluation should be based on the following metals, in the order presented: uranium, iron, manganese, nickel, and chromium. Uranium is first analyzed, the ratio calculated, and if the ratio is above the limit in Table 3-1, the transfer is allowed. If the uranium ratio is not above the limit, each metal is evaluated in a similar manner until a result which passes the ratio is obtained, or until reasonable efforts in dilution indicate that the ratio is not exceeded.

\subsubsection{Transfers from the DST System to the 242-A Evaporator}

Before the transfer of waste to the 242-A Evaporator, plutonium concentrations from the tank considered for processing will be obtained from sampling. Only liquids that meet corrosion criteria specified in Section 4.0 will be transferred to the 242-A Evaporator. Corrosion criteria will ensure that the $\mathrm{pH}$ remains above the $\mathrm{pH}$ of 8 required for criticality. The batch transferred will be analyzed for total plutonium or plutonium-239. If the feed plutonium equivalent exceeds $0.005 \mathrm{~g} / \mathrm{L}$, the $242-\mathrm{A}$ Evaporator will not process the waste.

Table 3-4. RDL and QC Criteria for Generator Criticality Evaluation (2 Sheets)

\begin{tabular}{|c|c|c|c|c|c|}
\hline \multirow[b]{2}{*}{ Analyte } & \multirow{2}{*}{$\begin{array}{l}\text { Analytical } \\
\text { Technique }\end{array}$} & \multicolumn{3}{|c|}{ QC Acceptance Criteria } & \multirow{2}{*}{$\begin{array}{l}\text { Recommended } \\
\text { Detection } \\
\text { Level }\end{array}$} \\
\hline & & $\begin{array}{c}\text { LCS } \\
\text { \%Recovery }\end{array}$ & $\begin{array}{c}\text { Spike } \\
\text { \%Recovery }{ }^{2}\end{array}$ & $\begin{array}{c}\text { Duplicate } \\
\text { RPD }^{3}\end{array}$ & \\
\hline $\begin{array}{l}{ }^{239 / 240} \mathrm{Pu} \\
\text { Total } \mathrm{Pu}\end{array}$ & $\begin{array}{c}\text { Solvent } \\
\text { extraction/AEA }\end{array}$ & $70-130 \%$ & $\mathrm{~N} / \mathrm{A}^{4}$ & $\leq 20 \%$ & $\begin{array}{c}0.001 \mathrm{~g} / \mathrm{L} \\
6.2 \mathrm{E}-02 \mu \mathrm{Ci} / \mathrm{mL}\end{array}$ \\
\hline Total U & $\begin{array}{c}\text { Laser-induced kinetic } \\
\text { phosphorescence }\end{array}$ & $80-120 \%$ & $75-125 \%$ & $\leq 20 \%$ & $\begin{array}{c}0.770 \mathrm{~g} / \mathrm{L} \\
770 \mu \mathrm{g} / \mathrm{mL}^{5}\end{array}$ \\
\hline${ }^{235 / 238} \mathrm{U}$ & $\begin{array}{c}\text { Solvent } \\
\text { extraction/AEA }\end{array}$ & $70-130 \%$ & $\mathrm{~N} / \mathrm{A}^{4}$ & $\leq 20 \%$ & $0.001 \mathrm{~g} / \mathrm{L}$ \\
\hline $\mathrm{Cr}$ & ICP/AES & $70-120 \%$ & $75-125 \%$ & $\leq 20 \%$ & $\begin{array}{c}0.135 \mathrm{~g} / \mathrm{L} \\
135 \mu \mathrm{g} / \mathrm{mL}^{s}\end{array}$ \\
\hline $\mathrm{Fe}$ & ICP/AES & $70-120 \%$ & $75-125 \%$ & $\leq 20 \%$ & $\begin{array}{c}0.160 \mathrm{~g} / \mathrm{L} ; \\
160 \mu \mathrm{g} / \mathrm{mL}^{s}\end{array}$ \\
\hline $\mathrm{Mn}$ & ICP/AES & $70-120 \%$ & $75-125 \%$ & $\leq 20 \%$ & $\begin{array}{c}0.032 \mathrm{~g} / \mathrm{L} ; \\
32 \mu \mathrm{g} / \mathrm{mL}^{\mathrm{s}}\end{array}$ \\
\hline
\end{tabular}


Table 3-4. RDL and QC Criteria for Generator Criticality Evaluation (2 Sheets)

\begin{tabular}{|l|c|c|c|c|c|}
\hline \multirow{2}{*}{ Analyte } & \multirow{2}{*}{$\begin{array}{c}\text { Analytical } \\
\text { Technique }\end{array}$} & $\begin{array}{c}\text { LCS } \\
\text { \%Recovery }\end{array}$ & $\begin{array}{c}\text { QC Acceptance Criteria } \\
\text { \%Recovery }\end{array}$ & $\begin{array}{c}\text { Duplicate } \\
\text { RPD }^{3}\end{array}$ & $\begin{array}{c}\text { Recommended } \\
\text { Detection } \\
\text { Level }\end{array}$ \\
\cline { 3 - 6 } & ICP/AES & $70-120 \%$ & $75-125 \%$ & $\leq 20 \%$ & $\begin{array}{c}0.105 \mathrm{~g} / \mathrm{L} ; \\
105 \mu \mathrm{g} / \mathrm{mL}^{5}\end{array}$ \\
\hline $\mathrm{pH}$ & pH meter & $+/-0.01$ & N/A & $\leq 20 \%$ & N/A \\
\hline
\end{tabular}

AEA = alpha energy analysis

ICP/AES = inductively coupled plasma/atomic emission spectroscopy

N/A $\quad=$ not applicable

$1_{\mathrm{LCS}}=$ Laboratory Control Sample. This sample is carried through the entire method. The accuracy of a method is usually expressed as the percent recovery of the LCS. The LCS is a matrix with known concentration of analytes that is processed with each preparation and analyses batch. It is expressed as percent recovery; i.e., the amount measured, divided by the known concentration, times 100 .

2For some methods, the sample accuracy is expressed as the percent recovery of a matrix spike (MS) sample. It is expressed as percent recovery; i.e., the amount measured, less the amount in the sample, divided by the spike added, times 100 . One MS is performed according to riser. If three samples are collected from a single riser, one MS is analyzed.

3RPD = Relative Percent Difference between the sample and duplicate results. Sample precision is estimated by analyzing duplicates. Acceptable sample precision is usually $<20 \%$ RPD if the sample result is at least 10 times the instrument detection limit.

$\mathrm{RPD}=(\mid$ Result $1-$ Result $2 \mid$ /average result $) \times 100$.

4Matrix spike analyses are not required for this method because a tracer is used to correct for analyte loss during sample preparation and analysis. The result generated using the tracer accounts for an inaccuracy of the method on the matrix. The reported results reflect this correction.

5 The minimum concentration of neutron absorber to meet the subcritical mass ratio when $239 / 240 \mathrm{Pu}=0.001 \mathrm{~g} / \mathrm{L}$. These limits are recommendations and not requirements. The logic in Figure 3-2 is used by the laboratory to assure detection limits are below the decision levels. 
Figure 3-2. Laboratory Detection Limit Decision Logic

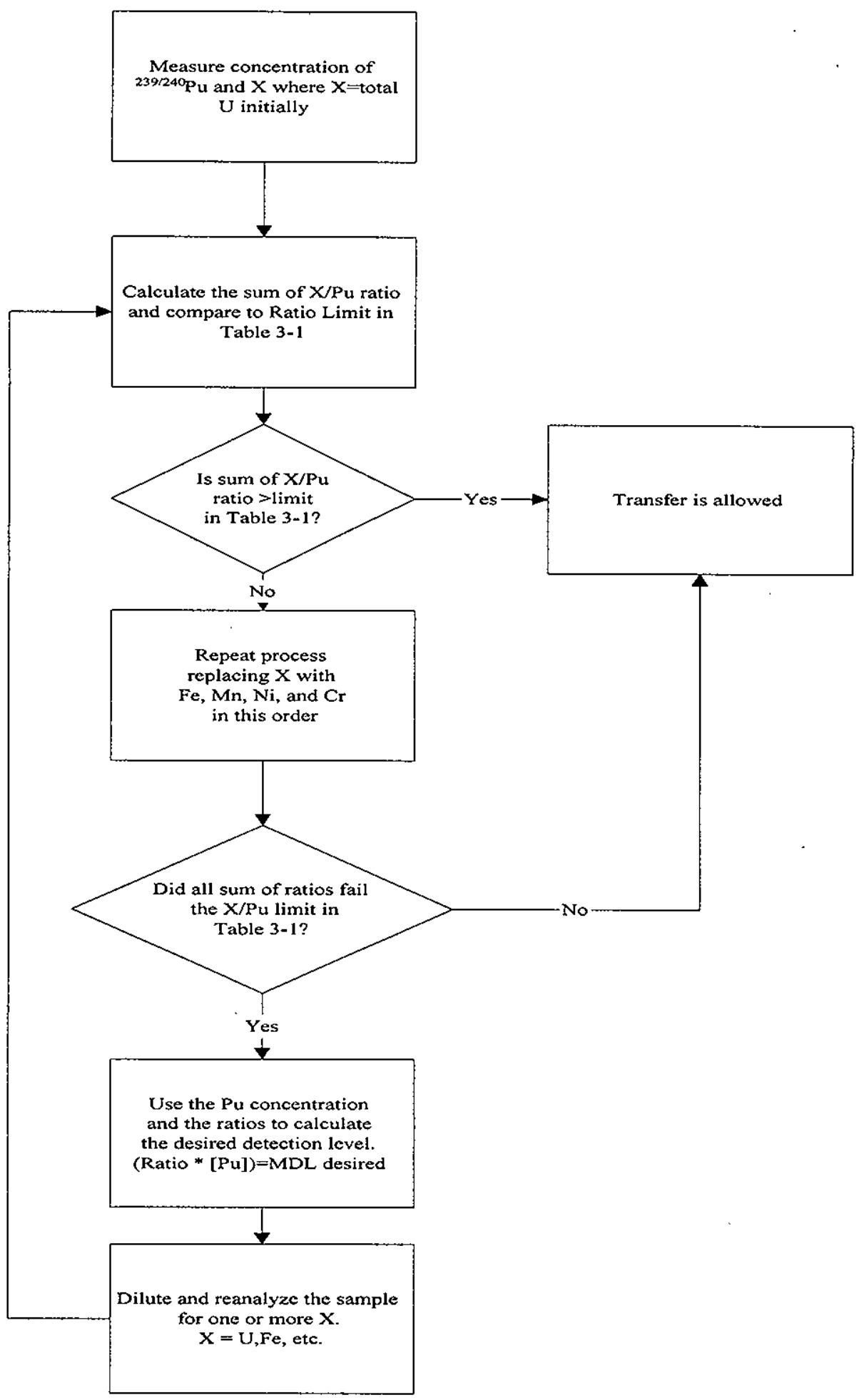


HNF-SD-WM-DQO-001, Rev. 3

This page intentionally left blank. 


\subsection{CORROSION}

\subsection{PROBLEM/QUESTION}

The following question posed by the decision makers was discussed and accepted.

Will any transfer. increase corrosion in pipes and tanks?

Both DOE and Ecology have acknowledged that corrosion in pipes occurs. Both parties agree on the need to control corrosion in the tanks. Both parties disagree on the meaning of "increase." Ecology has indicated that increase means "increase beyond a minimal value based on best available technology." The DOE has indicated that increase means from current corrosion rates.

The result is that the two parties have not agreed upon the need to implement treated flush water after transfers. The DOE and Ecology have agreed on the following tank corrosion specifications to mitigate corrosion in the tanks.

\subsection{INPUTS}

The established inputs to evaluate corrosion potential for all tanks and piping systems are hydroxide $\left[\mathrm{OH}^{-}\right]$, nitrate $\left[\mathrm{NO}_{3}^{-}\right]$, and nitrite $\left[\mathrm{NO}_{2}^{-}\right]$. Inputs are slightly different for tanks depending upon the temperature, $\mathrm{T} \leq 100^{\circ} \mathrm{C}\left(212^{\circ} \mathrm{F}\right)$ and $\mathrm{T}>100^{\circ} \mathrm{C}\left(212^{\circ} \mathrm{F}\right)$.

\subsubsection{Tank Composition}

Temperatures $\left(\mathrm{T} \leq 100^{\circ} \mathrm{C}\left(212^{\circ} \mathrm{F}\right)\right)$

Variable

$\underline{\text { Specification Limit }}$

For $\left[\mathrm{NO}_{3}^{-}\right] \leq 1.0 \underline{\underline{\mathrm{M}}}$ :

$\left[\mathrm{OH}^{-}\right]$

$0.010 \underline{\mathrm{M}} \leq\left[\mathrm{OH}^{\circ}\right] \leq 5.0 \underline{\mathrm{M}}$

$\left[\mathrm{NO}_{2}^{-}\right]$

$0.011 \underline{\mathrm{M}} \leq\left[\mathrm{NO}_{2}^{-}\right] \leq 5.5 \underline{\mathrm{M}}$

$\left[\mathrm{NO}_{3}^{-}\right] /\left(\left[\mathrm{OH}{ }^{-}\right]+\left[\mathrm{NO}_{2}^{-}\right]\right)$

(For solutions below $75^{\circ} \mathrm{C}\left(167^{\circ} \mathrm{F}\right)$, the $\left[\mathrm{OH}^{-}\right]$maximum limit is $8.0 \underline{\mathrm{M}})$ 
For $1.0 \underline{\mathrm{M}}<\left[\mathrm{NO}_{3}{ }^{-}\right] \leq 3.0 \underline{\mathrm{M}}$ :

$\left[\mathrm{OH}^{-}\right]$

$0.1\left(\left[\mathrm{NO}_{3}^{-}\right]\right) \leq\left[\mathrm{OH}^{-}\right]<10 \underline{\mathrm{M}}$

$\left[\mathrm{OH}^{-}\right]+\left[\mathrm{NO}_{2}^{-}\right] \quad \geq 0.4\left(\left[\mathrm{NO}_{3}^{-}\right]\right)$

For $\left[\mathrm{NO}_{3}^{-}\right]>3.0 \underline{\mathrm{M}}$ :

$\left[\mathrm{OH}^{-}\right]$

$\left[\mathrm{OH}^{-}\right]+\left[\mathrm{NO}_{2}^{-}\right]$

$\left[\mathrm{NO}_{3}^{-}\right]$ $\geq 1.2 \mathrm{M}$

$$
0.3 \underline{\mathrm{M}} \leq\left[\mathrm{OH}^{-}\right]<10 \underline{\mathrm{M}}
$$

$\leq 5.5 \underline{\mathrm{M}}$

For waste temperatures $>100^{\circ} \mathrm{C}\left(212^{\circ} \mathrm{F}\right)$ for $\mathrm{AY}$ and $\mathrm{AZ}$ tanks, the previously stated limits apply with the exception that $\left[\mathrm{OH}^{-}\right]$ must be $<4 \underline{\mathrm{M}}$.

\subsubsection{Input Basis for Hydroxide, Nitrite, Nitrate}

The failure mechanisms are outlined to allow understanding of the concentration of the ions that prevent corrosion. Premature failure of carbon steel components in hot nitrate solutions can be caused by stress corrosion cracking (SCC). In the absence of residual stresses approaching yield strength, failure of carbon steel components can still occur by pitting. At the Savannah River Site (SRS), SCC occurred in non-stress relieved tanks. The non-stress relieved carbon steel waste tanks also contained waste with hydroxide and nitrite compositions outside the specification limits leading to SCC. Similar failures were also noted at the Hanford Site in the SSTs. These failures have also been attributed to SCC caused by nitrate (Anantatmula et al. 1994). Based on laboratory experiments, waste composition specifications were developed at the SRS (Ondrejcin et al. 1979) that would mitigate accelerated corrosion of carbon steel by pitting and SCC in SRS wastes. Because of the similarities between the waste compositions, the tank steel types and the operating conditions at the Hanford Site and SRS, it was recommended that the corrosion specifications in use at the SRS be used at the Hanford Site (Moore 1979) for the DSTs. The technical basis document for waste tank corrosion specifications (Kirch 1984) lists the concentration ranges of hydroxide and nitrite relative to nitrate in waste solutions. The concentrations listed result in waste solutions that are not corrosive to tank steel and waste transfer equipment. The DSTs were stress relieved and, thus far, no failures have been observed in the Hanford Site DSTs. Additional substantiation of limits when nitrate is $<1.0 \underline{\mathrm{M}}$, is found in Danielson and Bunnell (1994).

The presence of adequate concentrations of hydroxide and nitrite and using correct ratios of these anions prevents pitting/SCC of carbon steel. The inputs in Section 4.2.1 are from Technical Basis for Waste Tank Corrosion Specifications (Kirch 1984), Characterization of the Corrosion Behavior of the Carbon Steel Liner in Hanford Single-Shell Tanks (Anantatmula et al. 1994), and 
Sludge Washing Materials Study: The Behavior of Carbon Steel in a Dilute Waste Environment (Danielson and Bunnell 1994). The nitrite, nitrate, and hydroxide concentrations are controlled in order to inhibit accelerated uniform corrosion, pitting corrosion, and SCC. If these phenomena are not controlled, deterioration of the tank will occur at a faster rate.

\subsubsection{Basis for Temperature and Hydroxide Criteria}

Carbon steel is prone to corrosion cracking in caustic solutions at temperatures $\geq 100^{\circ} \mathrm{C}\left(212^{\circ} \mathrm{F}\right)$. This is the reason for choosing $100^{\circ} \mathrm{C}\left(212^{\circ} \mathrm{F}\right)$ as a critical temperature. At temperatures below $75^{\circ} \mathrm{C}\left(167^{\circ} \mathrm{F}\right)$, the 1984 Pacific Northwest Laboratory experiments (Divine et al. 1985) did not indicate any problems associated with an increase in hydroxide at greater than $5 \underline{\mathrm{M}}$. Corrosion tests were performed using synthetic waste solutions at temperatures ranging from $40^{\circ} \mathrm{C}$ to $177^{\circ} \mathrm{C}\left(104^{\circ} \mathrm{F}\right.$ to $\left.350^{\circ} \mathrm{F}\right)$ using American Society for Testing and Materials procedures A 537 and A 516. The tests were substantiated using actual waste solutions. Tests at the low temperatures $\left(\leq 100^{\circ} \mathrm{C}\left[212^{\circ} \mathrm{F}\right]\right)$ at hydroxide and nitrite concentrations at or above the previous specification minimum of $0.01 \underline{\mathrm{M}}$ hydroxide concentration and $0.011 \underline{\mathrm{M}}$ nitrite showed corrosion rates below 1 mil per year. Therefore, $8 \mathrm{M}$ for temperatures below $75^{\circ} \mathrm{C}\left(167^{\circ} \mathrm{F}\right)$ and nitrate concentrations $\leq 1.0 \underline{\mathrm{M}}$ was established as the lower specification limit (Kirch 1984).

\subsubsection{Evaluation of Pipe Flushing}

Ecology and DOE do not agree on the need to implement a requirement to use treated water for flushing pipes after transfers of waste. Both parties need to agree on a path forward for resolution of this issue at a later time.

\subsubsection{Definition of Caustic Depletion and Deficient}

A tank that repeatedly buffers the caustic added, results in hydroxide below criteria. Sufficient caustic must be added to overcome the buffering effect. A caustic deficient tank is one that previous analysis has determined to be out of specification.

\subsubsection{Flush Water}

Both treated and untreated flush water are considered along with waste shipment. In most cases, the impact of flush water is negligible due to its lack of buffering and small volume relative to the volume transferred. 


\subsection{BOUNDARIES}

Transfers discussed include:

- DST to DST

- SST to DST

- Generator transfers into DSTs, excluding the 242-A Evaporator

- DCRTs

- 242-A Evaporator to DSTs

- Piping between these systems

- 204-AR waste transfer station

- Catch tanks that are part of the DST system.

DCRTs are temporary holding tanks used during waste transfers. DCRTs are between sending and receiving tanks.

The 204-AR waste transfer station is a stainless-steel waste transfer unit. Stainless steel is susceptible to corrosion by chloride ions; therefore, specific criteria for chloride for the 204-AR waste transfer station are included.

Catch tanks that are part of the DST system are included in this DQO. The catch tanks collect spills, run-off and DST type waste. DST waste may pass through these tanks during transfers within the DST system.

\subsection{DECISION RULES/LOGIC}

The logic for the corrosion specifications is presented first. The use of the corrosion specifications to determine whether to make the transfers is presented in Sections 4.4.2 through 4.4.5.

\subsubsection{Corrosion Specifications Stated as Decision Rules}

The following decision rules apply to intra-DST transfers, generator to DST transfers, and 242-A Evaporator to DST transfers, and 204-AR transfers. The decision rules for DCRTs exclude the criteria of $\left[\mathrm{NO}_{3}^{-}\right] /\left(\left[\mathrm{OH}^{-}\right]+\left[\mathrm{NO}_{2}^{-}\right]\right)<2.5$. Requiring the ratio to be met in DCRTs would require significant addition of caustic to mitigate corrosion in a number of waste streams from west area. Therefore, it was management's decision not to incorporate the ratio in DCRTs. However, some 
transfers from SSTs into DSTs bypass DCRTs. DCRT corrosion specifications are contained in WHC (1998). The ratio is met in the receiving DST.

1. If the temperature is above $75^{\circ} \mathrm{C}\left(167^{\circ} \mathrm{F}\right)$ and $\leq 100^{\circ} \mathrm{C}\left(212^{\circ} \mathrm{F}\right)$, and the nitrate concentration is $\leq 1.0 \mathrm{M}$, the hydroxide concentration must be $0.010 \underline{\mathrm{M}} \leq\left[\mathrm{OH}^{-}\right] \leq 5.0 \mathrm{M}$; nitrite must be $0.011 \underline{\mathrm{M}} \leq\left[\mathrm{NO}_{2}^{-}\right] \leq 5.5 \underline{\mathrm{M}}$, and $\left[\mathrm{NO}_{3}^{-}\right] /\left(\left[\mathrm{OH}^{-}\right]+\left[\mathrm{NO}_{2}{ }^{-}\right]\right)<2.5$.

2. If the temperature is $\leq 75^{\circ} \mathrm{C}\left(167^{\circ} \mathrm{F}\right)$ and the nitrate concentration is $\leq 1.0 \mathrm{M}$, the hydroxide concentration must be $0.010 \mathrm{M} \leq\left[\mathrm{OH}^{-}\right] \leq 8.0 \mathrm{M}$; nitrite concentration must be $0.011 \underline{\mathrm{M}} \leq\left[\mathrm{NO}_{2}^{-}\right] \leq 5.5 \underline{\mathrm{M}}$, and $\left[\mathrm{NO}_{3}^{-}\right] /\left(\left[\mathrm{OH}^{-}\right]+\left[\mathrm{NO}_{2}^{-}\right]\right)<2.5$.

3. If the temperature is $\leq 100^{\circ} \mathrm{C}\left(212^{\circ} \mathrm{F}\right)$ and the nitrate concentration is $1.0 \mathrm{M}<\left[\mathrm{NO}_{3}^{-}\right]$ $\leq 3.0 \mathrm{M}$; the hydroxide concentration must be $0.1\left(\left[\mathrm{NO}_{3}^{-}\right]\right) \leq\left[\mathrm{OH}^{-}\right]<10 \underline{\mathrm{M}}$, and the $\left[\mathrm{OH}^{-}\right]$ $+\left[\mathrm{NO}_{2}^{-}\right] \geq 0.4\left(\left[\mathrm{NO}_{3}^{-}\right]\right)$.

4. If the temperature is $\leq 100^{\circ} \mathrm{C}\left(212^{\circ} \mathrm{F}\right)$ and the nitrate concentration is $>3.0 \mathrm{M}$; the hydroxide concentration must be $0.3 \mathrm{M} \leq\left[\mathrm{OH}^{-}\right]<10 \mathrm{M}$, and the $\left[\mathrm{OH}^{-}\right]+\left[\mathrm{NO}_{2}^{-}\right] \geq 1.2 \mathrm{M}$, and $\left[\mathrm{NO}_{3}^{-}\right] \leq 5.5 \underline{\mathrm{M}}$.

5. If the temperature is $>100^{\circ} \mathrm{C}\left(212^{\circ} \mathrm{F}\right)$, the limits in Rules 1 through 4 apply, with the exception that the hydroxide concentration must be $<4$ M.

\subsubsection{Transfers from Generators to DSTs}

In order to make a transfer from a generator to a DST, data must be obtained from both the generator and the DST. Details of sample collection and analysis are found in Section 4.6. The following paragraphs outline the decision logic used once data are obtained.

Before transfer, generators are required to provide analytical data collected within five years of the transfer for the concentrations of nitrate, nitrite, and hydroxide (Mulkey 1998). The concentration range for each analyte is included on the waste profile sheet, which is required by the DST Waste Acceptance Plan (Mulkey 1998). Along with the profile sheet, results of at least two samples collected by generators are provided to DST operations for evaluation before waste transfer. The QC data listed in Table 4-1 must be provided with the sample data. Waste generators must provide a full data set within $2 \mathrm{yr}$ of transfer with annual verification of the short list of analytes as required by the DST Waste Analysis Plan (Mulkey 1998).

Figure 4-1 shows the combination of specifications for the generator and DST receiving tank that are covered by decision rules. DST data from the receiving tank generated within five years of the transfer may be used, or new sample data may be obtained. The logic shown in Figure 4-3 is used to determine whether existing data are used or new data are obtained. 
Figure 4-1. Decision Logic for Generator to DST Transfer

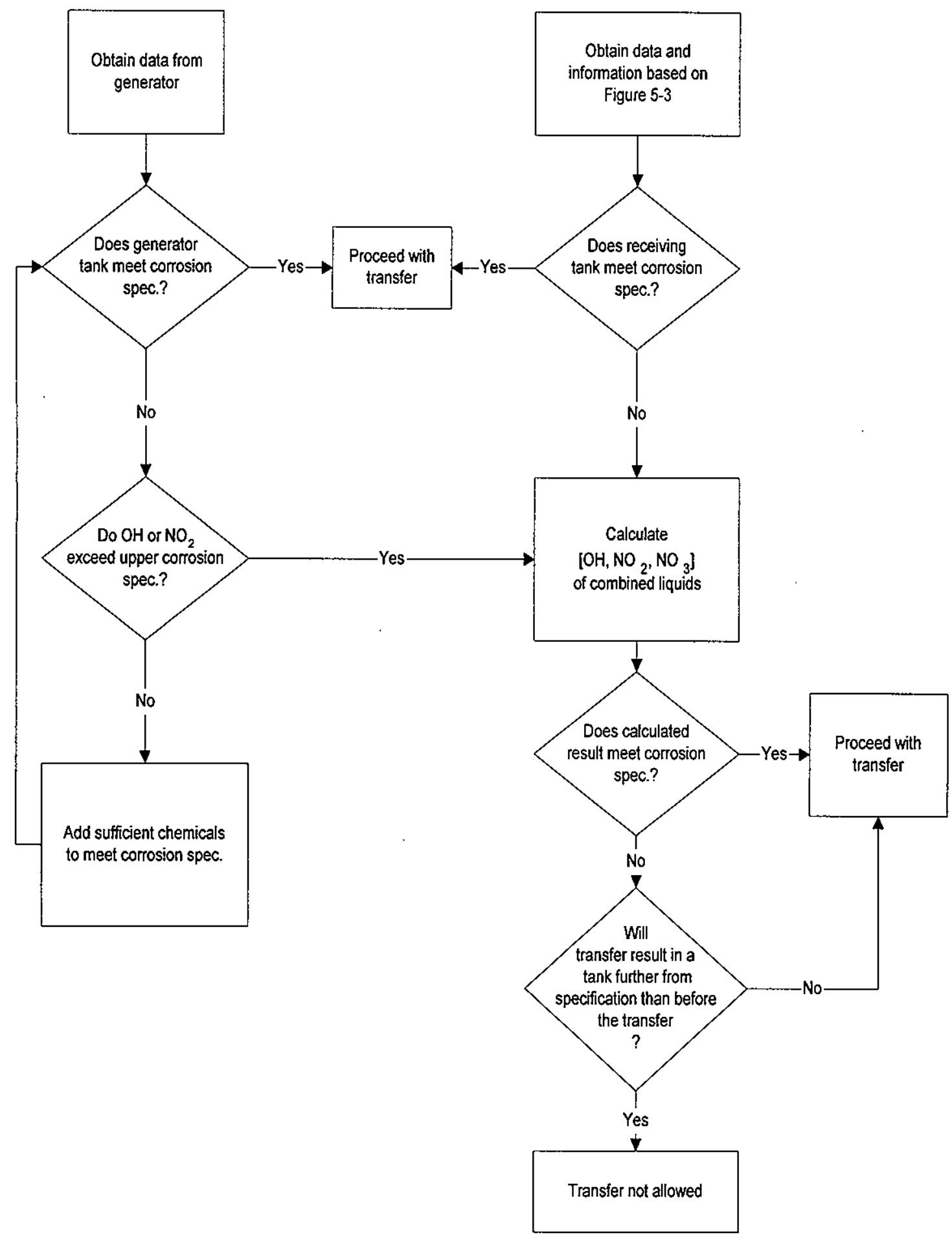


Two results are obtained from the generator. If a single result from a sample does not meet specifications, the result will be rechecked by the laboratory. If the result is out of specification, the result will not be removed as an outlier, but will be used in any calculations or assessment for transfer. The approach allows the worst-case concentration to be used to evaluate waste for transfer as opposed to an average.

1. Transfers shall not make an in-specification tank out-of-specification. Transfers are allowed, provided the resulting concentration in the DST is not further from specification than the starting concentrations. If the generator's waste meets specifications for nitrate, nitrite, and hydroxide, but the DST receiving the waste does not meet specifications, calculations of the final theoretical concentration after transfer are performed.

If the generator's waste does not meet corrosion specifications, the generator may be required to add appropriate chemicals to meet specifications, or chemicals may be added in-line by Tank Farm Operations for waste received by the 204-AR unit. Additions take place before movement of the waste to the receiving DST.

2. If the generator's waste exceeds the maximum hydroxide limit and is being used to mitigate a DST waste that is low in hydroxide, the generator's waste may be accepted. From the known concentrations and volumes of the wastes, calculations are performed to determine the final concentration of the waste. As part of a mitigation plan, small volumes of generator waste exceeding the hydroxide limit may be accepted. The commingling of out-of-specification waste that is not part of a mitigation action is not acceptable. Once the mitigation effort is complete, grab sampling is required to quantify corrosion parameters.

3. It is possible to transfer in-specification waste from a waste generator into an inspecification DST and the resulting mixture be out-of-specification. For example, the generator's waste may have a $\left[\mathrm{NO}_{3}^{-}\right]>3 \underline{\mathrm{M}}$ and the receiver DST may have a $\left[\mathrm{NO}_{3}{ }^{-}\right]<1 \underline{\mathrm{M}}$. Both may be in-specification, but upon completion of transfer, the receiver DST may now have a $1 \underline{\mathrm{M}}<\left[\mathrm{NO}_{3}{ }^{-}\right]<3 \underline{\mathrm{M}}$. Therefore, if both the generator and receiving DST are both within specification and within the same specification range, transfer may proceed. If the subject waste streams are both in-specification, but are in differing ranges, the final mixture will be evaluated to ensure compliance. 
Figure 4-2. Decision Logic for DST-to-DST or SST-to-DST Transfer

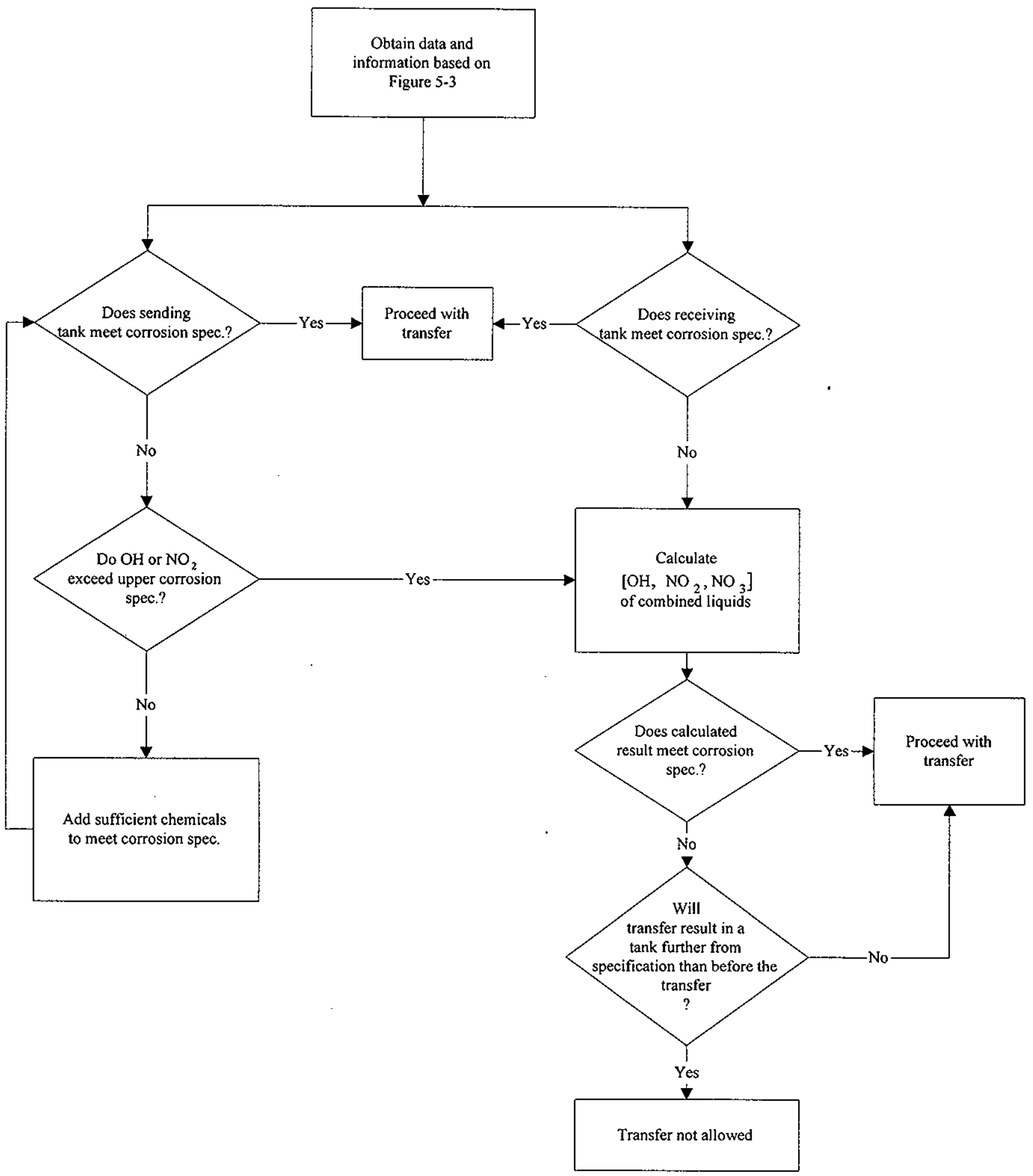




\subsubsection{DST to DST Transfers}

Figure 4-2 shows the combination of specifications for the generator and DST receiving tank that are covered by decision rules.

1. If the DST sending tank waste meets specifications for nitrate, nitrite, and hydroxide, but the DST receiving the waste does not meet specifications, calculations of the final theoretical concentration after transfer are performed. The commingling of out-of-specification waste that is not part of a mitigation action is not acceptable. Once the mitigation effort is complete, grab sampling is required to assess whether mitigation was successful.

2. If the DST sending tank waste exceeds corrosion specifications and the DST receiving the waste does meet specifications, calculations of the final theoretical concentration after transfer are performed. Transfers shall not make an in-specification tank out of specification. Waste that exceeds corrosion specifications can be with in-specification waste if it is part of an effort to mitigate corrosion in the sending tank or if it does not result in tank waste that is further out of specification. Once the mitigation effort is complete, grab sampling of both sending and receiving tanks is required to assess the results of mitigative actions.

3. If both the DST sending and receiving tank meet specifications, the transfer can proceed.

4. It is possible to transfer in-specification waste from a waste generator into an inspecification DST and the resulting mixture be out-of-specification. For example, the generator's waste may have a $\left[\mathrm{NO}_{3}^{-}\right]>3 \underline{\mathrm{M}}$ and the receiver DST may have a $\left[\mathrm{NO}_{3}{ }^{-}\right]<1 \underline{\mathrm{M}}$. Both may be in-specification, but upon completion of transfer, the receiver DST may now have a $1 \underline{\mathrm{M}}<\left[\mathrm{NO}_{3}{ }^{-}\right]<3 \underline{\mathrm{M}}$. Therefore, if both the generator and receiving DST are both within specification and within the same specification range, transfer may proceed. If the subject waste streams are both in-specification, but are in differing ranges, the final mixture will be evaluated to ensure compliance.

\subsubsection{Double-contained Receiver Tanks}

DCRTs will meet the same specifications as DST-to-DST transfers outlined in Section 4.4.3. Invoking the specification on the DCRTs is done to accomplish the site-wide consistency in dealing with waste containment for carbon-steel tanks.

For saltwell pumping, the source SST does not have to be adjusted. Waste composition data are used to calculate corrosion-specific adjustments necessary at the DCRT. 


\subsubsection{2-A Evaporator to DSTs}

Transfers from the 242-A Evaporator to DSTs are evaluated against the DST corrosion requirements via the waste compatibility assessment that is performed before waste is transferred to the 242-A Evaporator. A predictive model is used to assess the concentration that the waste undergoes in the 242-A Evaporator. Before sending the waste to the 242-A Evaporator, the model must show that the resulting slurry produced by the 242-A Evaporator will meet corrosion criteria. Analysis of the slurry after processing for corrosion specification parameters is required. Data are obtained from a sample collected from the slurry tank or input pipe to slurry tank during or after batch processing. This is done to ensure that transfers from the 242-A Evaporator to the DSTs meet the same specifications as a generator-to-DST transfer. The following decision rules apply:

- If the predicted slurry concentration does not meet corrosion specifications, transfer is not allowed.

- If the sample results obtained from the slurry tank or from the run-down line do not meet corrosion criteria, hydroxide and nitrite will be added until corrosion criteria are met.

\subsubsection{Piping Systems}

No decision rules exist because DOE and Ecology have not agreed on implementation of treated flush water.

\subsubsection{4-AR Transfer Station}

If chloride concentration $<0.035 \underline{\mathrm{M}}$ and $7<\mathrm{pH}<14$ for tank trailers, waste can be placed in 204-AR facility.

\subsubsection{Catch Tanks Within DST System}

Catch tanks that are within the DST system must meet the same criteria as those imposed on DST to DST transfers.

\subsection{UNCERTAINTY OR CHANCE OF MAKING INCORRECT DECISION}

The consequence of making incorrect decisions are used to assess the concentrations requiring the greatest accuracy and precision and do not absolve the contractor from meeting the criteria. 


\subsubsection{Consequences of an Incorrect Decision}

To evaluate the acceptable uncertainty, an initial assessment of the consequences of the wrong decision are evaluated. A potential consequence of increased corrosion going undetected is failure of the tank before the waste is retrieved for treatment. The consequence of taking action to prevent corrosion when no action is needed results in spending additional money unnecessarily.

The consequence of making an incorrect decision is more severe as one decreases the concentration of hydroxide and nitrite. In dilute solutions the corrosion protection offered by the appropriate concentrations of hydroxide and nitrite may be insufficient to prevent an increase in corrosion.

The technical basis document indicates that at hydroxide concentrations above $0.01 \underline{\mathrm{M}}$ with nitrate concentrations $\leq 1.0 \mathrm{M}$, the corrosion was $<1 \mathrm{~mm}$ per year (Kirch 1984). At lower concentrations, it becomes more difficult to quantify the hydroxide and nitrite concentrations. Therefore, an assessment of the confidence of the measurement near the critical decision limits at the lower concentrations of hydroxide $(0.01 \underline{\mathrm{M}})$ and nitrite $(0.011 \underline{\mathrm{M}})$ was performed.

\subsubsection{Existing Data}

Existing data from compatibility transfers which met the specification criteria were evaluated and a summary of the data is presented in Appendix B. The analytical precision criteria is presented for duplicate analyses in Appendix B. The data were used to assess whether the $20 \%$ relative percent difference (RPD) would be sufficient to assess whether the results were below specification at concentration near the lower concentration limits. RPD is a measure of precision referenced in Chapter 1 of SW-846 (EPA 1997) which is calculated as follows:

$$
R P D \%=\frac{\mid \text { Result } 1-\text { Result } 2 \mid}{\text { Average of Results }} 100
$$

Graphs of the nitrite and hydroxide RPD are presented in Appendix B. The following equation for relative standard deviation (RSD) with the number of samples equal to two, based on laboratory duplicates, follows:

$$
R S D \%=\frac{R P D}{\sqrt{2}} 100
$$




\subsubsection{Assessment of the Decision Error}

A $90 \%$, one-sided confidence limit for the mean was calculated to assess whether a $15 \%$ RSD would be sufficient to determine if the mean concentration (either hydroxide or nitrite) was above the specification limit. Twenty percent is recommended by the EPA methods used for nitrate and nitrite. No EPA method exists for the hydroxide determination, however, laboratory controls indicate that $20 \%$ is achievable routinely by the laboratory. For hydroxide results (per sample basis) with a mean concentration $>0.015 \mathrm{M}$, the lower limit of a one-sided $90 \% \mathrm{CI}$ for the mean (using an RSD of $20 \%$ ) was $>0.01 \underline{\mathrm{M}}$. Since the lower limit will vary dependent on the agreement between the laboratory results, the hydroxide concentration must undergo additional evaluation by the laboratory and operations engineering to assure that the tank is above the actual specification $(0.01 \underline{\mathrm{M}})$. This evaluation should calculate, for each sample with a mean concentration between $0.01 \underline{\mathrm{M}}$ and $0.015 \underline{\mathrm{M}}$, the one-sided $90 \% \mathrm{CI}$ for the mean. The one-sided $90 \% \mathrm{CI}$ is calculated as follows:

$$
\text { lower limit }=\text { mean }-t_{(0.90,1)} x \frac{s}{\sqrt{N}}
$$

For nitrite results (per sample basis) with a mean concentration greater than $0.015 \mathrm{M}$, the lower limit of a one-sided $90 \%$ CI for the mean (using an RSD of 20\%) was $>0.011$ M. Since the lower limit will vary dependent on the agreement between the laboratory results, the nitrite concentration must undergo additional evaluation by the laboratory and operations engineering to assure that the tank is above the actual specification $(0.011 \underline{\mathrm{M}})$. This evaluation should calculate, for each sample with a mean concentration between $0.01 \underline{\mathrm{M}}$ and $0.015 \underline{\mathrm{M}}$, the one-sided $90 \% \mathrm{CI}$ for the mean.

\subsection{SAMPLING DESIGN}

\subsubsection{Transfers From DST-to-DST and SST-to-DST}

4.6.1.1 DST Grab Sampling Logic. The logic of when to collect a sample versus the use of calculated historical results, is presented in Figure 4-3. The logic considers the age of the data, the number of transfers into a tank, and the closeness of the result versus the action/specification limit, and whether the historical data and process knowledge show that the tank exhibits caustic depletion. The closeness of the result to the action limit is assessed to determine when greater precision is needed to allow a decision to be made per Section 4.5.

Data are defined as information used to address the safety issues specified in the compatibility DQO. Data may consist of analytical results obtained from sampling or calculations based upon 
analytical results obtained from previous sampling events. The following is a discussion of the major decision points in Figure 4-3. 
Figure 4-3. DST Grab Sampling Decision Logic

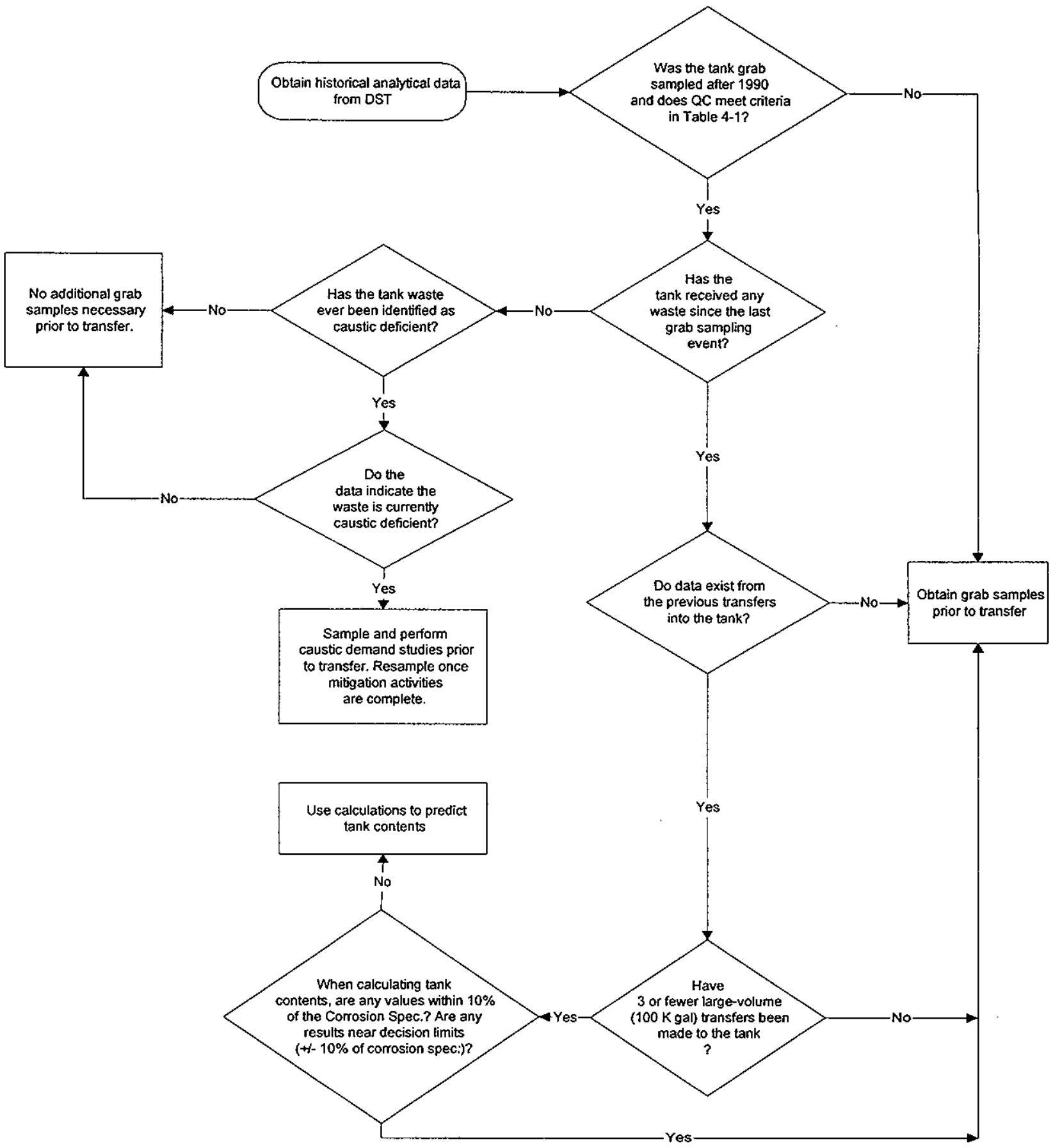




\section{Was the tank supernatant sampled within five years of the transfer?}

The DST Waste Analysis Plan (Mulkey 1998) indicates that analyses must be performed within five years of the transfer and must have sufficient quality to meet regulatory purposes. The QC supporting data collected will be reviewed against the criteria in Table 4-1. If the QC results meet the criteria, the data is a candidate for use in the evaluation for waste transfer. The subsequent logic shown in Figure 4-3 must meet criteria in addition to the QC criteria for the data to be used in transfer evaluations.

\section{Obtain grab samples before transfer.}

It is required that grab samples be taken and analyzed before the transfer occurs. The analyses results required are nitrate, hydroxide, and nitrite. Any information or data that indicates the tank to be caustic-deficient must be considered. The sampling requirement applies to both the sending and receiving tanks.

\section{Has the tank received any waste since the last grab sampling event?}

Transfers may cause changes in hydroxide concentration.

\section{Do data exist from previous transfers into the tank?}

Answering this question assures that the contents of transfers into the tank are known and helps maintain an accurate inventory of the tank's content. In this case, data can be analytical data or detailed process knowledge.

Do data contain all analytes as specified in the corrosion section of this DQO?

This assures that all required information is available.

\section{Have $\leq 3$ large-volume $(100 \mathrm{~K}$ gal $)$ transfers been made to the tank?}

This provides a check to make sure numerous transfers do not occur without a sampling effort that quantifies calculated concentrations. This provides a check to make sure numerous transfers that affect parameters of concern do not occur without a sampling effort to assure calculated concentrations accurately represent the actual waste concentration. The number three was chosen arbitrarily but should be sufficient to allow operational flexibility and still ensure accurate inventory. The number three is for large transfers and just includes SST and DST transfers to a DST.

When calculating tank contents, are any values within $10 \%$ of an action limit? 
If three or fewer transfers have been made into a tank, sampling is not required and an estimation of the tank's content may be used for the compatibility assessment. Quantification of the tank's content by analysis is required when the calculated result nears a specification limit. This action helps ensure that limits are not exceeded.

\section{Has the tank waste ever been identified as caustic deficient?}

Some tanks have shown a tendency for a reduction of hydroxide level. Because the corrosion specifications require the maintenance of specified hydroxide levels, it is prudent to quantify current hydroxide levels of waste in tanks that have historically displayed a reduction in hydroxide levels.

\section{Do data indicate that the waste is currently caustic deficient?}

If existing information (process history or data collected within five years of transfer) indicates that the caustic level is still sufficient, then additional analyses are not required.

If the existing information indicates that the tank is caustic deficient, as indicated by not being able to maintain the hydroxide concentration via sufficient addition of caustic, the tank must be sampled and analyzed for caustic depletion.

\section{Sample and perform caustic demand study before transfer.}

Requires that current information be obtained for both the tendency of the waste to react with caustic, and current hydroxide levels. After completion of mitigation activities, hydroxide, nitrate, and nitrite analyses are performed to show that the mitigation was successful.

4.6.1.2 Number and Location of Samples. Grab samples are obtained from tanks to quantify the corrosion parameters (hydroxide, nitrite, and nitrate concentrations) or for caustic mitigation. Figure 5-3 presents the logic for determining when a sampling event is required. The process for obtaining grab samples includes:

- Initiate a change request to the grab sample schedule. Upon approval, add subject tank to the tank characterization grab sample schedule.

- Prepare process memo requesting grab samples. The process memo specifies sample number, sample type, sample location, sample elevation, cable length, and any additional instructions.

The equipment used for grab sampling is an open device, such as a bottle attached to a string. The device is about $0.30 \mathrm{~m}(1 \mathrm{ft})$ long. There is a small difference between cable length and sample depth due to the difference in distance between sample mouth and where the cable is attached to the sampler. When sample depth is determined, the distance is measured to the 
mouth of the sample container. The actual sample depth is not a precise number since there are a number of items that could cause small variation in actual sample depth. However, there is no need for precise measurement of actual sample depth. Per the sampling logic, samples are supposed to be representative of $100+\mathrm{cm}(40+\mathrm{in}$.) of fluid. The liquid level (LL) governs the number of samples. Following is the recommended strategy:

- If the LL of waste is $<100 \mathrm{~cm}$ (40 in.), one grab sample will be obtained.

- If $100 \mathrm{~cm}$ (40 in.) $<\mathrm{LL} \leq 254 \mathrm{~cm}$ (100 in.), obtain two grab samples at different depths that are representative of the waste.

- If $\mathrm{LL}>254 \mathrm{~cm}$ (100 in.), obtain three to four grab samples with at least one grab sample per $254 \mathrm{~cm}$ (100 in.).

Collect at least one field duplicate sample at one depth for assessment of sampling precision. In cases where the liquid is interstitial to solids, drainable liquid portions from segments from various depths may be collected. Because data assessment is performed by sample depth, as opposed to an average, the depth of the sample must be clearly documented and reported.

4.6.1.3 Analytes and Quality Control. The analytes include nitrate, nitrite, and hydroxide. When caustic depletion is being evaluated, as in the case of mitigation, the hydroxide demand test is performed. This test is also called caustic demand. Table 4-1 lists the accuracy requirement as a function of spike recovery $(\% \mathrm{R})$, the precision requirement as a function of $\mathrm{RPD}$, and the internal laboratory process QC that is quantified by the LCS. The method detection limits are specified at levels well below the lowest hydroxide decision level of $0.01 \mathrm{M}$ and the nitrite level of $1.0 \mathrm{M}$, and below the nitrate level of $1.0 \mathrm{M}$.

The caustic demand is performed by measuring the amount of caustic required to override the buffering effect of the tank sample. Spiking for accuracy is not effective for QC because the laboratory cannot recreate the buffering effect in the sample. Appropriately standardizing the solutions used for the titrations is part of the analytical method and is the only effective QC for evaluating accuracy.

4.6.1.4 Catch Tanks. Catch tanks that have received spills or runoff that is not exempted in Section 9.0 require sampling using the same number of samples as a generator to DST transfers discussed below. This approach was selected because catch tanks are small and collection by depth is not appropriate. When sampling is required, the analysis will be performed per Table 4-1. Catch tanks that have received similar waste as DSTs, have not received spills, and for which process knowledge allows evaluation of the contents do not require sampling and analysis. 


\subsubsection{Number and Location of Samples Generator-to-DST Transfers}

Tanks used by generators have a much smaller volume than the DSTs or SSTs. The generator tanks typically have an agitator or other mixing device. Some generator tanks have limited sampling access. In order to check for precision, two samples will be collected from the tank and each sample will be analyzed as an independent sample by the laboratory. Sufficient volume of one of the samples must be collected to allow the laboratory to perform spikes or duplicate analyses as required in Table 4-1.

If the same waste stream is transferred over a year or more, samples must be collected at least once per year.

Table 4-1. Recommended Detection Limits and Analytical Quality Control

\begin{tabular}{|c|c|c|c|c|c|}
\hline \multirow[b]{2}{*}{ Analyte } & \multirow{2}{*}{$\begin{array}{l}\text { Analytical } \\
\text { Technique }\end{array}$} & \multicolumn{3}{|c|}{ QC Acceptance Criteria } & \multirow{2}{*}{$\begin{array}{l}\text { Recommended } \\
\text { Detection } \\
\text { Level }^{4}\end{array}$} \\
\hline & & $\underset{\text { \%CS }}{\text { LCcovery }}{ }^{1}$ & $\begin{array}{c}\text { Spike } \\
\text { \%Recovery }{ }^{2}\end{array}$ & $\begin{array}{c}\text { Duplicate } \\
\text { RPD }^{3}\end{array}$ & \\
\hline $\mathrm{OH}$ & Potentiometric titration & $80-120 \%$ & N/A & $\leq 20 \%$ & $\begin{array}{l}0.007 \underline{\mathrm{M}} \\
125 \mu \mathrm{g} / \mathrm{mL}\end{array}$ \\
\hline $\mathrm{NO}_{2}$ & IC/conductivity & $80-120 \%$ & $75-125 \%$ & $\leq 20 \%$ & $\begin{array}{c}0.005 \underline{\mathrm{M}} \\
258 \mu \mathrm{g} / \mathrm{mL}\end{array}$ \\
\hline $\begin{array}{l}\text { Caustic } \\
\text { demand }\end{array}$ & $\begin{array}{l}\text { Standard addition/ } \\
\text { potentiometric titration }\end{array}$ & N/A & $\mathrm{N} / \mathrm{A}^{\mathrm{s}}$ & Report & N/A \\
\hline $\mathrm{NO}_{3}$ & IC/conductivity & $80-120 \%$ & $75-125 \%$ & $\leq 20 \%$ & $\begin{array}{c}0.01 \mathrm{M} \\
620 \mu \mathrm{g} / \mathrm{mL}\end{array}$ \\
\hline $\mathrm{Cl}^{6}$ & IC/conductivity & $80-120 \%$ & $75-125 \%$ & $\leq 20 \%$ & $\begin{array}{c}0.006 \mathrm{M} \\
213 \mu \mathrm{g} / \mathrm{mL}\end{array}$ \\
\hline
\end{tabular}

IC = ion chromatography.

${ }^{1} \mathrm{LCS}=$ Laboratory Control Sample. This sample is carried through the entire method. The accuracy of a method is usually expressed as the percent recovery of the LCS. The LCS is a matrix with a known concentration of analytes that is processed with each preparation and analyses batch. It is expressed as percent recovery; i.e., the amount measured, divided by the known concentration, times 100 .

${ }^{2}$ For some methods, the sample accuracy is expressed as the percent recovery of a MS sample. It is expressed as percent recovery, i.e., the amount measured, less the amount in the sample, divided by the spike added, times 100 . One MS is performed per riser. If three samples are collected from a single riser, one MS is analyzed.

${ }^{3} \mathrm{RPD}=$ Relative percent difference between the laboratory sample and laboratory duplicate results. Sample precision is estimated by analyzing laboratory duplicates that are subsamples from the field sample. Acceptable sample precision is usually $<20 \% \mathrm{RPD}$ if the sample result is at least 10 times the instrument detection limit. Each laboratory sample is prepared and analyzed in duplicate.

${ }^{4}$ Sample detection limits vary depending on the amount of sample and dilution factors. The recommended limits are based on sample sizes specified in laboratory standard operating procedures and assume no dilution. Recommended detection limits are specified to be below the action limits. Reported 
sample detection limits may vary.

${ }^{5} \mathrm{~A}$ known amount of hydroxide is added to an aliquot of the sample. The goal is not the measurement of the absolute amount of caustic in the sample, but a determination of the caustic required to overcome the buffering effect of the waste and reach a pH stated by the client. The QC includes a reagent blank, analysis of a known hydroxide standard without sample, and a laboratory duplicate.

${ }^{6}$ Applies only to 204-AR waste transfer station. Does not apply to other DSTs, SSTs, DCRTs and 242-A Evaporator.

\subsubsection{Double-contained Receiver Tanks}

Should a liquid of sufficient depth to allow sampling (100 cm [40 in.] or more) remain in a DCRT, and the material remain in the tank for some time, a minimum of two samples must be obtained.

\subsubsection{Transfers Between the 242-A Evaporator and the DST System}

Before transferring waste to the 242-A Evaporator, hydroxide, nitrate, and nitrite concentrations from the tank considered for processing will be obtained from sampling. A predictive model will be used to assess the final concentration of these parameters in the 242-A Evaporator slurry after processing. A predictive model must show that the resulting slurry will meet corrosion criteria before the waste is transferred to the 242-A Evaporator.

Data taken from the slurry during or after processing are used to assess the criteria for transfer in Sections 4.2.1 and 4.4.1. The QC method and detection limits specified in Table 4-1 must be met.

\subsection{DATA ASSESSMENT}

The result from each field sample collected at various depths will be individually compared to the specifications. If any one of the three exceed the specification limit, the laboratory notifies the shift manager of the exceedance. The shift manager requests that the result be rechecked. This recheck is not the RPD from a duplicate result that was acceptable. Analyzing one sample in duplicate is part of the normal QC and is done prior to reporting any data. If the result is believed to be accurately reported, a plan for mitigation is established for the tank. If each value is within the specification, the mean result of the three values is entered into the database for the tank. 


\subsection{ORGANIC AND ENERGETIC REACTION}

\subsection{PROBLEMS/QUESTIONS}

Following is the proposed question for the compatibility DQO as related to organics:

Will conditions be such, because of organic material and heat load in the receiving tank, to pose a safety hazard (runaway reaction)?

The group reviewed the proposed questions in light of all potential safety problems related to organics and energetics. In addition to general safety issues, the safety issues in the static state DQOs were also considered. The questions in the static state solvent and complexant DQOs were reviewed, and it was determined that no additional questions are needed for the compatibility DQO.

Initial discussions focused on the solvent content as related to the transfer of waste. In most DST systems, the aqueous waste that is more dense than solvent is pumped from the bottom of the tank. Organic Solvent Topical Report (Cowley et al. 1999), indicated that a layer of organic solvent is needed to create a safety problem.

\subsubsection{Background for Organic Complexants}

During the defense mission at the Hanford Site, organic complexants were used during fission product recovery at B Plant. These organic complexants were discharged to the waste tanks where they mixed with sodium hydroxide, sodium nitrate, sodium nitrite, and other inorganic constituents already present in the tank. In the presence of oxidizing materials, such as nitrates or nitrites, organic complexants can serve as a fuel source and support a runaway if heated to high temperatures. For the purposes of this DQO, organic fuel is defined as organic complexants and their decomposition products that, in the presence of an oxidizing material, are capable of supporting a a bulk runaway accident scenario (e.g., ethylenediaminetetraacetic acid (EDTA), hyroxyethylethylenediaminetriacetic acid [HEDTA], ED3A, NTA, IDA, glycine, unsymmetrical ethylenediaminediacetic acid, symmetrical ethylenediaminediacetic acid).

The scenario for bulk runaway is (1) the waste drying or a loss of active cooling (on a tank with a high heatload) causes the waste to heat up to the self-accelerating decomposition temperature, (2) the chemical heating raises the waste temperature which in turn accelerates the chemical reaction, (3) this accelerating bulk runaway continues until the chemical reactants are consumed. The high temperatures and gases produced over-pressurize the tank and radioactive and toxic materials are released to the environment. 
The organic complexants involved in the cesium and strontium recovery in B-Plant operations were transferred to the waste tanks in alkaline solutions. During the extended time of waste management and storage, the organic complexants have undergone decomposition reactions (i.e., changes in structure and concentration). In the latter stages of decomposition, the carbon in these chemical species may oxidize to low energy species (e.g., oxalate, formate, or carbonate).

The original organic complexants are highly soluble in the aqueous waste. Recent studies indicate that the organic complexants and their decomposition fragments are still contained in the liquids (Meacham et al. 1999). Only sodium oxalate would precipitate from the waste solutions.

Organic fuel is a hazard for bulk runaway if present in high quantities, and if the tank waste could be self-boiling if active ventilation were lost.

\subsubsection{Background for Organic Solvents}

The following summarizes the approach used to evaluate the organic solvent safety issue that affects compatability. The summary is from the Organic Solvent Topical Report (Cowley et al. 1999).

The approach to resolution of the organic solvent safety issue has matured since the safety analysis on Tank 241-C-103 (Postma et al. 1994) was completed in 1994. The original accident scenario assumed catastrophic failure of the tank dome during an organic solvent burn if an SST did not have adequate vent path. Failure of the dome led to radiological consequences above risk evaluation guidelines. Preliminary calculations showed that the solvent pool area would have to be larger than $1 \mathrm{~m}^{2}$ to create enough pressure to collapse the tank dome. The original approach required identifying tanks containing significant quantities (i.e., greater than a $1 \mathrm{~m}^{2}$ puddle) of organic solvent and ensuring an adequate vent path in those tanks that contain significant organic solvent.

Tank structural integrity was re-examined in 1996 as part of the Authorization Basis upgrade (Noorani 1997). Analyses (Han 1996) showed that the tank dome would not fail catastrophically under the pressures developed during an organic solvent fire. Instead, the dome would develop cracks and fissures to release the internal pressure and stay mostly intact. Revision 0 of this report showed radiological consequences were mostly the result of the splash from catastrophic failure of the dome. Ensuring adequate vent path was rendered moot by the tank structural integrity analysis.

Although Revision 0 of this report showed that the radiological consequences fell within guidelines. Toxicological consequences still exceed the risk evaluation guidelines. Therefore, the earlier approach still relied on characterization to determine how many solvent tanks existed. If few solvent tanks existed, then the facility-wide accident frequency might be low enough to bring the risk within the evaluation guidelines. 
The effects of jet mixing and aerosol depletion are included in the radiological and toxicological consequence calculations of Cowley et al. (1999). The revised consequence calculations show that the solvent fire hazard falls below risk evaluation guidelines when controls are applied. This is true even if all tanks were assumed to contain organic solvent.

Based on this assessment, no additional analysis is needed to support compatability. A visual examination for solvent layers is recommended.

\subsection{DECISIONS}

Two decisions were posed.

1. In order to transfer waste, the decision is whether the combined waste from the sending and receiving tanks contains sufficient water to mitigate a bulk runaway. That is, does the latent heat of water vaporization (energy required to change liquid water to vapor) exceed the chemical energy potential.

2. Do the combined wastes from the sending and receiving tanks have sufficient solvent layers that, if ignited, could cause a safety problem in the tank?

\section{$5.3 \quad$ INPUT AND BOUNDARIES}

The boundary of this DQO is the supernatant (liquid) phase pumped during transfers. Transfers discussed include:

- DST to DST

- SST to DST

- Generator transfers into DSTs, excluding the 242-A Evaporator

- DCRTs

- Piping between DST systems

- 242-A Evaporator slurry to DSTs

- Catch tanks within the DST system.

Catch basins and tanks used to capture raw water or snow melt are exempted from testing per Section 9.0. In order to train operators in running the 242-A Evaporator or to test equipment in the 242-A Evaporator, clean water and/or process condensate are run through the 242-A Evaporator system. The transfer of this water to the DST system is exempted from testing provided the water does not contain free-floating organics. Table 5-1 lists the boundaries and associated inputs. 
Table 5-1. Boundaries and Inputs

\begin{tabular}{|c|c|c|}
\hline Boundary & Decision Input* & Reason for Decision Input \\
\hline $\begin{array}{l}\text { DST-to-DST } \\
\text { Generator-to-DST transfer, SST } \\
\text { to DST transfer } \\
\text { Exemptions from testing: } \\
\text { Waste known to consist of } \\
\text { primarily water, such as raw } \\
\text { water line breaks and snow melt. }\end{array}$ & $\begin{array}{l}\text { For the sending tanks, use historical } \\
\text { data or obtain new data for: } \\
\text { - Total organic carbon (TOC) } \\
\text { concentration }<52 \mathrm{~g} / \mathrm{L} \\
\text { Visual inspection for solvent } \\
\text { layering }\end{array}$ & $\begin{array}{l}\text { Assess existing data from tanks and } \\
\text { identify tanks with the potential to } \\
\text { generate net exothermic reactions } \\
\text { that might propagate a combustion } \\
\text { event. } \\
\text { Visual inspection is used to } \\
\text { determine the presence of solvents. } \\
\text { Layering may be indicative of } \\
\text { organics. Waste containing organic } \\
\text { layers is not accepted. Any waste } \\
\text { with }>52 \text { g/L TOC must be diluted } \\
\text { and undergo case-by-case } \\
\text { evaluation. }\end{array}$ \\
\hline $\begin{array}{l}\text { 242-A Evaporator-to-DST. } \\
\text { Exempt from analysis are the } \\
\text { training/process equipment runs } \\
\text { using water for training staff in } \\
\text { operation of the } 242-A \\
\text { Evaporator. }\end{array}$ & $\begin{array}{l}\text { Visual for organic layers; energetics } \\
\text { and percent moisture are obtained } \\
\text { from samples collected before } \\
\text { staging the waste for } 242-A \\
\text { Evaporator feed and are required by } \\
\text { the current } 242-A \text { Evaporator DQO } \\
\text { (Von Bargen 1995). If the waste feed } \\
\text { meets the criteria, the waste } \\
\text { processed through the plant and } \\
\text { discharged to the DST system will } \\
\text { also meet the criteria because the } \\
242-\text { A Evaporator operation does not } \\
\text { add organics. Also, an assessment is } \\
\text { performed before processing the } \\
\text { waste to ensure that the } 242-A \\
\text { Evaporator slurry meets DST } \\
\text { discharge requirements and is } \\
\text { compatible with the slurry receiver } \\
\text { DST before processing. } \\
\text { After processing, the } 242-A \\
\text { Evaporator slurry is sampled per the } \\
\text { criteria in Table 5-2. }\end{array}$ & $\begin{array}{l}\text { In order to transfer waste to the } \\
\text { 242-A Evaporator, the waste is } \\
\text { evaluated based on the feed } \\
\text { material exotherm/endotherm ratios } \\
\text { and predictive calculations to } \\
\text { assure that the waste is acceptable } \\
\text { for processing. The returning } \\
\text { slurry must meet DST criteria and a } \\
\text { waste profile must be provided. } \\
\text { The criteria and profile for the } \\
\text { slurry are met via the predictive } \\
\text { evaluation based on the feed. If the } \\
\text { predicted exotherm/endotherm and } \\
\text { moisture do not meet generator } \\
\text { criteria, the waste is not processed } \\
\text { through the } 242-\mathrm{A} \text { Evaporator. }\end{array}$ \\
\hline
\end{tabular}

*Based on Meacham et al. (1999).

\subsubsection{DSTs, DCRT and Catch Tank Bulk Runaway Screening Criteria}

DSTs, DCRTs, and catch tanks contain mostly aqueous waste and the available water provides a large heat sink for any exothermic chemical reactions that could occur. It is possible to rule out 
bulk runaway through a simpler energy balance comparing the available theoretical chemical energy with the energy required to change liquid water into vapor. Bulk runaway is not possible if the energy required to change liquid water into vapor is greater than available theoretical chemical energy (Meacham et al. 1999).

Heat generated by a chemical reaction would be absorbed by the surrounding water, and tank waste temperatures would remain below about $120^{\circ} \mathrm{C}$ (the boiling temperature of the supernatant). In the Organic Complexant Topical Report (Meacham et al. 1999), provides detailed assessment of the relationship between headpsace temperature and tank heatload. After full evaluation using TOC and water inventories for $28 \mathrm{DSTs}$, the result was that bulk runaway is not possible under current storage conditions.

For transfers into DSTs, a similar evaluation was performed. The minimum water concentration in a potential incoming transfer is about $50 \mathrm{wt} \%$, and the corresponding energy required to change liquid water into vapor would be $1.6 \mathrm{E} 6 \mathrm{~J}$ per kg of waste to begin to shift the current energy balance. The TOC equivalent (using the heat of combustion of Na3 HEDTA with sodium nitrate, $3.7 \mathrm{E} 7 \mathrm{~J}$ per $\mathrm{kg}$ of carbon) is about $4.3 \mathrm{wt} \%$ or $52 \mathrm{~g}$ of TOC per liter. Tanks that receive waste transfers that contain TOC concentrations $>52 \mathrm{~g} / \mathrm{L}$ need to be reevaluated for bulk runaway.

Waste transfers do not change the results of the DST assessment as long as the total heatload will not cause the waste supernatant to boil. The heatload required for bulk boiling was calculated in Meacham et al. (1999) as 21,700 watts. If the heatload in a DST exceeds 21,700 watts, then the tank needs to be evaluated for bulk runaway per Meacham et al. (1999).

Six DCRTs underwent a similar evaluation and the energy required to change liquid water into vapor exceeds the available theoretical chemical energy by about two orders of magnitude. Bulk runaway reactions are not credible for the DCRTs.

Catch tanks are used to collect a small amount of liquid. Three catch tanks that typify the typical catch tank content were evaluated in the same manner previously described. An additional historical process knowledge review on the contents of the other tanks was performed. The high water and low TOC concentrations indicate no potential for bulk runaway reactions in the catch tanks. Therefore, no analysis of catch tanks for organics is required.

\subsubsection{Single-shell Tanks}

SST are either passively ventilated or actively ventilated. Only one SST, C-106, requires water for evaporative cooling. The past safe storage time was compared to the cooling time. Meacham et al. (1999) provides discussion that proves that for the passively ventilated tanks, temperatures in the tank waste will continue to decline, even as the waste slowly dries and the thermal conductivity decreases. 
For the fifteen actively ventilated tanks, seven tanks do not contain sufficient organic material to fuel a bulk runaway. For seven additional tanks the cooling time was calculated along with what the time average temperature in the waste tanks would under passive ventilation alone. Excluding Tank C-106, the characteristic times of cooling are shorter than the current safe storage time of $17 \mathrm{yr}$ and the temperatures under passive ventilation are less than historical highs.

Tank $\mathrm{C}-106$ requires water cooling and an assessment of the energy balance used to evaluate DSTs indicated that bulk runaway was not possible (Meacham et al. 1999).

\subsubsection{Piping Between DST and SST Systems}

A bulk runaway reaction is not credible in a pipe.

\subsubsection{2-A Evaporator Slurry to DST}

An initial evaluation of the feed to the 242-A Evaporator includes differential scanning calorimetry (DSC). The TOC and DSC information is used to predict the ultimate concentration of material in the slurry remaining after evaporation.

Because initial evaluation of the waste to be staged to the 242-A Evaporator will disallow the transfer of any waste that may show a chance of a propagating reaction via energetics and moisture evaluation, no waste containing organics that would cause a propagating reaction shall be allowed in the 242-A Evaporator feed tank. Based on analysis and modeling, waste containing separable organic layers is not allowed to be transferred to the 242-A Evaporator.

Once the evaporation process is completed, the slurry is transferred back to the DSTs. DSC is not required on the slurry for the following reasons: (1) the water content of the slurry is well above $17 \%$ water and this amount of water content will mitigate any propagating reaction; (2) volatiles provide much of the chance for fire or explosion and are removed during evaporation, leaving behind non-volatile material; and (3) past process data have shown exotherm-to-endotherm ratios of the feed to be near zero.

\subsubsection{Basis for Total Organic Carbon Action Level}

A discussion in Section 5.3.1 presents the information used to assess the TOC content and provides the basis of the TOC criteria. Tanks that receive waste transfers that contain TOC concentrations $>52 \mathrm{~g} / \mathrm{L}$ need to be reevaluated for bulk runaway. 


\subsection{DECISION RULE}

While the technical basis for the complexant indicates that only a TOC analysis is required routinely for the SST to DST and DST to DST transfers, the Operating Specification Documents (OSDs) have not been updated to include these changes (OSD-T-151-00007, -00013, and -00017) (PHMC 1998a, 1998b, 1998c). Therefore, two sets of logic exist. One set of logic will be used until the OSDs are updated to meet the criteria in Meacham et al. (1999) as discussed in Sections 5.4.1 and 5.4.2. After the OSDs are updated, the logic will be made consistent with Meacham et al. (1999), as discussed in Section 5.4.3.

\subsubsection{For all Transfers Made Before OSD and DST Waste Acceptance Plan (Mulkey 1998) Updates}

Samples are collected per Section 5.6. Two aliquots from each field sample collected at various levels in the tank are analyzed by DSC. These aliquots are considered laboratory duplicates and are evaluated individually.

- If the ratio of exotherms to endotherms of both aliquots from each sample is $<1$, the transfer is allowed.

- If the source waste has no separable organic layer, and if both aliquots of any sample from the source and receiving wastes have ratios of the exotherms versus endotherms $>1$, the transfer is not allowed without additional evaluation to determine if it may be safely stored in the DST system.

- If either aliquot generates a ratio $>1$, another pair of laboratory duplicates is analyzed from the same original field sample and all four results are reported. The transfer will not be allowed without additional evaluation to determine if it may be safely stored in the DST system.

\subsubsection{SST to DST, 242-A Evaporator Slurry to DST, Generator to DST Transfers For Transfers Before OSD and DST Waste Acceptance Plan (Mulkey 1998) Updates}

- If the $w t \%$ free water $\geq 20 \%$, and the criteria from Section 5.4.1 are acceptable, proceed with the transfer; otherwise evaluate the TOC as follows.

- If the $\mathrm{wt} \%$ free water $<20 \%$, and the TOC $<4.5+0.17$ (wt $\%$ free water), and the criteria from Section 5.4.1 are acceptable, proceed with the transfer, otherwise do not transfer waste. 


\subsubsection{Decision Logic After OSD and DST Waste Acceptance Plan (Mulkey 1998) Updates}

After the OSDs are updated to reflect the latest technical basis (Meacham et al. 1999), the following logic may be used for DST to DST, 242-A Evaporator slurry to DST, generator to DST, and SST to DST transfers. Figures 5-1 and 5-2 outline the updated logic.

- If an incoming waste transfer exceeds $52 \mathrm{~g} / \mathrm{L}$ TOC, then the RPP process engineers must reassess the tanks for bulk runaway.

- If an incoming waste transfer is less than $52 \mathrm{~g} / \mathrm{L}$ TOC, then the transfer may proceed.

- If either duplicate exceeds the $52 \mathrm{~g} / \mathrm{L}$ TOC, then another pair of duplicates is analyzed from the same original field sample and all four results are reported. The transfer will not be allowed without additional evaluation and approval by RPP process engineers.

The logic for feed to the 242-A Evaporator is as follows:

- If the ratio of exotherm to endotherm is $\leq 1$, then the transfer to the 242-A Evaporator is allowed.

- If the ratio of exotherm to endotherm is $>1$, then the transfer to the 242-A Evaporator requires special approval by the 242-A Evaporator process engineer.

\subsection{UNCERTAINTY}

The consequence of making incorrect decisions are used to assess the concentrations requiring the greatest accuracy and precision and do not absolve the contractor from meeting the criteria.

The existing data are graphed in Appendix B for the DSC results from all compatibility evaluation transfers. The graph shows the exotherm to endotherm ratios for each individual measurement. The laboratory duplicates are presented. All measurements are well below the ratio of 1 . Data are sufficiently below the criteria to allow assessment of the results. No additional precision specification is needed for DSC.

Past information indicates that free water is consistently above $20 \%$ in all systems; therefore, no evaluation of the free water or TOC criteria was performed. 


\subsection{SAMPLING DESIGN}

Table 5-2 summarizes the sampling design for each type of transfer.

Table 5-2. Summary of Organic Sample Design/Action Limits

\begin{tabular}{|c|c|c|c|}
\hline Boundary/Transfer & $\begin{array}{c}\text { Number of Samples/ } \\
\text { Locations }\end{array}$ & Analytes & Action Limits \\
\hline \multicolumn{4}{|c|}{ Criteria and Design Until OSDs and DST Waste Acceptance Plan (Mulkey 1998) are Updated } \\
\hline \multirow{4}{*}{$\begin{array}{l}\text { SST, } \\
\text { 242-A Evaporator slurry, } \\
\text { Generator }\end{array}$} & \multirow{4}{*}{$\begin{array}{l}\text { Sections } 5.6 .1 \text { and } 5.6 .2 \\
\text { as applicable logic of } \\
\text { Figure } 5-3 \text { for SSTs }\end{array}$} & $\begin{array}{l}\text { TOC (analyze only if free } \\
\text { water } \leq 20 \% \text { ) }\end{array}$ & $\begin{array}{l}<4.5 w t \%+0.17 w t \% \\
\text { free water }\end{array}$ \\
\hline & & DSC & $\begin{array}{l}\text { Ratio exotherm to } \\
\text { endotherm } \leq 1\end{array}$ \\
\hline & & $\begin{array}{l}\text { Thermogravimetric } \\
\text { analysis (TGA) }\end{array}$ & free water $>20 \%$ \\
\hline & & Visual & no separable layer \\
\hline \multirow[t]{2}{*}{$\begin{array}{l}\text { DST, sending tank, } \\
\text { 242-A Evaporator feed. }\end{array}$} & \multirow[t]{2}{*}{$\begin{array}{l}\text { Section } 5.6 .1 \text { and logic of } \\
\text { Figure } 5-3\end{array}$} & DSC & $\begin{array}{l}\text { Ratio exotherm to } \\
\text { endotherm } \leq 1\end{array}$ \\
\hline & & Visual & No separable layer \\
\hline \multicolumn{4}{|c|}{ Criteria and Design After OSDs and DST Waste Acceptance Plan (Mulkey 1998) are Updated } \\
\hline $\begin{array}{l}\text { DST to DST, SST to } \\
\text { DST, 242-A Evaporator } \\
\text { to DST, Generator to } \\
\text { DST }\end{array}$ & $\begin{array}{l}\text { Sections } 5.6 .1 \text { and } 5.6 .2 \\
\text { and Figure 5-3 }\end{array}$ & TOC & $<52 \mathrm{~g} / \mathrm{L}$ \\
\hline \multirow[t]{2}{*}{ DST to 242-A Evaporator } & \multirow[t]{2}{*}{$\begin{array}{l}\text { Section } 5.6 .1 \text { and logic of } \\
\text { Figure } 5-3\end{array}$} & DSC & $\begin{array}{l}\text { Ratio exotherm to } \\
\text { endotherm } \leq 1\end{array}$ \\
\hline & & Visual & No separable layer \\
\hline
\end{tabular}

\subsubsection{Number and Location of Samples SSTs and DSTs, 242-A Evaporator}

Grab samples are obtained from the sending and receiving tanks for DSC analysis. The process for obtaining the grab samples includes:

- Initiation of a change request to the grab sample schedule. Upon approval, the subject tank is added to Tank Characterization's grab sample schedule.

- Preparation of a process memorandum requesting grab samples. The process memorandum specifies sample number, sample type, sample location, sample elevation, cable length, and any additional instructions. 
The equipment used for grab sampling is an open device, such as a bottle attached to a string. The device is about $0.30 \mathrm{~m}(1 \mathrm{ft})$ long. The LL governs the number of samples. The following is the recommended strategy:

- If the LL of waste is $<101 \mathrm{~cm}$ (40 in.), one grab sample will be obtained.

- If $101 \mathrm{~cm}(40 \mathrm{in}$.) $<\mathrm{LL} \leq 254 \mathrm{~cm}(100 \mathrm{in}$.), obtain two grab samples at different depths.

- If $L L>254 \mathrm{~cm}$ (100 in.), obtain three to four grab samples with at least one grab per $254 \mathrm{~cm}$ (100 in.).

In cases where the liquid is interstitial to solids, drainable liquid portions from segments from various depths may be collected. For tanks containing salt cake, liquid samples may also be obtained from the salt well screen. Where applicable, data assessment is performed by sample depth, as opposed to an average. The depth of the sample must be clearly documented and reported.

Samples from the 242-A Evaporator slurry are collected either in the runout line or the slurry tank. Collect at least one field duplicate sample at one depth for assessment of sampling precision.

\subsubsection{Number and Location of Samples for Generator-to-DST Transfers}

Tanks used by generators have a much smaller volume than the DSTs or SSTs. The generator tanks typically have an agitator or other mixing device. Some generator tanks have limited sampling access. In order to check for precision, two samples will be collected from the tank and each sample will be analyzed as an independent sample by the laboratory. Sufficient volume of one the samples must be collected to allow the laboratory to perform spikes or duplicate analyses as required in Table 5-3.

\subsubsection{Analytes and QC}

Table 5-3 presents the recommended detection levels and analytical QC used for the analyses. 
Table 5-3. Recommended Detection Limits and Analytical QC

\begin{tabular}{|c|c|c|c|c|c|}
\hline \multirow{2}{*}{ Analyte } & \multirow{2}{*}{$\begin{array}{l}\text { Analytical } \\
\text { Technique }\end{array}$} & \multicolumn{3}{|c|}{ QC A.cceptance Criteria } & \multirow{2}{*}{$\begin{array}{l}\text { Recommended } \\
\text { Detection } \\
\text { Level }{ }^{4}\end{array}$} \\
\hline & & $\begin{array}{c}\text { LCS } \\
\text { \%Recovery }\end{array}$ & $\begin{array}{c}\text { Spike } \\
\text { \%Recovery }\end{array}$ & $\begin{array}{l}\text { Duplicate } \\
\text { RPD }^{3}\end{array}$ & \\
\hline TOC & $\begin{array}{l}\text { Silver catalyzed } \\
\text { persulfate oxidation }\end{array}$ & $80-120 \%$ & $75-125 \%$ & $\leq 20 \%$ & $\begin{array}{c}8.0 \mathrm{E}-03 \mathrm{wt} \% \\
(80 \mu \mathrm{g} / \mathrm{mL})\end{array}$ \\
\hline $\mathrm{DSC}^{6}$ & $\begin{array}{l}\text { Differential Scanning } \\
\text { Calorimetry }\end{array}$ & $80-120 \%$ & $N / A^{5}$ & $\leq 30 \%$ & none \\
\hline $\mathrm{TGA}^{7}$ & $\begin{array}{l}\text { Thermal gravimetric } \\
\text { analysis }\end{array}$ & $80-120 \%$ & $\mathrm{~N} / \mathrm{A}$ & $\leq 20 \%$ & N/A \\
\hline
\end{tabular}

${ }^{1} \mathrm{LCS}=$ Laboratory Control Sample. This sample is carried through the entire method. The accuracy of a method is usually expressed as the percent recovery of the LCS. The LCS is a matrix with known concentration of analytes that is processed with each preparation and analyses batch. It is expressed as percent recovery; i.e., the amount measured, divided by the known concentration, times 100 .

${ }^{2}$ For some methods, the sample accuracy is expressed as the percent recovery of a MS sample. It is expressed as percent recovery; i.e., the amount measured, less the amount in the sample, divided by the spike added, times 100. One MS is performed per riser. If three samples are collected from a single riser, one MS is analyzed.

${ }^{3} \mathrm{RPD}=$ Relative percent difference between the sample and duplicate results. Sample precision is estimated by analyzing laboratory duplicates that are subsets of the original sample. Acceptable sample precision is usually $\leq 20 \%$ RPD if the sample result is at least 10 times the instrument detection limit. All samples are analyzed in duplicate. The RPD pertains only to the laboratory duplicates. Field duplicate results are reported but the RPD criteria do not apply.

${ }^{4}$ Sample detection limits vary depending on the amount of sample and dilution factors. The recommended limits are based on sample sizes specified in laboratory standard operating procedures and assume no dilution. Recommended detection limits are specified to be below the action limits. Reported sample detection limits may vary.

${ }^{5} \mathrm{~N} / \mathrm{A}=$ Not applicable, because of the small size of the sample, and it is impossible to know the compound producing the endotherm or exotherm. Therefore, a meaningful spike cannot be made.

${ }^{6}$ Required on all transfers until OSDs and DST Waste Acceptance Plan (Mulkey 1998) are updated to HNF-3588 (Meacham et al. 1999) criteria. After update only required on 242-A Evaporator feed.

${ }^{7}$ Required until OSDs DST Waste Acceptance Plan (Mulkey 1998) are updated to HNF-3588 (Meacham et al. 1999) criteria. After update, not required for any transfer. 
Figure 5-1. Decision for 242-A Evaporator

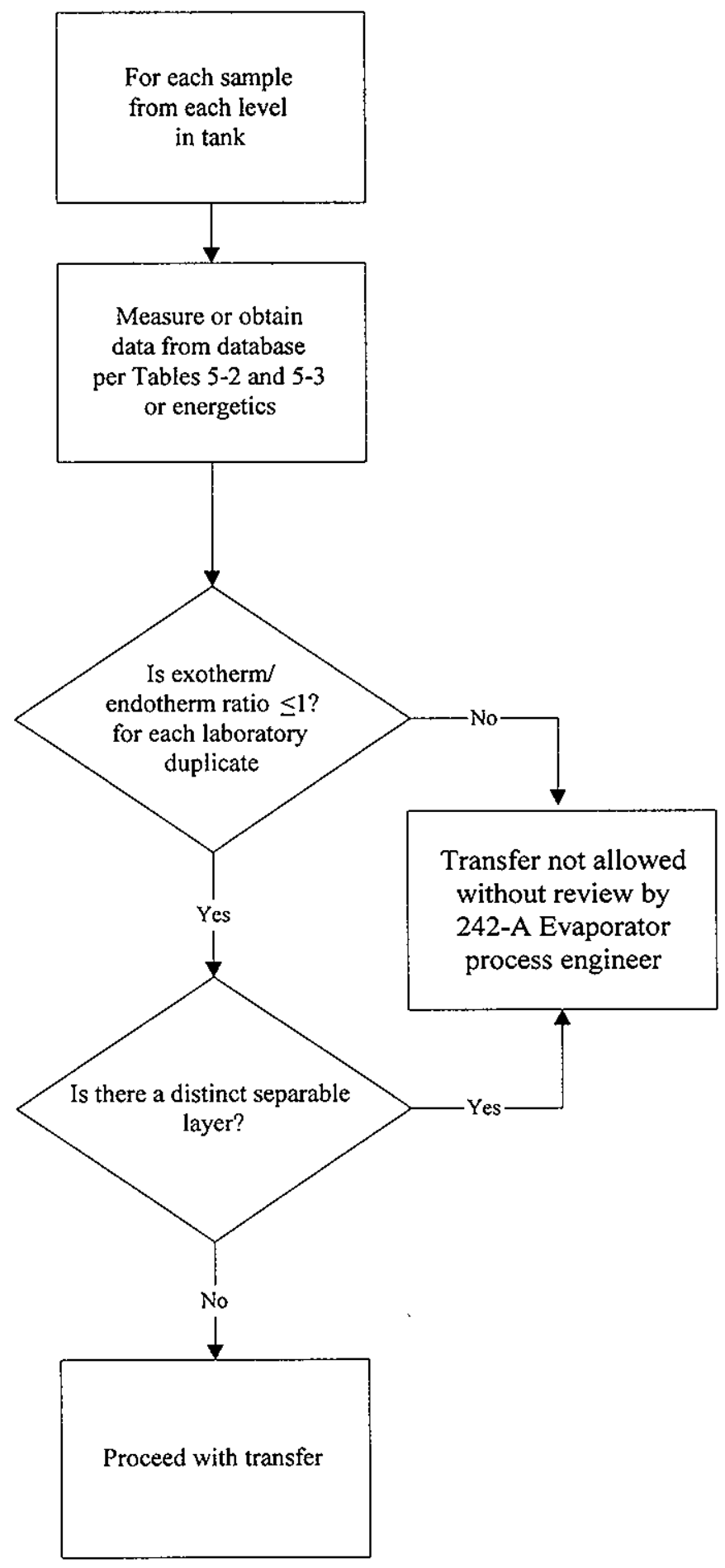


Figure 5-2. Decision Logic for DST Transfers, SST to DST Transfers, Generator Transfers*

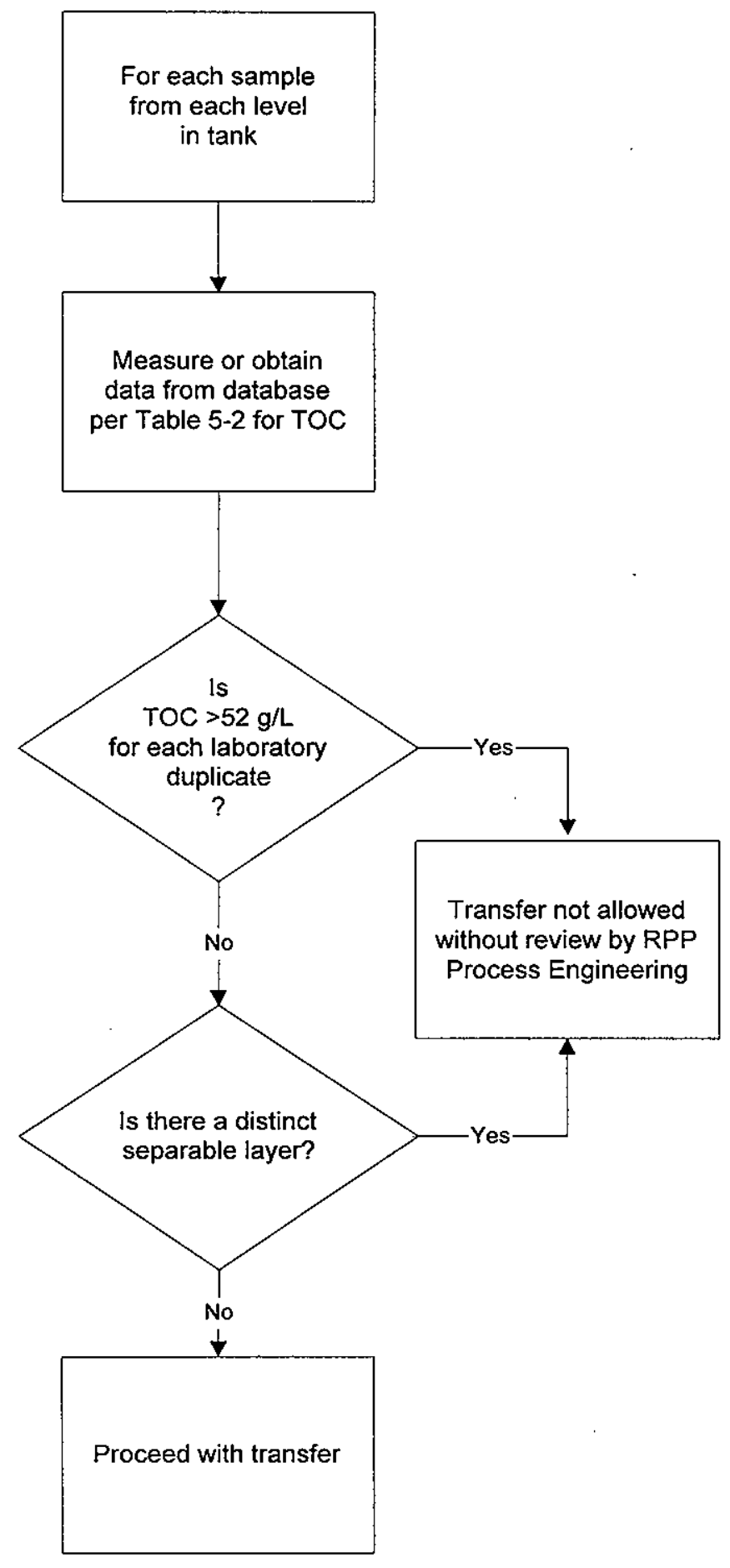

*Logic to be applied after ODSs and SST Waste

Acceptance Plan (Mulkey 1998) updates 
HNF-SD-WM-DQO-001, Rev. 3

Figure 5-3. DST/SST Grab Sample Logic

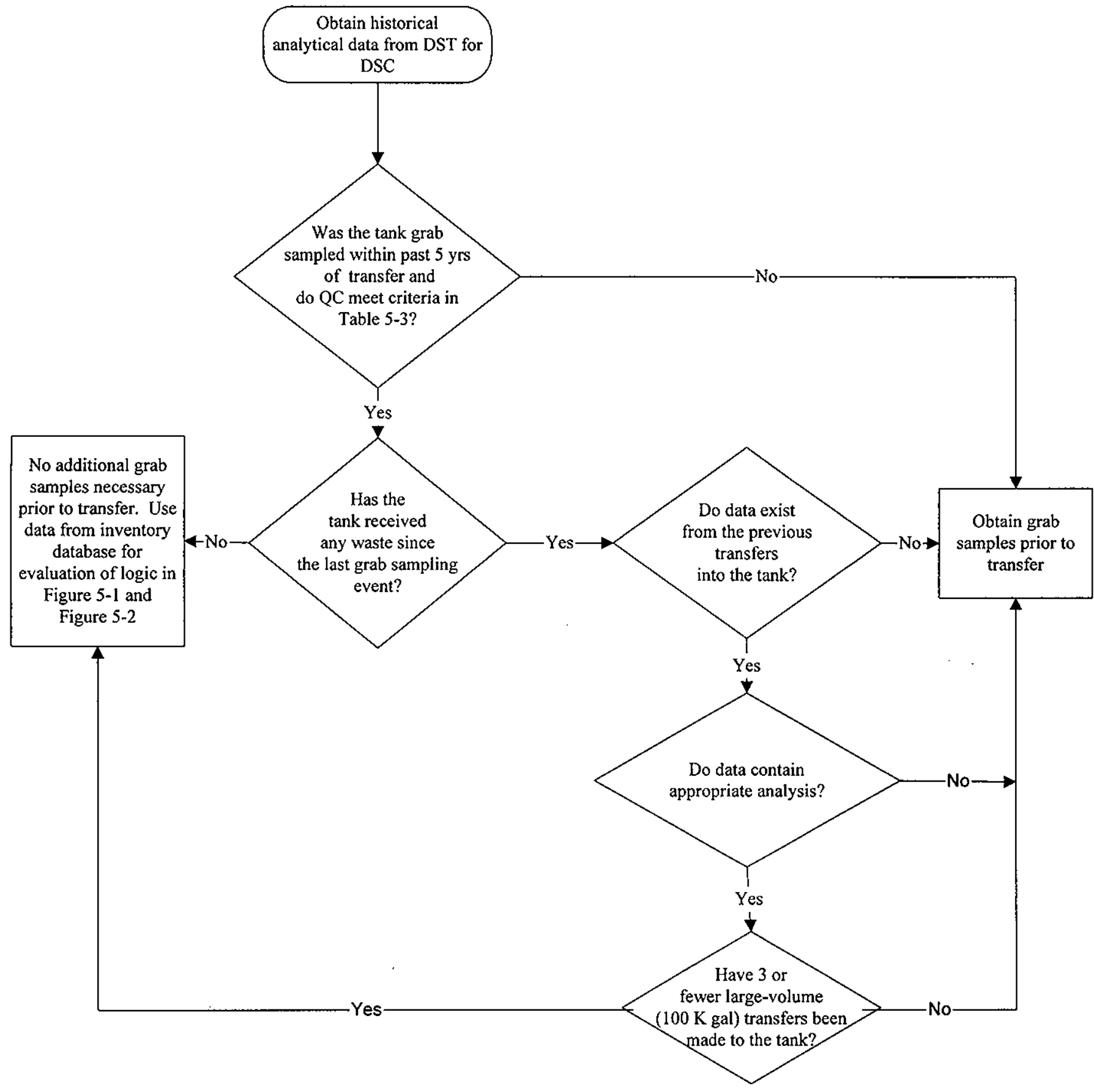




\subsection{FLAMMABLE GAS}

\subsection{PROBLEM}

There are 177 waste storage tanks containing over $210,000 \mathrm{~m}^{3}$ ( 55 million gal) of mixed hazardous wastes at the Hanford Site. The wastes in the tanks generate and sometimes retain and release FG. Gas retention and release in static state tanks is addressed in Flammable Gas Tank Safety Program: Data Requirements for Core Sample Analysis Developed Through the Data Quality Objectives Process (Benar 1995).

The problem that must be addressed in this DQO process is:

Under transfer conditions, the potential may exist in some transfers from waste generators to DSTs, the 242-A Evaporator to the DSTs, SSTs to DSTs, and in piping to generate $F G$ that when coupled with an ignition source, could result in a breach of tank containment.

This document defines the decision strategy that must be followed for all of the previously mentioned transfers so that potentially dangerous conditions can be predicted and appropriate mitigation measures applied. This document defines the type, quantity, and quality of data to be collected, and the algorithms and models that are applied to predict generation of FG.

\section{Background}

All tank wastes generate FGs. In order for FG to be a safety problem, a mixture of gaseous fuel and oxidizer at concentrations greater than the lower flammability limit (LFL) of the mixture must be present. The gas generation rate is determined by the thermodynamic and kinetic conditions of the waste material present. Generation rates differ between tanks depending on the composition temperature and radiation level of each tank. Once generated, the FG may be retained below the waste surface and/or released into the tank headspace. In DSTs, active ventilation prevents buildup of FG in the headspace.

Two types of gas release behavior have been observed: steady-state release and gas release events (GREs). A GRE is the sudden release of FG from the waste matrix into the tank headspace. The focus of this DQO process is to predict waste transfers that could cause GREs. The predictions will allow decision makers to either take mitigative action or not transfer the waste. 


\subsection{DECISIONS}

The primary question asked by decision makers is:

\section{Will conditions result that will cause a FG hazard?}

The focus of this DQO process is the transfer of waste between tanks. The general criterion for GRE prevention is to maintain FG levels in the headspace below $25 \%$ of the LFL. The criterion is based on the Standard on Explosion Prevention Systems (NFPA 69).

In order to understand the mechanism for generating gas levels that are $25 \%$ of the LFL, the mechanisms causing gas release are being studied. The focus of this DQO process is to use the current knowledge of the mechanisms of GRE to establish criteria to prevent transfers that could cause GREs to exceed the criteria.

The primary question is divided into three secondary questions:

- Will transfer cause FG release and retention in the sending tank in excess of $25 \%$ of the $L F L$ ?

- Will transfer cause FG release and retention in the piping in excess of $25 \%$ of the LFL?

- Will transfer cause $F G$ release and retention in the receiving tank in excess of $25 \%$ of the LFL?

The decision logic required to address each question is presented in the following sections.

\subsubsection{Will Transfer Cause Flammable Gas Release and Retention in the Sending or the Receiving Tank in Excess of $25 \%$ of the Lower Flammability Limit?}

The goal of answering this decision is to leave a tank in a safe condition once transfer is complete. The depth of the non-convective layer and the supernatant SpG must be measured in the receiving tank before waste transfer. The $\mathrm{SpG}$ of the supernatant of the sending tank must be measured. An estimation of the depth (inches) and $\mathrm{SpG}$ after transfer is used to calculate the product of the $\mathrm{SpG}$ times the depth product of the material in the receiving tank after transfer.

After transfer will the product of the depth of the non-convective solids $\left(D_{s}\right)$ and the convective waste or supernatant $\mathrm{SpG}<148$ in the resulting receiving tank?

$$
D_{s} * \mathrm{SpG}<148 \text {. }
$$


If the answer is yes, the transfer can be performed. If the answer is no, the transfer must be examined on a case-by-case basis to determine if it may be stored safely in the DST system. Two additional questions that must be asked follow.

- After transfer, will the weighted mean specific gravity from the entire tank be $\leq 1.41$ SpG? If the answer is yes, the transfer can be performed.

- Is the time to $25 \%$ LFL acceptable? The acceptance limits are based on modeling as discussed below. Information input to the model includes ammonia, TOC, and aluminum.

\subsubsection{Basis for Criteria}

\subsubsection{Summary of Gas Generation. In the Flammable Gas Project Topical Report} (Johnson et al. 1997), a summary of the current understanding of gas generation, gas retention, and gas release is presented. Understanding the mechanisms for production of the various gases should allow future operations to prevent conditions that promote generation of hydrogen, ammonia, and nitrous oxide. Knowledge about the composition is needed to allow an understanding of the flammability characteristics. The effects of radiation on generation of the gases (Meisel et al. 1993) and the thermal degradation of the organic species (Barefield et al. 1996) through studies of synthetic waste mixture have already been evaluated. The current focus has been on testing actual waste samples.

The thermal generation studies indicate that the mechanism of hydrogen generation from chelators such as EDTA and HEDTA involve extensive fragmentation of those molecules. Aluminate and nitrite ions are thought to initiate the decomposition. Formaldehyde is thought to be the primary hydrogen-generating intermediate. The gaseous by-products of HEDTA are presented in Barefield et al. (1996). The products are ammonia, nitrous oxide, nitrogen and hydrogen, with ammonia having the most product and hydrogen the least.

Radiolytic reactions also generate gases. Studies using simulants to understand the hydrogen generation efficiency for the various chelators are presented in Meisel et al. (1991). The yield of the reactions increased in the presence of oxygen. Hydrogen yield was lowest when no organics were present. The studies indicated that formaldehyde generated via both thermal and radiolytic fragmentation is an especially important source of hydrogen.

Mass spectrometry analysis of grab samples from the headspaces of 25 Hanford Site tanks have been collected and analyzed to assess the gas composition. The ratio of hydrogen to $\mathrm{N}_{2} \mathrm{O}$ indicated a wide range ( 33 to 0.40) (Johnson et al. 1997). The retained gas sampler is being used to obtain data from the gases without dilution by air. The initial samples from Tank $241-\mathrm{AW}$ 101 indicated that nitrogen, ammonia, hydrogen and nitrous oxide were the major gases present. 


\subsubsection{Summary of Mechanisms for Spontaneous Release Mechanisms and Release Rates.} In order to understand how FG levels reach $25 \%$ of the LFL, the mechanisms causing gas release have been studied and are published by Stewart et al. (1996). Stewart's report presents information that indicates that the major cause of a GRE is buoyant rollover in the tanks.

\subsubsection{Relationship Between Non-Convective Solids Depth and Convective Waste Specific} Gravity. Work by Estey and Guthrie (1996a) was performed to develop new or additional control limits intended to minimize accumulation of gas within the DSTs. The results of the work indicate an empirical link between the depth of the non-convective waste (solids, sludges, saltcake, and crust) and the SpG of the convective waste (Estey and Guthrie 1996a).

Figure 6-1, which is a copy of Figure 6a from a plot of the measured change in tank level divided by a measured change in atmospheric pressure (differential of length versus pressure [dL/dP]) versus the $\mathrm{D}_{\mathrm{s}} * \mathrm{SpG}$ of the liquid. DSTs with documented rollover or buoyant displacement behavior, give products greater than 250, and all DSTs with no history of rollover or buoyant displacement behavior, give products of less than 150 . Therefore, the initially proposed limit of the product is 150 .

6.2.2.4 Uncertainty Evaluation. The data from the memorandum that documents the work by Estey and Guthrie (1996b) was statistically evaluated. The results from the uncertainty evaluation are discussed in Section 6.6. The result of the uncertainty evaluation indicated that the acceptable limit based on the distribution was 148 as opposed to 150 .

6.2.2.5 Relationship Between Rollover and Gas Release Models. Subsequent work based on Stewart et al. (1996) work has been done by Meyer and Terrones (1996) to develop models that explain and predict rollover and GRE behavior. This document provides initial information as to why the $\mathrm{SpG}$ of the convective layer is important in the empirical work done by Estey and Guthrie (1996b). The model presented is based on the density differential that drives rollover. This document is an initial attempt to provide a potential gas release model for rollover that is the key mechanism for GRE.

6.2.2.6 Summary. The early studies on Tank 241-SY-101 indicate that the large episodic release of FG is not observed in other tanks. Five other DSTs exhibit the episodic release, but to a much smaller extent. Mitigation steps have been taken for Tank 241-SY-101 and resulted in closing the unreviewed safety question for the tank. It has been determined that there are no mechanisms for large, spontaneous release from waste stored in SSTs. Small spontaneous releases do occur. Gas monitoring has shown that the steady-state releases of gas are not a concern, because the ventilation system effectively removes the steady emission of the gases. Flammability controls that include ventilation, monitoring, and ignition source controls have been installed for all DSTs and SSTs. 
HNF-SD-WM-DQO-001, Rev. 3

6-5 
HNF-SD-WM-DQO-001, Rev. 3

Figure 6-1. Plot of dL/dP Versus Waste Depth * Waste SpG for All DSTs 
Continued work is being done with actual waste to assess the mechanisms of gas generation. Once mechanisms are better understood, improved mitigation systems can be put in place. The DQO process uses the most recent empirical formula to screen transfers of the waste that may result in a GRE.

\subsubsection{Basis of Specific Gravity Specification}

The use of SpG to indicate gas accumulation potential in tank waste has been evaluated and there is evidence that it is an appropriate limiting factor for prevention of forming FG (Reynolds 1994). The six largest average SpG values for DST wastes are from the six DSTs on the FG Watch List. The limiting SpG value is between 1.43 (the smallest value for a Watch List tank) and 1.40 (the largest value for a non-Watch List tank).

A statistical analysis of available SpG data from seven DSTs was performed to estimate the variability associated with the average SpG for a DST. Each tank was considered individually. The variability estimates were then used to calculate one-sided $95 \%$ confidence intervals for Tank 241-AN-105 (the FG Watch List DST with the smallest SpG). For six of the seven variability estimates $(85 \%)$, the lower limit of the one-sided $95 \%$ confidence interval was $>1.41$. These results provide evidence that 1.41 is an acceptable threshold for gas accumulation (Campbell 1999).

\subsubsection{Retention and Release of Flammable Gas in Pipes}

The major question related to FG is: Will transfer cause FG release and retention in the piping in excess of $25 \%$ LFL?

A non-convective layer must be present to hold the gases to allow conditions for a GRE to occur. Flushing of the pipes removes any major quantities of solids that form a non-convective layer. Normal conditions in piping do not allow the potential of a GRE. The air movement and the fact that both ends of the pipe exit to tanks and are not capped allows movement of air and gases. Therefore, there is no reason to perform analysis for FG in the piping systems.

\subsubsection{Basis for Assessment of Time to Lower Flammable Limit}

The assessment methods for DST and DCRT time to 25\% LFL differ and are presented below.

6.2.5.1 DST Time to 25\% LFL. Before any planned waste transfer, it must be verified that the minimum time to reach $25 \%$ of the LFL for the tank vapor space, assuming loss of primary ventilation, will remain $<7$ days using the methodology in $\mathrm{Hu}$ (1997). The ammonia 
concentration is required because this is the primary gas that is generated by the DSTs that is flammable. The TOC of the soluble carbon in the supernate is required because as the TOC increases, the time to LFL increases (Cox et al. 1997). Increases in aluminum concentration cause increases in hydrogen, thereby increasing the time to LFL (Cox et al. 1997, Hu 1997).

6.2.5.2 DCRT time to $25 \%$ LFL. Before any planned saltwell transfer into a DCRT, it must be verified that the DCRT vapor space will remain $<25 \%$ LFL using the methodology contained in HNF-SD-WM-CN-118 (Hedengren et al. 1997). The same input parameters are required for the reasons previously discussed.

\subsection{INPUTS}

The analyses required are the SpG obtained from sampling and the depth of the solids that are obtained from the most current waste tank summary report, or DST monthly inventory and material balance report.

Either analyses or process knowledge or historical data collected within five years of the transfer for ammonia, TOC and aluminum are required for input to the model.

\subsection{BOUNDARY}

The boundary of this DQO process is the supernatant (liquid) phase pumped during transfers. Transfers discussed include:

- DST to DST

- SST to DST

- Generator transfers into DSTs, excluding the 242-A Evaporator

- DCRTs

- Piping between DST systems

- 242-A Evaporator slurry to DSTs

- Catch tanks within the DST system.

Catch basins and tanks used to capture raw water or snow melt are exempted from testing. In order to train operators in runining the 242-A Evaporator or to test equipment in the 242-A Evaporator, clean water is run through the 242-A Evaporator system. The transfer of this water to the DST system is exempted from testing per Section 9.0 of this document.

\section{Double-contained Receiver Tanks}


DCRTs are temporary holding tanks used during transfer and are not used for waste storage. DCRTs are between sending and receiving tanks. Transfers between DSTs and/or SSTs that are via DCRTs require evaluation of the ammonia concentrations.

\subsection{DECISION RULE}

The following paragraph applies to the following transfers:

- DST to DST,

- Catch tanks

- $\quad$ SST to DSTs

- 242-A Evaporator to DSTs.

The depth of solids and $\mathrm{SpG}$ of the liquid is measured in the receiving tanks. The SpG of the supernatant is measured in the sending tank. Calculate the product of the inches of solids and the $\mathrm{SpG}$ in the receiving tank after transfer. If the product of the material in the receiving tank is $\leq 148$, the transfer is allowed. If the product of the material in the receiving tank is $>148$, the transfer is not allowed.

For generators, the product of solids depth and $\mathrm{SpG}$ cannot be calculated because the depth of solids is not measured in the generators tank. Tank farms does not control the depth of solids in the generator tanks; therefore, the $\mathrm{SpG}$ of the liquid is provided by the generator. The volume of catch tanks is small and the depth of solids is impractical and would not significantly alter the total solids depth in the DST that receives the waste; therefore, no solids sampling is required. The SpG measurement is required on the supernate.

For all transfers to DSTs, the weighted mean SpG for the commingled waste must remain $\leq 1.41$. If the weighted mean $\mathrm{SpG}>1.41$, the transfer must be evaluated on a case-by-case basis to determine the potential of the commingled waste to trap gas.

Before any planned waste transfer into a DST, it must be verified that the minimum time to reach $25 \%$ of the LFL for the tank vapor space, assuming loss of primary ventilation will remain $<7$ days using the methodology in $\mathrm{Hu}$ (1997). If the model shows that the time to reach $25 \%$ of the LFL remains $<7$ days, the waste may be transferred. If the model shows that the time to reach $25 \%$ of the LFL remains $>7$ days, the transfer must be evaluated on a case-by-case basis to determine the potential of the commingled waste to trap gas (Hu 1997). Inputs to the model include ammonia, TOC and aluminum.

Before any planned saltwell waste transfer into a DST via a DCRT, it must be verified that the minimum time to reach $25 \%$ of the LFL for the tank vapor space will meet criteria presented using the methodology in Hedengren et al. (1997). If the model shows that the time to reach $25 \%$ of the LFL exceeds criteria in Hedengren et al. (1997), the transfer must be evaluated on a 
case-by-case basis to determine the potential of the commingled waste to trap gas. Inputs to the model include ammonia, TOC and aluminum.

The volume of catch tanks is small and the depth of solids is impractical and would not significantly alter the total solids depth in the DST that receives the waste; therefore, no solids sampling is required. The SpG measurement is required on the supernate.

\subsection{UNCERTAINTY}

To evaluate the uncertainty, the data presented in Figure 6-1 were separated into two populations. The first population consists of data from tanks that are not on the Watch List. These tanks exhibited products between zero and 141.48. The second population consisted of tanks that are on the Watch List (exhibiting FG behavior). These tanks had products $>241.08$. The mean, standard deviation, and one-sided tolerance limits were calculated for each population. It was assumed that the data are from a normal distribution. A one-sided tolerance interval estimates a single limit above (or below) which at least a specified proportion $\mathrm{P}$ of the population lies with specified probability $1-\alpha$. For specified values of $1-\alpha$ and $P$, the lower tolerance limit is given by

$$
\text { Lower Tolerance Limit }=\text { mean }+\mathrm{K} * \mathrm{~S}
$$

and the upper tolerance limit is given by

$$
\text { Upper Tolerance Limit }=\text { mean }+\mathrm{K} * \mathrm{~S}
$$

where:

$$
\begin{aligned}
& \mathrm{S}=\text { standard deviation and } \\
& \mathrm{K}=\text { a constant which is a function of } \mathrm{n}, 1-\alpha \text {, and } \mathrm{P} .
\end{aligned}
$$

For the first population, non-Watch List tanks, upper tolerance limits were calculated varying both the specified proportion (P) and the specified probability $(1-\alpha)$. The specified proportion varied from 95 to $75 \%$ and the specified probability (confidence level) also varied from 95 to $75 \%$. The following statement can be made if $\alpha=0.10$ and $P=0.95$. One can be $90 \%$ confident that at least $95 \%$ of the non-Watch List tank products in the population are $<148$.

For the second population, Watch List tanks, lower tolerance limits were calculated varying both the specified proportion (P) and the specified probability $(1-\alpha)$. The specified proportion varied from 95 to $75 \%$ and the specified probability (confidence level) also varied from 95 to $75 \%$. The following statement can be made using $\alpha=0.10$ and $\mathrm{P}=0.95$. One can be $90 \%$ confident that at least $95 \%$ of the non-Watch List tank products in the population are above 140 . 
For each unique $1-\alpha$ and $\mathrm{P}$ combination, the upper tolerance limit for the first population was compared to the lower tolerance limit for the second population. The overlap of these tolerance limits were evaluated. The parameter choices $(1-\alpha$ and $P)$ that exhibited the most reasonable balance of confidence, least overlap and most reasonable proportion of the population were selected as the basis for determining the boundary between non-Watch List tank products and Watch List tank products. The parameter choices are $1-\alpha=90 \%$ and $\mathrm{P}=95 \%$. The resulting statements are provided above.

The overlap of the two distributions ranges from 140 to 148 . In this range, there is a $10 \%$ chance of making an incorrect assessment from either perspective. However, DOE management and technical staff believed that this was an acceptable risk and that the risk was evenly balanced in both directions.

\subsection{SAMPLING DESIGN}

\subsubsection{Number and Location of Samples from SSTs and DSTs}

Grab samples are obtained from the sending tanks for determining $\mathrm{SpG}$.

The equipment used for grab sampling is an open device, such as a bottle attached to a string. The device is approximately $40 \mathrm{~cm}$ (12 in.) long. The sample must be obtained from the liquid layer. If no separate liquid layer is present in the sending tank, it automatically passes this evaluation.

For the tanks containing salt cake, liquid samples may be obtained from the saltwell screen. Collect at least one field duplicate sample at one or more depths. At least one sample is collected in duplicate, sent to the laboratory and analyzed as two separate samples. Grab samples for ammonia, TOC and aluminum are collected per Section 5.6.1 and analyzed per Table 6-1.

\subsubsection{Number and Location of Samples for the Generators}

Generator's tanks are much smaller volume than the DSTs or SSTs. The generator tanks typically have an agitator. Generator tanks do not have risers and multiple access ports for sampling. One access port designed for sampling is available. Due to the configuration, two samples will be collected from the tank at the sample sampling port or location, and each sample will be analyzed as an independent sample by the laboratory. Samples are analyzed for SpG, ammonia, TOC, and aluminum per the requirements in Table 6-1. 


\subsubsection{Number and Location of Samples for the 242-A Evaporator}

The number of samples and collection methods are presented in the 242-A Evaporator DQO process (Von Bargen 1996).

\subsubsection{Catch Tanks Within the DST System}

Catch tanks that have received spills or runoff that is not exempt in Section 9.0 require sampling using the same number of samples as a generator to DST transfers discussed below. This approach was selected because catch tanks are small and collection by depth is not appropriate. The analyses required are $\mathrm{SpG}$, ammonia, $\mathrm{TOC}$ and aluminum of the supernate.

\subsubsection{Analytes and Quality Control}

Samples will be collected for SpG. Recommended reporting limits, LCS, MS/matrix spike duplicate do not apply to SpG.

Tank farm collects data related to solids depth. The depth is determined by either sludge level measurement or the tank's temperature profile.

Either historical data or new measurements may be used for determining the concentration of the ammonia, TOC and aluminum in the DSTs. Historical data must be from samples collected within five years of the transfer. Table 6-1 presents the analytes and QC criteria.

Table 6-1. Recommended Detection Limits and Analytical Quality Control

\begin{tabular}{|c|c|c|c|c|c|}
\hline \multirow[b]{2}{*}{ Analyte } & \multirow{2}{*}{$\begin{array}{l}\text { Analytical } \\
\text { Technique }\end{array}$} & \multicolumn{3}{|c|}{ QC Acceptance Criteria } & \multirow{2}{*}{$\begin{array}{c}\text { Recommended } \\
\text { Detection } \\
\text { Level }^{4}\end{array}$} \\
\hline & & $\begin{array}{c}\text { LCS } \\
\text { \%Recovery } 1\end{array}$ & $\begin{array}{c}\text { Spike } \\
\text { \%Recovery } 2\end{array}$ & $\begin{array}{l}\text { Duplicate } \\
\text { RPD }^{3}\end{array}$ & \\
\hline Ammonia & $\begin{array}{l}\text { Selected Ion Electrode } \\
\text { or Ion Chromatography }\end{array}$ & $80-120 \%$ & $75-125$ & $\leq 20 \%$ & See footnote 4 \\
\hline TOC & Persulfate oxidation & $80-106 \%$ & $75-125 \%$ & $\leq 20 \%$ & See footnote 4 \\
\hline Aluminum & $\begin{array}{l}\text { Inductively Coupled } \\
\text { Plasma }\end{array}$ & $80-120 \%$ & $75-125 \%$ & $\leq 20 \%$ & See footnote 4 \\
\hline SpG & Gravimetric & N/A & N/A & N/A & N/A \\
\hline
\end{tabular}

ILCS = Laboratory Control Sample. This sample is carried through the entire method. The accuracy of a method is usually expressed as the percent recovery of the LCS. The LCS is a matrix with a known concentration of analytes that is processed with each preparation and analyses batch. It is expressed as percent recovery; i.e., the amount measured, divided by the known concentration, times 100 . 
2For some methods, the sample accuracy is expressed as the percent recovery of an MS sample. It is expressed as percent recovery, i.e., the amount measured, less the amount in the sample, divided by the spike added, times 100. One MS is performed per riser. If three samples are collected from a single riser, one MS is analyzed.

$3 \mathrm{RPD}=$ Relative percent difference between the laboratory sample and laboratory duplicate results.

Sample precision is estimated by analyzing laboratory duplicates that are subsamples from the field sample. Acceptable sample precision is usually $<20 \% \mathrm{RPD}$ if the sample result is at least 10 times the instrument detection limit. Each laboratory sample is prepared and analyzed in duplicate.

4 Sample detection limits vary depending on the amount of sample and dilution factors. No specific action limits for each analyte are listed in the modeling information. Therefore, no detection limits are presented.

This page intentionally left blank. 


\subsection{EMISSIONS}

\subsection{PROBLEM/QUESTION}

The problem/question from the decision makers:

Will transfer result in safety hazard to personnel caused by gaseous emissions because of chemical reactions?

Issues related to air permitting are excluded from this DQO process. This DQO process focuses on personnel exposure to gaseous emissions during the transfer of waste, as opposed to particulate. Particulate emissions are expected to be very minimal because they would be collected by high-efficiency particulate air (HEPA) filters.

\section{Conceptual Model}

The model for each tank consists of material moving from the sending tank to the receiving tank via pipes and, in some cases, through a DCRT. Potential exposure to personnel was evaluated at each step.

Exposure from a sending tank is minimal, compared to a receiving tank, because a decrease in waste level would tend to draw atmospheric air into the tank. Emissions from the receiving tank can be the result of volume displacement in the pipes and tank, and from emissions resulting from mixing.

The piping is either underground or double-contained when above ground. Piping systems are leak checked before transfer. Based on these facts, little chance for emission exposure from the piping exists.

The DCRTs are used as temporary holding tanks along the transfer path. DCRT vaults have stacks, but the tanks do not have active ventilation systems. A search ensued for historical emission data from DCRTs, but none relating to toxic compounds was found.

Emissions from mixing in the receiving tank depend on:

- the flow rate into the tank,

- the entry level of the waste into the tank,

- the level of waste in the tank before and during transfer, 
- the initial and final concentration in the headspace, temperature of the waste, chemical reactions, whether active or passive ventilation occurs,

- the volume of headspace in the tank, and

- the number of tanks feeding one stack.

Typically, four tanks are vented via one stack. As the number of tanks are vented by one stack increases, the volume of air blowing through the stack increases, thus, diluting the concentration exiting the stack.

DSTs have an exhauster. If the exhauster is not working, transfers are not made to a DST.

The DQO team reviewed the job hazard analysis and the Hanford Safety Plan. These documents do require evaluation of the job performed by the individual to assess whether personnel monitoring is necessary. All stacks have radioactivity monitors and HEPA filters to control safety issues. Selected exhaust stacks have ammonia monitors and HEPA filters to control safety issues.

\subsection{BACKGROUND}

The background information includes the Toxic Chemical Considerations for Tank Farm Releases (Van Keuren et al. 1996), Tank Waste Remediation System Basis for Interim Operations (LMHC 1997), the Tank Waste Remediation System Technical Safety Requirements, (LMHC 1996), tank headspace data from the Tank Waste Information Network System (TWINS) database, and from an additional database that contained data from limited personnel monitoring.

\subsubsection{Facility Safety Analysis Report, Basis for Interim Operations, and Safety Analysis Requirements Report Results for Toxic Gas Release}

The FSAR and BIO provide results from the risk of release of toxic chemicals and gases in accident scenarios. The data used to support the risk assessments included chemical concentrations, chemical limits, and a method for summing the fractional contributions of risk for each chemical presented in Van Keuren et al. (1996). Assessments included both worst-case and maximum steady-state release scenarios. The gas composition and concentrations used in the Safety Analysis Requirements Report (SARR) were based on Tank 241-C-103, which is considered the worst-case tank for organic gases, and Tank 241-SY-101, which is considered the worst-case tank for ammonia and nitrous oxide. Van Keuren et al. (1996) includes a summary of Section 3.1.3 from the SARR, which outlines the Headspace Gas Inventory Evaluation, and Table 3-2 of the SARR, which provides the worst-case composite and maximum steady-state 
composite concentrations derived from the worst-case for each contaminant in the respective tanks that is the basis for the SARR's results.

The SARR addressed both onsite and offsite receptors. The maximum onsite receptor (individual) was located $100 \mathrm{~m}$ ( $300 \mathrm{ft}$ ) from the release point at ground level. The maximum offsite receptor distance was based on the minimum distance from the nearest tank or transfer line to the Hanford Site boundary. The Columbia River is the boundary for the north and east. The information was input to the GXQ atmospheric dispersion model described in the Atmospheric Dispersion Models for the Potential Accident Consequence Assessment at Nuclear Power Plants, Regulatory Guide 1.145 (NRC 1982). The GXQ is used to calculate the continuous release atmospheric dispersion coefficient $(\mathrm{x} / \mathrm{Q})$. The peak concentration calculation methods for gaseous toxic chemical releases are based on gaseous toxic material source concentrations(s) and the volume release rate of the gaseous source and the $\mathrm{x} / \mathrm{Q}$ factor. Both continuous and puff release values were examined.

The chemical risk guidelines depend on the frequency of the event and whether the maximum onsite or offsite exposure is being evaluated. The four frequency categories are described in Table 3-6 in Van Keuren et al. (1996). Emergency Response Planning Guidelines (ERPGs) are described in Table 3-7 and page 21 of Appendix B of Van Keuren et al. 1996. For the purposes of this DQO process, the permissible exposure limit-time weighted average (PEL-TWA) was chosen as opposed to the ERPGs. The PEL-TWA are based on the average airborne exposure in an 8-hour work shift of a 40-hour week.

The steps used to compare risk guidelines are presented in Van Keuren et al. (1996). The FSAR and $\mathrm{BIO}$ indicate that ammonia is the predominant contaminant with substantially higher concentrations than the other contaminants. The BIO indicates the hazard analysis performed for mixing incompatible material resulting in toxic gas release produced a scenario that includes the addition of sodium hydroxide to a DCRT, resulting in the release of ammonia. LMHC (1997) presents the section of the BIO that provides the details of this scenario. The Chemical Reaction in a DCRT Leading to a Toxic Release (Powers 1996), provides the calculations used for the accident scenario outlined.

The results of the evaluation of the mixing of incompatible material indicated that ammonia concentrations are below the risk guidelines for an anticipated event for both the ERPG- 1 and PEL-TWA of $17 \mathrm{mg} / \mathrm{m}^{3}$. Based on these results, no safety controls are required.

The BIO, FSAR, and SARR present accident scenarios and evaluate the effect of a toxic gas release to onsite receptors at $100 \mathrm{~m}(300 \mathrm{ft})$ and to offsite receptors. These documents do not evaluate exposure to staff working in the Tank Farms within $100 \mathrm{~m}$ (300 ft) of a stack during transfer of waste. 


\subsubsection{Existing Data}

In order to assess exposure to workers near the stack during transfer, the team examined data from the TWINS database and the Rotary Mode Core Sampling Toxic Air Pollutants spreadsheet that contained data from tank headspace analyses and headspace data taken in support of rotary core sampling. Data from the Hanford Industrial Hygiene Database included a limited amount of personnel monitoring. The personnel monitoring data were collected by placing personnel monitors on pipefitters working on transfer lines from a SST. The data were not collected during transfer, because transfers are not done during pipe maintenance. However, pipe maintenance of a SST represents direct exposure to residual in the pipe and to gases escaping from the stacks near the pipe during repair.

The concentration of the contaminants in the headspace from the TWINS database with the highest concentrations were compared to the Occupational Health and Safety Administration (OSHA) threshold limit values (TLVs) and criteria for immediate danger to life and health (IDLH), as shown in Table 7-1. TLVs are the lower criteria and the analytes that exceed the TLVs are ammonia, tributyl phosphate (TBP), biphenyl, and nitrous oxide (Table 7-2).

Personnel monitoring for biphenyl was not conducted. Biphenyl was found in the headspace of Tanks 241-TX-118, 241-C-101, and 241-C-102, with Tank 241-C-102 producing the highest concentration. Process history indicated that the only tank known to contain biphenyl is Tank 241-C-103.

\subsection{DECISIONS}

Can generation and release of toxic gases or gaseous chronic irritants be prevented by prescreening or segregation of waste? The first step is to identify any analytes that are toxic gases or that are chronic irritants whose generation could be prevented by screening of waste before transfer. If prescreening will prevent generation of these gases, the transfer decisions will include the prescreening.

The strategy to address this decision involves the following steps:

1. Identify any toxic gases or chronic irritants currently identified in the waste that exceed PEL or TLV criteria.

2. Determine whether generation of the gas could be predicted by prescreening the supernatant in the tank before transfer. 
3. If prescreening will assist in segregation of the waste to prevent gas generation and release, the screening should be done, otherwise the screening will be deemed unnecessary.

Table 7-1. Toxic Contaminants and Corresponding Safety Levels and Tank Concentrations (2 Sheets)

\begin{tabular}{|c|c|c|c|c|}
\hline $\begin{array}{c}\text { NIOSH } \\
\text { Guide - } \\
\text { June } \\
1994 \\
\text { (page) }\end{array}$ & Chemical & $\begin{array}{l}\text { OSHA Limit } \\
\text { (ppm) } \\
\text { (TLV) }\end{array}$ & $\begin{array}{l}\text { IDLH } \\
(\mathrm{ppm})\end{array}$ & $\begin{array}{c}\text { Tank Vapor } \\
\text { Space Content } \\
\text { (ppm) }\end{array}$ \\
\hline 034 & 1,3-Butadiene* & $1(2)$ & 2000 & $0 . \overline{34}$ \\
\hline 064 & Chloroform* & $50(10)$ & 500 & .02 \\
\hline 120 & 1,4-Dioxane* (Dioxane)- & $100(25)$ & 500 & .02 \\
\hline$\overline{026}$ & Benzene* & I ST5 (10) & 500 & 0.9 \\
\hline 054 & Carbon tetrachloride* & $\begin{array}{l}10 \mathrm{C} 25((5) \\
(10 \mathrm{ST})) \mathrm{pk}-5 \\
\min -200\end{array}$ & 200 & 0.34 \\
\hline 208 & Dichloromethane (Methylene chloride)* & $500 \mathrm{Cl} 1000(50)$ & 2300 & 1.8 \\
\hline 002 & Acetaldehyde* & $200(25 \mathrm{C})$ & 2000 & 0.45 \\
\hline 300 & $\begin{array}{l}\text { Perchloroethylene } \\
\text { (Tetrachloroethylene)* }^{*}\end{array}$ & $\begin{array}{l}100 \mathrm{C} 200 \\
((25)(100 \mathrm{ST}))\end{array}$ & 150 & 0.11 \\
\hline 014 & Ammonia & $\begin{array}{l}\text { ST 50 } \\
((25)(35 \mathrm{ST}))\end{array}$ & 300 & 1605 \\
\hline 136 & Ethylene dibromide* & $\begin{array}{l}2030 \mathrm{C}, \mathrm{pk}-5 \\
\min -50\end{array}$ & 100 & 0.02 \\
\hline 232 & n-Nitrosodimethylamine* & none & ND & 0.32 \\
\hline 314 & Tributyl phosphate & $5(0.2)$ & 30 & 5.1 \\
\hline 120 & Diphenylamine & none & ND & 0.003 \\
\hline 120 & Biphenyl (Diphenyl) & $.2(0.2)$ & 100 & 0.44 \\
\hline 226 & Nitrobenzene & $1(1)$ & 200 & 0.003 \\
\hline 114 & 1,1-Dimethylhydrazine* & $0.5(0.01)$ & 15 & 0.003 \\
\hline 226 & p-Nitrochlorobenzene* & $\begin{array}{l}1 \mathrm{mg} / \mathrm{m}^{3} \text { skin } \\
(0.1)\end{array}$ & 100 & 0.008 \\
\hline 210 & Methyl hydrazine* & $\mathrm{C} 0.2(0.1)$ & 20 & 0.002 \\
\hline $\mathrm{NL}$ & Acetophenone & $(10)$ & ND & 0.005 \\
\hline 234 & Nitrous Oxide $\left(\mathrm{N}_{2} \mathrm{O}\right)$ & none, $(50)$ & ND & 947 \\
\hline 2 & Acetone (2-Propanone) & $1000,(250)$ & 2500 & 12 \\
\hline 38 & n-Butyl alcohol (1-Butanol) & $100,(\mathrm{C} 50)$ & $\begin{array}{c}1400 \\
\text { (LEL) }\end{array}$ & 22 \\
\hline 310 & Toluene (Methyl benzene) & $200,(100)$ & 500 & 1.2 \\
\hline
\end{tabular}


Table 7-1. Toxic Contaminants and Corresponding Safety Levels and Tank Concentrations (2 Sheets)

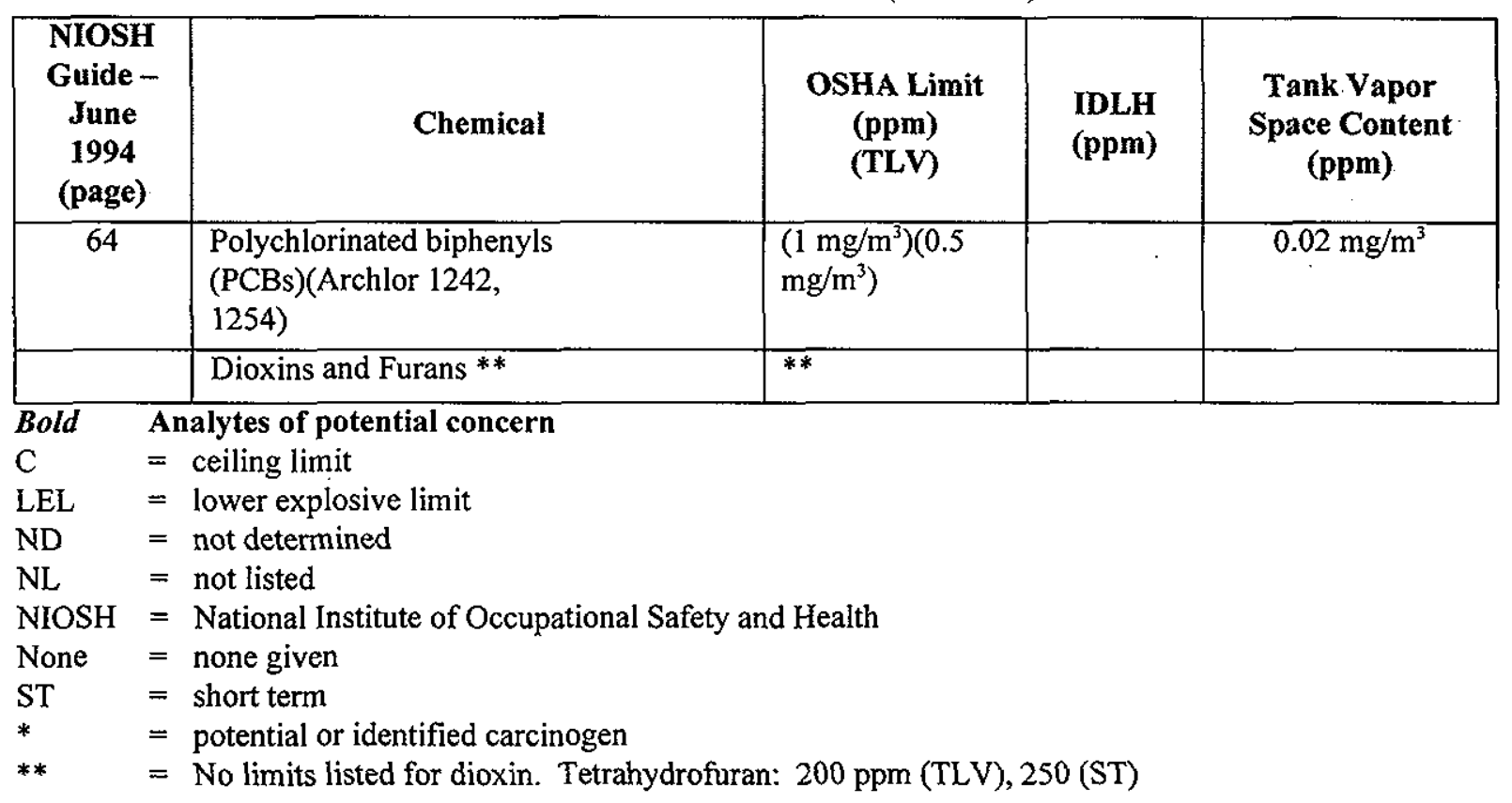

Table 7-2. Analytes That Exceed Limit of Concern in Tank Headspace

\begin{tabular}{|l|c|c|c|}
\hline \multicolumn{1}{|c|}{ Analyte } & Limit of Concern & $\begin{array}{c}\text { Limit Value } \\
\text { (TLV, ppm) }\end{array}$ & $\begin{array}{c}\text { Highest Tank } \\
\text { Vapor Space } \\
\text { Value (ppm) }\end{array}$ \\
\hline Ammonia & TLV (8-hr exposure) & 25 & 1605 \\
\hline Tributyl phosphate & TLV (8-hr exposure) & 0.2 & 5.1 \\
\hline Biphenyl & TLV (8-hr exposure) & 0.2 & 0.44 \\
\hline Nitrous oxide & TLV (8-hr exposure) & 50 & 947 \\
\hline
\end{tabular}

\subsection{INPUTS}

Table 7-3 lists the inputs and their source. 
Table 7-3. Input Versus Source

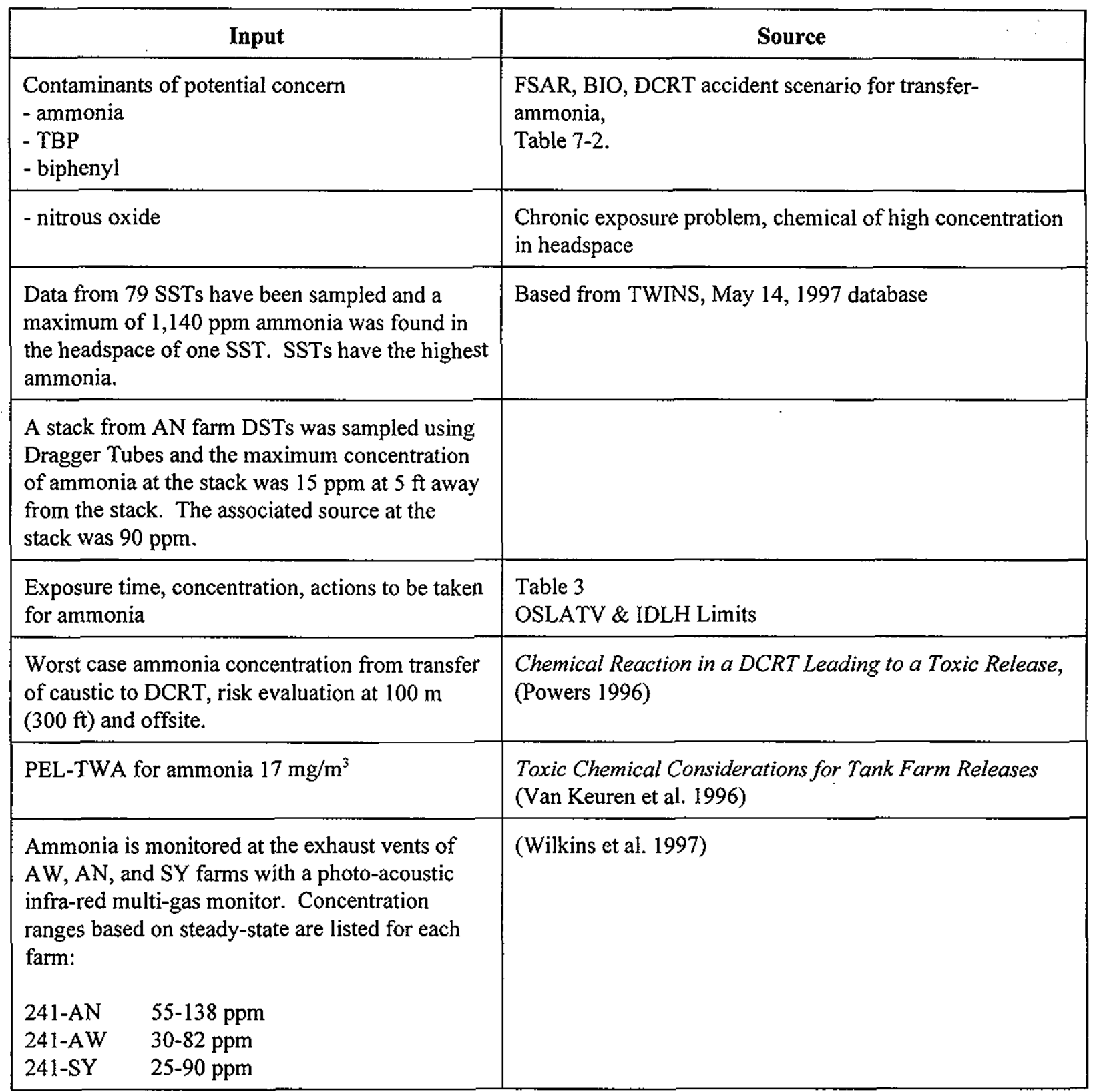

\subsubsection{Potential Action Levels}

There are three action levels, as shown in Table 7-4. The TLV is concentration based on the length of time the person is exposed to the contaminant. Following are the levels for ammonia, followed by the exposure time, and the protection needed. 
Table 7-4. Level, Exposure Time, and Protective Actions for Ammonia

\begin{tabular}{|l|l|l|}
\hline \multicolumn{1}{|c|}{ Level } & \multicolumn{1}{c|}{ Allowed Exposure Time } & \multicolumn{1}{c|}{ Action } \\
\hline $25 \mathrm{ppm}$ (TLV) & $8 \mathrm{hr}$ & none \\
\hline 35 short-term exposure limit & $15 \mathrm{~min}, 4$ times in $8 \mathrm{hr}$ & none \\
\hline $\begin{array}{l}300 \mathrm{ppm} \\
\text { IDLH }\end{array}$ & none & $\begin{array}{l}\text { Need air purifying respirator or } \\
\text { external air source }\end{array}$ \\
\hline
\end{tabular}

\subsubsection{Evaluation of Gas Evolution Mechanisms}

In order to assess whether any screening should be done, the mechanisms for gas evolution were examined for biphenyl, TBP, nitrous oxide, and ammonia.

7.4.2.1 Biphenyl. The evolution of biphenyl would involve the benzene radical. Any waste that was placed in the tank that contained benzene rings could be a potential source for the biphenyl. Many mechanisms for generation are possible if the initial benzene ring is present. No waste was routinely disposed that contained significant quantities of benzene rings. Kerosene was used in select processes; however, the concentration in relationship to the total waste should be low. None of the SARRs or other documents have focused on monitoring biphenyl or the mechanisms for generation in Hanford tank waste because of its low concentration. Biphenyl has been reported in three tank headspace analyses. The biphenyl was identified by library search as a tentatively identified compound and may be subject to misidentification.

Because no obvious starting compound is readily identified, and no direct mechanistic relationship between specific compounds and the biphenyl exists, no logical compound could be identified for screening.

7.4.2.2 TBP. TBP was widely used at the Hanford Site and is potentially in many, if not all, tanks. TBP is not a reaction product. Because its use and presence in many tanks is well known, screening for TBP would not preclude mixing; therefore, no screening is recommended.

7.4.2.3 Nitrous Oxide and Ammonia. Reaction mechanisms for generation of these gases have been studied in research done by Argonne National Laboratory in support of Hanford Site tank waste systems (Meisel et al. 1991, 1992, 1993; Barefield et al. 1996, Bryan et al. 1996; Bryan and Pederson 1996). The reaction mechanisms include radiolytic and thermal decomposition of water and some organic species, and chemical reactions involving organic complexants and solvents. The gases studied include $\mathrm{H}_{2}, \mathrm{~N}_{2} \mathrm{O}, \mathrm{N}_{2}, \mathrm{O}_{2}$, and $\mathrm{NH}_{3}$. Some basic information from the study is listed below. 
- The generation of $\mathrm{N}_{2} \mathrm{O}$ requires the presence of organic molecules; however, the nitrogen atoms in the $\mathrm{N}_{2} \mathrm{O}$ come from inorganic sources such as nitrite and nitrate.

- The yield of the $\mathrm{N}_{2} \mathrm{O}$ depends on the dose rate and suggests that a first-order reaction intermediate competes with a second-order reaction of the same intermediate. As the temperature increases, the first order reaction speeds up and dominates.

- The nitrogen in the ammonia is produced by radiolysis degradation of the chelators such as EDTA.

- Oxalate or formate that are known degradation products have negligible effect on generation of hydrogen and generated no $\mathrm{N}_{2} \mathrm{O}$ upon radiolysis.

- Generation of $\mathrm{N}_{2} \mathrm{O}$ is lower in the slurry than in the waste simulant.

- Hydroxylamine is a possible degradation product, which generates both $\mathrm{N}_{2} \mathrm{O}$ and $\mathrm{N}_{2}$ in the standard simulant at $60^{\circ} \mathrm{C}\left(140^{\circ} \mathrm{F}\right)$.

- Radiolytic $\mathrm{N}_{2} \mathrm{O}$ yields are strongly reduced by $\mathrm{Cr}(\mathrm{III})$ in solution or slurry simulants. It also reduces the rate of thermal generation of $\mathrm{N}_{2} \mathrm{O}$ from $\mathrm{NH}_{2} \mathrm{OH}$ at $60^{\circ} \mathrm{C}\left(140^{\circ} \mathrm{F}\right)$. This supports the postulate that the hydroxylamine is an intermediate in the mechanism of $\mathrm{N}_{2} \mathrm{O}$ generation.

\subsubsection{Emission Release Mechanisms}

7.4.3.1 Organic and Nitrous Oxide. The release of these compounds is dependant upon items that change the volatility of the compounds. The factors that are most likely to change volatility are: (1) changes in temperature and (2) aerosol formation. Generally, these compounds will be released at rates that are proportional to temperature and exposed surface area. Emissions can also be influenced by the amount of mixing, which occurs in the waste and whether or not aerosols are formed. Mixing changes the distribution of the compounds in the waste and would tend to increase emissions since more atoms of a volatile chemical migrate to the surface. Aerosol formation results in an increase in the exposed surface area and will result in increased emission rates.

It is impractical to control these release mechanisms. Waste temperature is not controlled other than to keep the temperature from exceeding specified limits. Aerosol formation is dependent upon waste influent delivery system design to the receiving tank and cannot be readily influenced. Discharge of waste below the surface would reduce aerosol formation, but is not recommended due to concerns of creating a natural siphon. Mixing occurs during the waste 
transfer process and cannot be prevented. In some tanks, mixers may also be used to periodically release emission so that a sudden large release does not occur.

7.4.3.2 Ammonia. Ammonia releases are dependent upon the same factors as listed for organics and $\mathrm{N}_{2} \mathrm{O}$ and in addition, it is dependent upon $\mathrm{pH}$ of the waste. Raising $\mathrm{pH}$ above 9 to 9.5 , will result in an increased emission rate due to a chemical change from an ion into a dissolved gas. Due to corrosion control limits it is necessary to maintain the waste at a pH level $>12$. This directly conflicts with controlling ammonia releases by maintaining the $\mathrm{pH}<9$. Ammonia releases are increased when the $\mathrm{pH}$ is raised. For SSTs undergoing stabilization, this point is generally the DCRTs. Ammonia releases from DCRTs have been addressed in the SARRs and control of these emissions was found to be unwarranted.

\subsection{BOUNDARIES}

The spatial boundaries are based on a human receptor $1.8 \mathrm{~m}(6 \mathrm{ft})$ off the ground at a location between the stack and $100 \mathrm{~m}(300 \mathrm{ft})$. The human receptor at $100 \mathrm{~m}(300 \mathrm{ft})$ and offsite are the next set of boundaries. These boundaries are the same as those used by the FSAR and BIO.

\subsection{DECISION LOGIC}

The FSAR and BIO indicate that the transfer of caustic to the DCRT provides the worst case

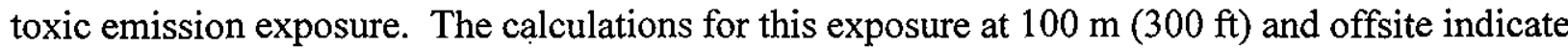
that no significant risk is expected using worst case assumptions during transfer. Therefore, no sampling is required at the $100 \mathrm{~m}(300 \mathrm{ft})$ and offsite boundaries.

The second question is whether chemical reactions, which generate emissions, could be prevented. Given the fact that the chemicals found in the headspace are not unique to one type of waste in select tanks and, given that adding caustic is required to prevent corrosion, no segregation of waste for the purpose of preventing gas generation is logical.

The third question is whether emission release mechanisms could be controlled and still allow transfers of waste. Section 8.4 .3 indicates that it is not practical to control the physical mixing of the material entering the tank, limited temperature control is done, and control of $\mathrm{pH}$ could only be accomplished if caustic were not added to control corrosion.

Based on the previous discussion, no actions could take place in transfer that prevent emissions. The protection of personnel in the area is already managed by the job hazards analysis when personnel enter the Tank Farm area. Therefore, no additional data is required and no additional actions should be taken. 


\subsection{UNCERTAINTY}

No samples are needed; therefore, no uncertainty evaluation is required.

\subsection{SAMPLING AND ANALYSIS DESIGN}

No samples are needed; therefore, no discussion is required. 
HNF-SD-WM-DQO-001, Rev. 3

This page intentionally left blank. 


\subsection{DETERMINATION OF BASELINE CHARACTERISTICS OF DST RECEIVING SALT WELL PUMPING WASTES}

Figure 8-1 shows the decision logic that will be used to determine the chemical and physical characteristics of the DST that will receive salt well pumping wastes. The grab samples used to characterize the receiving tank should be subjected to the same analysis and QC that apply to the safety issues discussed in preceding sections. The same decision logic and uncertainty analysis that was applied to the individual safety issues should be applied to determine if the receiving tank is compatible with the salt well wastes. 
Figure 8-1. Salt Well Receiver Double-Shell Tank Grab Sampling Decision Logic

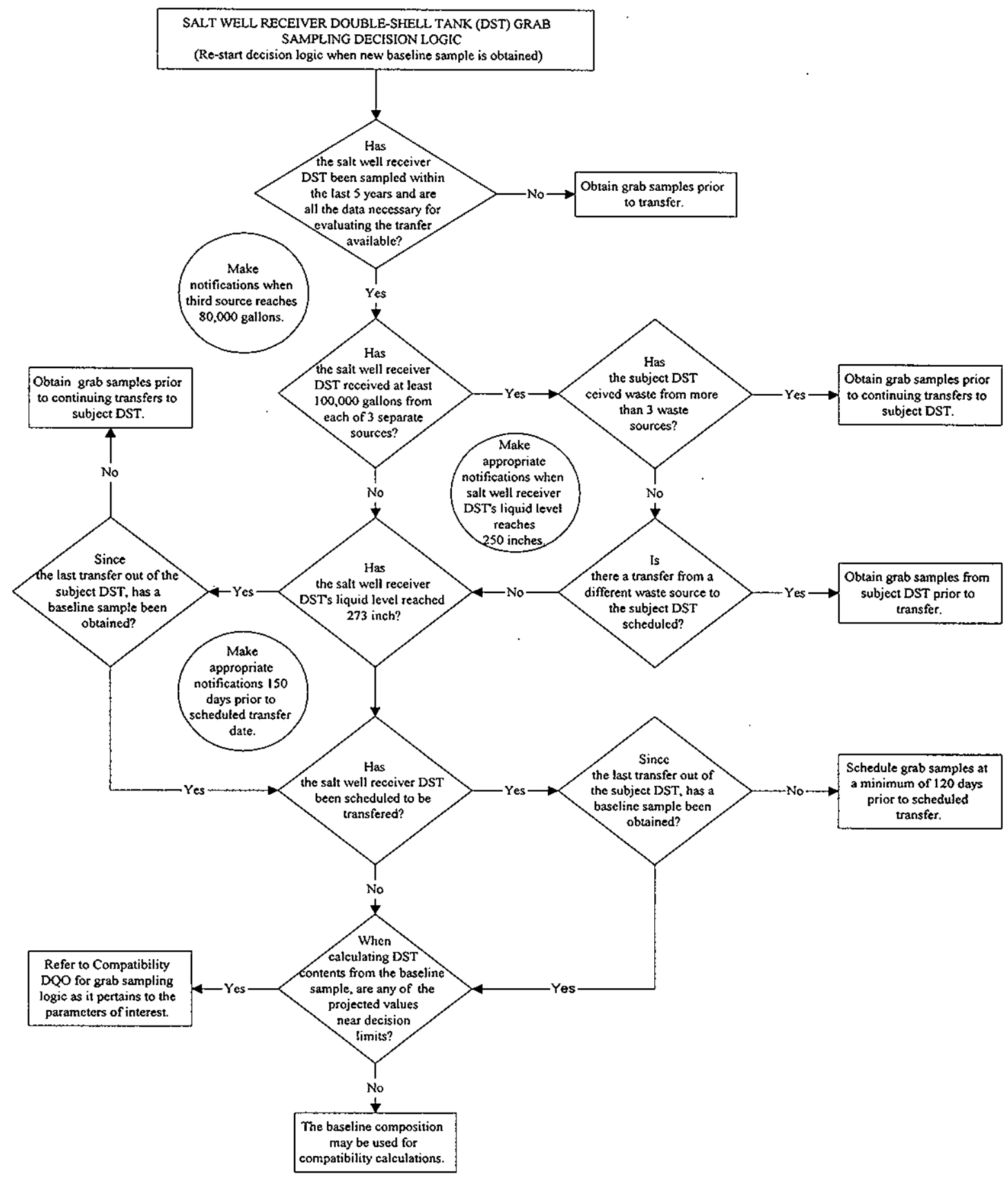




\subsection{EXCEPTIONS TO THE WASTE SAMPLING AND ANALYTICAL REQUIREMENTS}

Certain additions to waste tanks are unlikely to cause any waste compatibility problems. Water used to pressure test waste transfer pipelines is one example of such an addition. Therefore, the types of additions to DSTs listed below are exempt from waste compatibility assessment. These exemptions apply only to waste generated by RPP. The exemptions do not apply to waste from generators that are not part of RPP (Campbell 1999).

- Potentially contaminated water (e.g., cooling water, rain water, snow melt, pipeline flush water, pipeline pressure test water, deentrainer flush water, airlift circulator flush water) with no chemicals added except for those required for tank corrosion control (i.e., sodium hydroxide and sodium nitrite).

- Small volumes (i.e., $\leq 0.25 \%$ of the existing receiver tank waste volume) of essentially organic-free aqueous waste containing any of the major inorganic sodium salts (i.e., aluminate, nitrate, nitrite, carbonate, sulfate, phosphate, fluoride and chloride), sodium hydroxide, trace metals or radionuclides.

- Highly dilute solutions of organic-free wastes that will form $<1 \%$ solids precipitates (by volume) when introduced into the receiving tank.

- Clean water and process condensate from 242-A Evaporator test runs that do not contain free-floating organics.

Note that the exempt additions described above must comply with the decision rules in the previous sections of this document. 
HNF-SD-WM-DQO-001, Rev. 3

This page intentionally left blank. 


\subsection{SUMMARY OF SAMPLING AND ANALYSIS DESIGN}

\section{$10.1 \quad$ INTRODUCTION}

This section addresses chemical compatibility and summarizes requirements by waste sender. Chemical compatibility is addressed by the review of the chemical reactivity numbers. The summary includes reference to the sections which contain the requirements for each analyte.

\subsection{GENERAL CHEMICAL COMPATIBILITY CRITERIA}

Input for determining chemical compatibility will consist of the reactivity group number(s) of the source and receiving waste. This is to be provided by the waste generator on a waste profile sheet in accordance with Mulkey (1998). Reactivity numbers can be obtained from Waste Analysis at Facilities that Generate, Treat, Store, and Dispose of Hazardous Wastes: A Guidance Manual (EPA 1994b), titled or from 40 CFR 265, Appendix V. Tables 10-1 through 10-4 summarize the criteria for waste transfer.

Table 10-1. Summary of Criteria for SST to DST Transfers (2 Sheets)

\begin{tabular}{|l|l|l|l|l|}
\hline \multicolumn{1}{|c|}{$\begin{array}{c}\text { Safety } \\
\text { Concern }\end{array}$} & \multicolumn{1}{|c|}{ Analyte(s) } & \multicolumn{1}{|c|}{$\begin{array}{c}\text { Criteria } \\
\text { (Section \#) }\end{array}$} & $\begin{array}{c}\text { Frequency and } \\
\text { Sampling } \\
\text { Locations } \\
\text { (Section \#) }\end{array}$ & \multicolumn{1}{|c|}{$\begin{array}{c}\text { Analytical QC } \\
\text { (Table \#) }\end{array}$} \\
\hline Retrieval & none & none & none & none \\
\hline Criticality & none & none & none & none \\
\hline Corrosion & $\begin{array}{l}\text { Nitrate, nitrite } \\
\text { demand }\end{array}$ & Sec. 4.4, Fig. 4-2 & Sec. 4.6.1 & Tbl. 4-1 \\
\hline $\begin{array}{l}\text { Organics, } \\
\text { Energetics }\end{array}$ & $\begin{array}{l}\text { Visual layers, } \\
\text { DSC*, } \\
\text { Free Water (TGA)* } \\
\text { TOC (as needed) }\end{array}$ & Sec. 5.4, Tbl 5-2 & Sec.5.6.1 & Tbl. 5-3 \\
\hline Flammable Gas & $\begin{array}{l}\text { SpG; ammonia, TOC, } \\
\text { Depth of solids/sludge, } \\
\text { aluminum }\end{array}$ & Sec. 6.5 & Sec. 6.7.1 & Sec. 6.7.4, \\
\hline Emissions & none & none & none & none \\
\hline
\end{tabular}

${ }^{*}$ Will be removed after update of OSDs. 
Table 10-2. DST to DST Transfers

\begin{tabular}{|l|l|l|l|l|}
\hline \multicolumn{1}{|c|}{$\begin{array}{c}\text { Safety } \\
\text { Concern }\end{array}$} & \multicolumn{1}{|c|}{ Analyte(s),} & \multicolumn{1}{|c|}{ Criteria(Section \#) } & $\begin{array}{c}\text { Frequency and } \\
\text { Sampling } \\
\text { Locations } \\
\text { (Section \#) }\end{array}$ & \multicolumn{1}{|c|}{$\begin{array}{c}\text { Analytical } \\
\text { QC(Table \#) }\end{array}$} \\
\hline Retrieval & none & none & none & none \\
\hline Criticality & none & none & none & none \\
\hline Corrosion & $\begin{array}{l}\text { Nitrate, nitrite, } \\
\text { hydroxide, caustic } \\
\text { demand }\end{array}$ & Sec. 4.4.3, Fig. 4-2 & Sec. 4.6.1, Fig. 4-3 & Tbl. 4-1 \\
\hline $\begin{array}{l}\text { Organics, } \\
\text { Energetics }\end{array}$ & $\begin{array}{l}\text { Visual layers, DSC, } \\
\text { TOC* }\end{array}$ & $\begin{array}{l}\text { Sec. 5.4, Tbl 5-2, } \\
\text { Fig. 5-2 }\end{array}$ & Sec. 5.6.1 & Tbl. 5-3 \\
\hline Flammable Gas & $\begin{array}{l}\text { SpG; Depth of solids, } \\
\text { sludge, ammonia, TOC, } \\
\text { aluminum }\end{array}$ & Sec. 6.5 & Sec. 6.7.1 & $\begin{array}{l}\text { Sec. 6.7.4, } \\
\text { Tbl. 6-1 }\end{array}$ \\
\hline Emissions & none & none & none & none \\
\hline
\end{tabular}

*TOC will be added after OSDS are updated and DSC will be removed.

Table 10-3. 242-A Evaporator to DST Transfers

\begin{tabular}{|l|l|l|l|l|}
\hline \multicolumn{1}{|c|}{$\begin{array}{c}\text { Safety } \\
\text { Concern }\end{array}$} & \multicolumn{1}{|c|}{ Analyte(s) } & \multicolumn{1}{|c|}{ Criteria(Section \#) } & $\begin{array}{c}\text { Frequency and } \\
\text { Sampling } \\
\text { Locations } \\
\text { (Section \#) }\end{array}$ & \multicolumn{1}{|c|}{$\begin{array}{c}\text { Analytical } \\
\text { QC(Table \#) }\end{array}$} \\
\hline Retrieval & none & none & none & none \\
\hline Criticality & none & none & none & none \\
\hline Corrosion & $\begin{array}{l}\text { Nitrate, nitrite, } \\
\text { hydroxide, caustic } \\
\text { demand (as needed) }\end{array}$ & Sec 4.4.5 & Sec. 4.6.4 & Tbl. 4-1 \\
\hline $\begin{array}{l}\text { Organics, } \\
\text { Energetics }\end{array}$ & $\begin{array}{l}\text { Visual layers, DSC, } \\
\text { Free Water (TGA),TOC } \\
\text { (as needed) }\end{array}$ & Sec. 5.4 & Sec. 5.6.1 & Tbl. 5-3 \\
\hline Flammable Gas & $\begin{array}{l}\text { SpG, ammonia, TOC, } \\
\text { aluminum }\end{array}$ & Sec. 6.5 & Sec. 6.7.3 & $\begin{array}{l}\text { Sec. 6.7.5, } \\
\text { Tbl. 6-1 }\end{array}$ \\
\hline Emissions & none & none & none & none \\
\hline
\end{tabular}


Table 10-4. DST to 242-A Evaporator Transfers

\begin{tabular}{|l|l|l|l|l|}
\hline \multicolumn{1}{|c|}{ Safety Concern } & \multicolumn{1}{|c|}{ Analyte(s) } & \multicolumn{1}{|c|}{ Criteria } & $\begin{array}{c}\text { Frequency and } \\
\text { Sampling Locations } \\
\text { (Section \#) }\end{array}$ & \multicolumn{1}{|c|}{$\begin{array}{c}\text { Analytical QC } \\
\text { (Table \#) }\end{array}$} \\
\hline Retrieval & None & None & None & None \\
\hline Criticality & Pu-239 or total Pu & 3.4 .2 & 3.7 .2 & Tbl 3-4 \\
\hline Corrosion & $\begin{array}{l}\text { Hydroxide, nitrite, } \\
\text { nitrate }\end{array}$ & Sec. 4.4.1 & Sec. 4.6.1.2 & $\begin{array}{l}\text { Sec. } 4.6 .1 .3 \text { and } \\
\text { Tbl 4-1 }\end{array}$ \\
\hline Organics, energetics & DSC & Sec. 5.4, Tbl 5-2 & Sec. 5.6.1 & Tbl 5-2 and 5-3 \\
\hline Flammable Gas & SpG and Sec. 6.7.3 & Sec. 6.4 & Sec. 6.7.3 & $\begin{array}{l}\text { Sec. 6.7.5 and } \\
\text { Tbl 6-1 }\end{array}$ \\
\hline Emissions & None & None & None & None \\
\hline
\end{tabular}

Table 10-5. Generator to DST Transfers

\begin{tabular}{|c|c|c|c|c|}
\hline $\begin{array}{c}\text { Safety } \\
\text { Concern }\end{array}$ & Analyte(s) & Criteria (Section \#) & $\begin{array}{l}\text { Frequency and } \\
\text { Sampling } \\
\text { Locations } \\
\text { (Section \#) }\end{array}$ & $\begin{array}{c}\text { Analytical QC } \\
\text { (Table \#) }\end{array}$ \\
\hline Retrieval & none & none & none & none \\
\hline \multirow[t]{4}{*}{ Criticality } & ${ }^{239} \mathrm{Pu}$ or Total plutonium & \multirow[t]{2}{*}{ sec. 3.4, Fig 3-1 } & \multirow[t]{4}{*}{ Sec. 3.7.1 } & \multirow{4}{*}{$\begin{array}{l}\text { Tbl. 3-4 and } \\
\text { Fig 3-2 }\end{array}$} \\
\hline & $235 / 238 \mathrm{U}$ or Total U & & & \\
\hline & $\begin{array}{l}\text { Neutron Absorbers (as } \\
\text { needed) }\end{array}$ & Fig. 3-1 & & \\
\hline & $\mathrm{pH}$ & Sec. 3.4, Fig 3-1 & & \\
\hline \multirow[t]{2}{*}{ Corrosion } & $\begin{array}{l}\text { Nitrate, nitrite, } \\
\text { hydroxide, } \\
\text { Caustic demand } \\
\text { (as needed) }\end{array}$ & Sec 4.4.2, Fig. 4-1 & \multirow[t]{2}{*}{ Sec. 4.6 .2} & \multirow[t]{2}{*}{ Tbl. 4-1 } \\
\hline & $\begin{array}{l}\text { Chloride (for waste } \\
\text { received by } 204-A R \text { ) }\end{array}$ & Sec. $4.4 .4,4.4 .7$ & & \\
\hline $\begin{array}{l}\text { Organics, } \\
\text { Energetics }\end{array}$ & $\begin{array}{l}\text { Visual layers, DSC, } \\
\text { Free Water (TGA),TOC } \\
\text { (as needed)* }\end{array}$ & Sec. 5.4 & Sec. 5.6 .2 & Tbl. 5-3 \\
\hline Flammable Gas & $\begin{array}{l}\text { SpG, ammonia, TOC, } \\
\text { aluminum }\end{array}$ & Sec. 6.5 & Sec. 6.7 .2 & $\begin{array}{l}\text { Sec. } 6.7 .5 \text { and } \\
\text { Tbl 6-1 }\end{array}$ \\
\hline Emissions & none & none & none & none \\
\hline
\end{tabular}

${ }^{*} \mathrm{After}$ OSD and DST Waste Acceptance Plan (Mulkey 1998) are updated, only visual and TOC is required. 
Table 10-6. Catch Tanks Receiving Spills or With Insufficient Process Knowledge

\begin{tabular}{|l|l|l|l|l|}
\hline \multicolumn{1}{|c|}{ Safety Concern } & \multicolumn{1}{|c|}{ Analyte(s) } & \multicolumn{1}{|c|}{ Criteria } & $\begin{array}{c}\text { Frequency and } \\
\text { Sampling Locations } \\
\text { (Section \#) }\end{array}$ & \multicolumn{1}{|c|}{$\begin{array}{c}\text { Analytical QC } \\
\text { (Table \#) }\end{array}$} \\
\hline Retrieval & None & None & None & None \\
\hline Criticality & $\begin{array}{l}\text { Pu-239 or total Pu, } \\
\text { U-235/238 or } \\
\text { Total U, pH, neutron } \\
\text { absorbers as needed } \\
\text { (Fe, total U, Mn, Ni, } \\
\text { Cr) }\end{array}$ & Fig 3-1 and Tbl 3-1 & Sec 3.7.1 & Tbl 3-4 and Fig 3-2 \\
\hline Corrosion & $\begin{array}{l}\text { Nitrate, nitrite, } \\
\text { hydroxide }\end{array}$ & Sec. 4.4.3, Fig 3-3 & Sec. 4.6.1, Fig 3-3 & Tbl 4-1 \\
\hline Flammable Gas & $\begin{array}{l}\text { SpG, ammonia, } \\
\text { TOC, aluminum }\end{array}$ & Sec. 6.5 & Sec. 6.7.4 & $\begin{array}{l}\text { Sec 6.7.5 and Tbl 6- } \\
1\end{array}$ \\
\hline Emissions & None & None & None & None \\
\hline
\end{tabular}




\subsection{ROLE OF WASTE COMPATIBILITY REQUIREMENTS FOR WASTE TRANSFERS CONDUCTED AS PART OF RETRIEVAL/DISPOSAL EFFORTS}

Many waste transfer operations will be conducted as part of the Privatization Program. These wastes will serve as the feed stream for the process that converts Hanford mixed wastes into glass forms for disposal. The current waste feed specifications that have been developed as part of the contractual relationship between DOE and the privatization contractor conducting this operation meet all of the safety requirements for compatibility. These specifications are found in the following documents:

- Data Quality Objectives for TWRS Privatization Phase 1: Tank Waste Transfer Control (Banning 1999b)

- Data Quality Objectives for TWRS Privatization Phase 1: Confirm Tank T is an Appropriate Feed Source for High-Level Waste Feed Batch X (Nguyen 1999a)

- Data Quality Objectives for TWRS Privatization Phase 1: Confirm Tank T is an Appropriate Feed Source for Low-Activity Waste Feed Batch X (Nguyen 1999b)

The compatibility DQO establishes no requirements that will interfere with the safe and efficient transfer of wastes for use as feed to the solidification process. None of the safe tank conditions established in the compatibility DQO will have an adverse impact on the ability of the RPP to retrieve the wastes from tanks used in the Privatization Program.

Future revisions of the compatibility DQO and DQOs governing the privatization effort will be reviewed to maintain this basis for safe and efficient transfer of wastes between tanks. 
HNF-SD-WM-DQO-001, Rev. 3

This page intentionally left blank. 


\subsection{REFERENCES}

40 CFR 264, 1995, "Standards for Owners and Operators of Hazardous Waste Treatment, Storage, and Disposal Facilities," Code of Federal Regulations, as amended.

40 CFR 265, "Interim Status Standards for Owners and Operators of Hazardous Waste Treatment, Storage, and Disposal Facilities," Code of Federal Regulations, as amended.

Anantatmula, R. P., M. J. Danielson, and E. B. Schwenk, 1994, Characterization of the Corrosion Behavior of the Carbon Steel Liner in Hanford Site Single-Shell Tanks, WHCEP-0772, Westinghouse Hanford Company, Richland, Washington.

Banning, D. L., 1999a, Data Quality Objectives for Sampling and Analysis, HNF-IP-0842, Vol IV, Rev. 1, Section 4.16, Lockheed Martin Hanford Corporation, Richland, Washington.

Banning, D. L., 1999b, Data Quality Objectives for TWRS Privatization Phase 1: Tank Waste Transfer Control, HNF-1802, Rev. 1, Lockheed Martin Hanford Corporation, Richland, Washington.

Barefield, E. K., D. Boatwright, A. Desphande, F. Doctorovich, C. L. Liotta, H. M. Neumann, and S. Seymore, 1996, Mechanisms of Gas Generation from Simulated SY Tank Farm Wastes; FY 1995 Progress Report, PNNL-11247, Pacific Northwest National Laboratory, Richland, Washington.

Benar, C. J., 1995, Flammable Gas Tank Safety Program: Data Requirements for Core Sample Analysis Developed Through the Data Quality Objectives Process, WHC-SD-WM-DQO004, Rev. 2, Westinghouse Hanford Company, Richland, Washington.

Bratzel, D. R., W. W. Schutz, and R. Vornehm, 1996, Tank Farm Nuclear Criticality Review, WHC-SD-WM-TI-725, Rev. 0, Westinghouse Hanford Company, Richland, Washington.

Bryan, S. A: and L. R. Pederson, 1996, Thermal and Combined Thermal and Radiolytic Reactions Involving Nitrous Oxide, Hydrogen, Nitrogen and Ammonia in Contact with Tank 241-SY-101 Simulated Wastes, PNNL-10748, Pacific Northwest Laboratory, Richland, Washington.

Bryan, S. A., C. M King, L. R. Pederson, S. V. Forbes, and R. L. Sell, 1996, Gas Generation from Tank 241-SY-103 Waste, PNNL-10978, Pacific Northwest National Laboratory, Richland, Washington. 
Campbell, T. A., 1998, 242-A Evaporator OSR Compliance Strategy for Radiological Source Strength, HNF-SD-WM-OCD-016, Rev. 2 Draft, waste Management Hanford, Inc., Richland, Washington.

Cowley, W. L., J. E. Meacham, J. M. Grigsby, and A. K. Postma, 1999, Organic Solvent Topical Report, HNF-4240, Rev. 0, Fluor Daniel Hanford, Inc., Richland, Washington.

Cox, W., J. Coleman, B. Colgan, B. Crea, P. Powell, and R. Webb, 1997, Tank Farms Operations Administrative Controls, HNF-1P-1266, Rev. 1, Fluor Daniel Hanford, Inc., Richland, Washington.

Danielson, M. J., and L. R. Bunnell, 1994, Sludge Washing Materials Study: The Behavior of Carbon Steel in a Dilute Waste Environment, TWRS PP-94-025, Pacific Northwest Laboratories, Richland, Washington.

Divine, J .R., W. M. Bowen, D. B. Mackey, D. J. Bates, and K. H. Pool, 1985, Prediction Equations for Corrosion Rates of A-537 and A-516 Steels in Double-Shell Slurry, Future PUREX, and Hanford Facilities Wastes, PNL-5488, Pacific Northwest Laboratory, Richland, Washington.

DOE, 1997, "Facility Safety," DOE Order 420.1, U.S. Department of Energy, Washington, D.C.

DOE-RL, 1998, Hanford Analytical Services Quality Assurance Requirements Documents, DOE/RL-96-89, Rev. 2, U.S. Department of Energy, Richland Operations Office, Richland, Washington.

EPA, 1994a, Guidance of the Data Quality Objectives Process, EPA QA/G-4,

U.S. Environmental Protection Agency Quality Assurance Management Staff, Washington, D.C.

EPA, 1994b, Waste Analysis at Facilities That Generate, Treat, Store, and Dispose of Hazardous Wastes, A Guidance Manual, PB94-963603, OSWER 9938.4-03, U.S. Environmental Protection Agency Quality Assurance Management Staff, Washington, D.C.

EPA, 1997, Test Methods for Evaluating Solid, Waste Physical/Chemical Methods, SW-846, 3rd Edition, as amended by Updates I (July, 1992), IIA (August, 1993), IXB (January, 1995), and III (1997), U.S. Environmental Protection Agency, Washington, D.C.

Estey, S. D., and M. D. Guthrie, 1996a, An Analysis of Parameters Describing Gas Retention/ Release Behavior in Double-Shell Tank Waste, WHC-SD-WM-TI-755, Westinghouse Hanford Company, Richland, Washington. 
Estey, S. D., and M. D. Guthrie, 1996b, Data Analysis and Criteria Development to Prevent Accumulation of DST Waste with Unacceptable Gas Retention Behavior, 74A10-96-029 (Internal Memo), Westinghouse Hanford Company, Richland, Washington.

Han, F. C., 1996, Structural Integrity and Potential Failure Modes of Hanford High-Level Waste Tanks, WHC-SD-TWR-RPT-002, Rev. 0, Westinghouse Hanford Company, Richland, Washington.

Hedengren, D.C., J. D. Bingham, S. A. Barker, M. M. Conner, and S. D. Estey, 1997, Calculation of Flammable Gas Mixtures in Double-Contained Receiver Tanks, HNF-SD-WM-CN-118, Rev. 0, MACTEC-Meier Associates LLC, Richland, Washington.

Hu, T. A., 1997, Calculations of Hydrogen Release Rate at Steady-State for Double-Shell Tanks, HNF-SD-WM-CN-117, Rev. 0, Lockheed Martin Hanford Corporation, Richland, Washington.

Johnson, G. D., W. B. Barton, R. C. Hill, J. W. Brothers, S. A. Bryan, P. A. Gauglitz, L. R. Pederson, C. W. Stewart, and L. H. Stock, 1997, Flammable Gas Project Topical Report, HNF-SP-1193, Rev. 2, U.S. Department of Energy, Richland Washington.

Kirch, N. W., 1984, Technical Basis for Waste Tank Corrosion Specifications, WHC-SD-WMTI-150, Rev. 0, Rockwell Hanford Operations, Richland, Washington.

LMHC, 1996, Tank Waste Remediation System Technical Safety Requirements, WHC-SD-WMTSR-006, Rev. J, Lockheed Martin Hanford Corporation, Richland, Washington.

LMHC, 1997, Tank Waste Remediation System Basis for Interim Operations, HNF-SD-WMBIO-001, Rev. 0, Lockheed Martin Hanford Corporation, Richland, Washington.

LMHC, 1998, Criticality Prevention Specification, CPS-T-149-000010, Rev. I-0, Lockheed Martin Hanford Corporation, Richland, Washington.

Meacham, J. E., Muhlestein, L. D., and M. R. Allen, 1997, Data Quality Objective to Support Resolution of the Organic Solvent Safety Issue, HNF-SD-WM-DQO-026, Rev. 0, Draft, Westinghouse Hanford Corporation, Richland, Washington.

Meacham, J. E., Cowley, W. L., and A. B. Webb, 1999, Organic Complexant Topical Report, HNF-3588, Rev. 0, DE\&S Hanford, Inc., Richland, Washington. 
Meisel, D., H. Diamond, E. P. Horowitz, C. D. Jonah, M. S. Matheson, M. C. Sauer, and J. C. Sullivan, 1991, Radiation Chemistry of Synthetic Waste, ANL-91/40, Argonne National Laboratory, Argonne, Illinois.

Meisel, D., C. D. Jonah, M. S. Matheson, M. C. Sauer Jr., F. Barnabas, E. Cerney, Y. Cheng, and T. Wojta, 1992, Radiation Chemistry of High-Level Wastes ANL/CHM Task Force on Gas Generation in Waste Tanks, ANL-92/40, Argonne National Laboratory, Argonne, Illinois.

Meisel, D., C. D. Jonah, S. Kapoor, M. S. Matheson, and M. C. Sauer, 1993, Radiolytic and Radiolytically Induced Generation of Gases from Synthetic Wastes, ANL-93/43, Argonne National Laboratory, Argonne, Illinois.

Meyer, P. A. and G. Terrones, 1996, Rollover and Gas Release Models for Hanford Double-Shell Waste Tanks, TWSMIT:091996 Rev. 1, Pacific Northwest National Laboratory, Richland, Washington.

Moore, E. L., 1979, Waste Solution Composition Limits for Salt Well Receiver Tanks, letter to B. P. Carl, Rockwell Hanford Operations, Richland, Washington.

Mulkey, C. H., 1998, Double-Shell Tank Waste Analysis Plan, HNF-SD-EV-053, Rev. 5, Lockheed Martin Hanford Corporation, Richland, Washington.

NFPA 69, Standard on Explosion Prevention Systems, 1997, National Fire Protection Association.

Nguyen, D. M., 1999a, Data Quality Objectives for TWRS Privatization Phase I: Confirm Tank $T$ is an Appropriate Feed Source for High-Level Waste Feed Batch X, HNF-1558, Rev. 1, Lockheed Martin Hanford Corporation, Richland, Washington.

Nguyen, D. M., 1999b, Data Quality Objectives for TWRS Privatization Phase 1: Confirm Tank $T$ is an Appropriate Feed Source for Low-Activity Waste Feed Batch X, HNF-1796, Rev. 2, Lockheed Martin Hanford Corporation, Richland, Washington.

Noorani, Y. G., 1997, Tank Waste Remediation System Basis for Interim Operation, HNF-SD-WM-BIO-001, Rev. 0-F, DE\&S Hanford, Inc. for Fluor Daniel Hanford, Inc., Richland, Washington.

NRC 1982, Atmospheric Dispersion Models for the Potential Accident Consequence Assessment at Nuclear Power Plants, Regulatory Guide 1.145, U.S. Nuclear Regulatory Commission, Washington, D.C. 
Ondrejcin, R. S., S. P. Rideout, and J. A. Donovan, 1979, "Control of Stress Corrosion Cracking in Storage Tanks Containing Radioactive Waste," Nucl. Tech., vol. 44, pp. 297-306.

PHMC, 1997a, Criticality Safety General Requirements, HNF-PRO-334, Rev. 0, Project Management Hanford Contract, Richland, Washington.

PHMC, 1997b, Criticality Safety Control of Fissionable Material, HNF-PRO-537, Rev. 0, Project Management Hanford Contract, Richland, Washington.

PHMC, 1997c, Criticality Safety Evaluations, HNF-PRO-539, Rev. 0, Project Management Hanford Contract, Richland, Washington.

PHMC, 1997d, Criticality Prevention Specifications for Tank Farms, HNF-PRO-540, Rev. 0, Lockheed Martin Hanford Corporation, Richland, Washington.

PHMC, 1998a, Unclassified Operating Specifications for the 241-AN, AP, AW, AY, AZ \& SY Tank Farms, OST-T-151-00007, Rev. H-21, Tank Farms Operating Specification Document, Project Management Hanford Contract, Richland, Washington.

PHMC, 1998b, Unclassified Operating Specifications forSingle-Shell Waste Storage Tanks, OST-T-151-00013, Rev. D-16, Tank Farms Operating Specification Document, Project Management Hanford Contract, Richland, Washington.

PHMC, 1998c, Operating Specifications for Aging-Waste Operations in 241-AY and 241-AZ, OST-T-151-00017, Rev. D10, Tank Farms Operating Specification Document, Project Management Hanford Contract, Richland, Washington.

Powers, T. B., 1996, Chemical Reaction in a DCRT Leading to a Toxic Release, WHC-SD-WM-CN-074, Rev. 0, Westinghouse Hanford Company, Richland, Washington.

Reynolds, D. A., 1994, "Evaluation of Specific Gravity versus Gas Retention," Internal Memo \#7E310-94-024, to N. W. Kirch, dated June 20, Lockheed Martin Hanford Corporation, Richland, Washington.

Rogers, C. A., 1993, An Analytical Model for Evaluating Subcritical Limits for Waste in Hanford Site Storage Tanks, WHC-SD-SQA-CSA-20356, (p. 4-5), Westinghouse Hanford Company, Richland, Washington.

Rogers, C. A., 1994, CSER 94-004: Criticality Safety of Double Shell Waste Storage Tanks, WHC-SD-SQA-CSA-20368, Rev. 0, Westinghouse Hanford Company, Richland, Washington. 
Serne, R. J., G. A. Whyatt, S. V. Mattigod, Y. Onishi, P. G. Doctor, B. N. Bjornstad, M. R. Powell, L. M. Liljegren, J. H. Westsik, N. J. Aimo, K. P. Recknagle, G. R. Golcar, T. B. Miley, G. R. Holdren, D. W. Jeppson, R. K. Biyani, and G. S. Barney, 1996, Fluid Dynamic Particulate Segregation, Chemical Processes, and Natural Ore Analog Discussions that Relate to the Potential for Criticality in Hanford Tanks, WHC-SD-WM-TI-757, Westinghouse Hanford Company, Richland, Washington.

Stauffer, L. A., 1997, Calculation Note: Hydrogen Generation Rates at Steady-State Flammable Gas Concentrations for Single-Shell tanks, HNF-SD-WM-CN-116, Rev. 0, Lockheed Martin Hanford Corporation, Richland, Washington

Stewart, C. W., M. E. Brewster, P. A. Gauglitz, L. A. Mahoney, P. A. Meyer, K. P. Recknagle, and H. C. Reid, 1996, Gas Retention and Release Behavior in Hanford Single-Shell Waste Tanks, PNNL-11391, Pacific Northwest National Laboratory, Richland, Washington.

Van Keuren, J. C., J. S. Davis, and M. L. Dentler, 1996, Toxic Chemical Considerations for Tank Farm Releases, WHC-SD-WM-SARR-011, Rev. 2, Westinghouse Hanford Company, Richland, Washington.

Von Bargen, B., 1995, 242-A Evaporator/Liquid Effluent Retention Facility Data Quality Objectives, WHC-SD-WM-DQO-014, Rev. 1A, Westinghouse Hanford Company, Richland, Washington.

WAC 173-303, "Dangerous Waste Regulations," Washington Administrative Code, as amended.

WHC, 1998, Criticality Prevention Specification for Double-Shell Tanks, CPS-T-149-00010, Rev. I-0, Lockheed Martin Hanford Corporation, Richland, Washington.

Whyatt, G. A., R. J. Serne, S. V. Mattigod, Y. Onishi, M. R. Powell, J. H. Westsik, L. M. Liljegren, G. R. Golcar, K. P. Recknagle, P. M. Doctor, V. G. Zhirnov, J. Dixon, D. W. Jeppson, and G. S. Barney, 1996, Potential for Criticality in Hanford Tanks Resulting from Retrieval of Tank Waste, PNL-11304, Pacific Northwest National Laboratory, Richland, Washington.

Wilkins, N. E., R. E. Bauer, and D. M. Ogden, 1997, Results of Vapor Space Monitoring of Flammable Gas Watch List Tanks, HNF-SD-WM-TI-797, Rev. 1, Lockheed Martin Hanford Corporation, Richland, Washington. 
HNF-SD-WM-DQO-001, Rev. 3

APPENDIX A

SIGNED AGREEMENT BETWEEN DOE AND ECOLOGY

A-1 
HNF-SD-WM-DQO-001, Rev. 3 
HNF-SD-WM-DQO-001, Rev. 3

\section{Approval}

Scope and Questions For Completion of Compatibility DQO

January 9, 1997
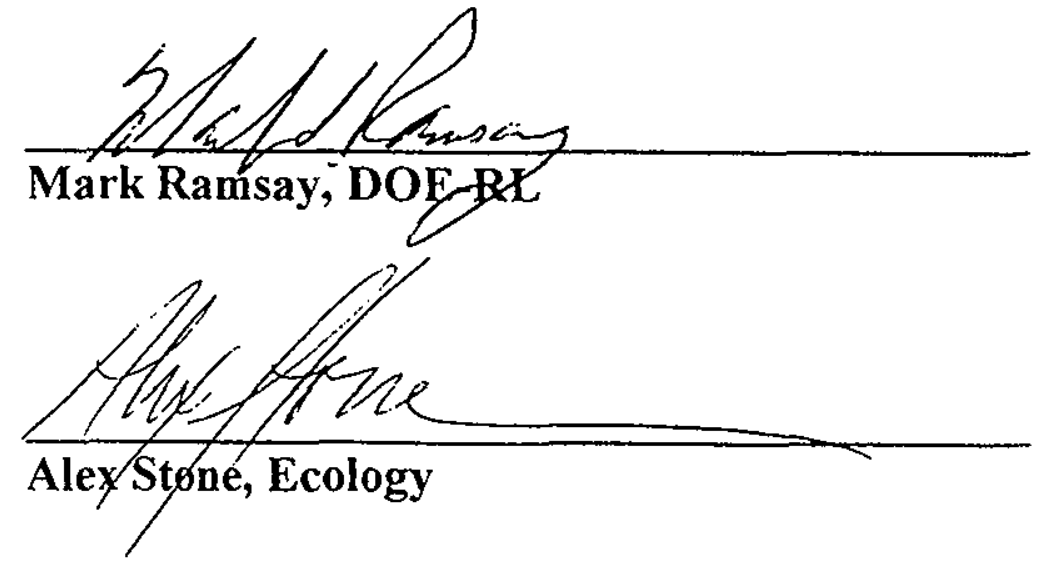
HNF-SD-WM-DQO-001, Rev. 3

January 9, 1997

\section{Scope and Questions For Completion of Compatibility DQO}

\section{General Approach For Revision to the DQO}

I. Focus on specific issues which need to be addressed.

2. $R L$ and Ecology are to agree on each specific issue before the issue is added as part of the global scope. RL and Ecology to resolve agreement on inclusion or exclusion of specific issues This resolution may involve technical support from Compatibility DQO Team members but this activity will be offline from the major DQO activity.

3. If another $D Q O$ has addressed a specific issue, then the requirements of that $D Q O$ shall be incorporated into the Compatibility DQO. Applicable information from the issue $D Q O$ s may be summarized and used in the Compatibility DQO, however information in the issue DQO may not be sufficient for this $\mathrm{DQO}$. The issue DQOs may provide technical support to the Compatibility $D Q O$. The reason the information is needed must also be placed in the Compatibility DQO

4.The DQO team will mutually determine when issues will be handled in the Compatibility DQO and will assure that the issues are within the scope of the DQO.

5. A running list of specific issues will be maintained. This list will consist of three separate sections which separate out the issues according to how they will be addressed by the Compatibility DQO. The separate part will be: 1) issues which are to be included, 2) issues which are to be excluded, and 3 ) issues on which Ecology and RL have not yet reached agseement.

Ecology and DOE must strive to reach consensus on issues in category \#3.

6. As a starting point the DQO proceeds according to the following positions:

a Major question is "Can the waste transfer" proceed without resulting in any unsafe conditions or conditions which preclude future disposal/retrieval?"

b. Specific issues need to be based on creating some unwanted hazard These hazards are to be based on one or more of the following which are taken from the regulations

1) Generate extreme heat or pressure, fire or explosion, or violent reaction.

2) Produce uncontrolled toxic mists, fumes, dusts, or gases in sufficient quantities to threaten human health.

3)Produce uncontrolled flammable fumes or gases in sufficient quantities to pose a risk of fire or explosions.

4) Damage the structural integrity of the device or facility containing the waste. 
5) Through other like means threaten human health or the environment.

(Taken from WAC 173-303-395(l)(b), 40 CFR 265.17, and 40 CFR 264.17)

c. Compatibility will just address safe waste transfer issues. Compatibility criteria will not allow transfers which preclude retrievaldisposal of the waste. If new or additional information changes the safety issues, the DQO will be changed to reflect the new or additional knowledge.

7. This revision will address just liquid transfers Present transfers primarily involve liquid transfers. Only three "solid" transfers are planned by the year 2000 and these will be evaluated on a case by case basis. Once these transfers have occurred there will be a better understanding of issues related to solids transfers.

Criticality: Will concentration of fissile material in the resulting or receiving $\operatorname{tank}(s)$ be sufficient to cause a criticality hazard?

Organics. Will conditions be such because of organic material in the receiving tank to pose a safety hazard (fire/explosion/runaway reaction)?

Flammable Gas: Will conditions result which will cause a flammable gas hazard?

\section{Chemical Reactions}

a. Energetics Will the conditions in the $\operatorname{tank}(s)$ be sufficient to sustain uncontrolled chemical reactions which pose a safety hazard?

b. Emissions - Will transfer result in safety hazard to personnel caused by gaseous emissions due to chemical reactions?

Add discussion in DQO about--Permit emission issues will be excluded.

Corrosion Will any transfer increase corrosion in pipes and tanks?

Retrieval/Dispesal: Will waste transfer adversely affect the ability to retrieval/disposal? 
HNF-SD-WM-DQO-001, Rev. 3

APPENDIX B

EXISTING DATA SUMMARY

B-1 


\section{APPENDIX B}

Table B-1. NO2 Data - Compatibility Tank Samples (2 Sheets)

\begin{tabular}{|c|c|c|c|c|}
\hline (1) & S.angle: & 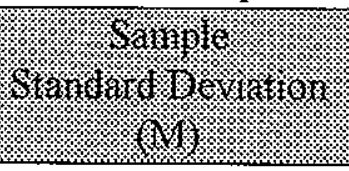 & 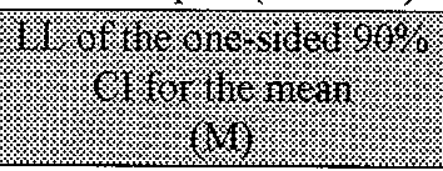 & $(2)$ \\
\hline A-101 & 0.980 & 0.012 & 0.955 & 1.66 \\
\hline$A-101$ & 3.507 & 0.072 & 3.350 & 2.91 \\
\hline A-101 & 3.635 & 0.023 & 3.585 & 0.90 \\
\hline AP-101 & 0.879 & 0.014 & 0.849 & 2.27 \\
\hline AP-101 & 0.840 & 0.002 & 0.836 & 0.34 \\
\hline $\mathrm{AP}-101$ & 1.017 & 0.009 & 0.998 & 1.24 \\
\hline AP-101 & 0.913 & 0.008 & 0.895 & 1.31 \\
\hline AP-101 & 0.908 & 0.004 & 0.901 & 0.55 \\
\hline $\mathrm{AP}-101$ & 0.883 & 0.019 & 0.842 & 2.98 \\
\hline AP-106 & 0.041 & 0.001 & 0.040 & 1.76 \\
\hline AP-106 & 0.669 & 0.006 & 0.655 & 1.36 \\
\hline AP-106 & 0.166 & 0.002 & 0.161 & 2.01 \\
\hline AP-108 & 0.081 & 0.001 & 0.079 & 1.29 \\
\hline $\mathrm{AP}-108$ & 0.081 & 0.003 & 0.075 & 4.92 \\
\hline AW-105 & 0.024 & 0.000 & 0.023 & 2.81 \\
\hline AW-105 & 0.024 & 0.000 & 0.023 & 1.98 \\
\hline AW-105 & 0.025 & 0.001 & 0.023 & 6.26 \\
\hline AW-105 & 0.023 & 0.000 & 0.023 & 1.48 \\
\hline AW-105 & 0.028 & 0.001 & 0.026 & 2.68 \\
\hline AW-105 & 0.037 & 0.002 & 0.034 & 5.79 \\
\hline $\mathrm{AY}-101$ & 0.738 & 0.017 & 0.701 & 3.27 \\
\hline AY-101 & 0.746 & 0.005 & 0.735 & 0.96 \\
\hline AY-101 & 0.824 & 0.003 & 0.817 & 0.50 \\
\hline AY-101 & 0.795 & 0.006 & 0.783 & 1.04 \\
\hline $\mathrm{AY}-101$ & 0.687 & 0.000 & 0.687 & 0.03 \\
\hline AY-101 & 0.849 & 0.011 & 0.825 & 1.84 \\
\hline AY-102 & 0.020 & 0.000 & 0.020 & 0.01 \\
\hline AY-102 & 0.020 & 0.000 & 0.019 & 3.39 \\
\hline AY-102 & 0.020 & 0.000 & 0.019 & 0.95 \\
\hline AY-102 & 0.019 & 0.000 & 0.018 & 0.29 \\
\hline AY -102 & 0.019 & 0.000 & 0.019 & 0.20 \\
\hline AY-102 & 0.018 & 0.000 & 0.017 & 2.50 \\
\hline AY-102 & 0.017 & 0.000 & 0.017 & 1.08 \\
\hline
\end{tabular}


HNF-SD-WM-DQO-001, Rev. 3

Table B-1. NO2 Data - Compatibility Tank Samples (2 Sheets)

\begin{tabular}{|c|c|c|c|c|}
\hline IIIII. & Sintivis & 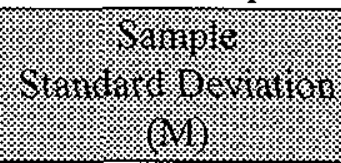 & 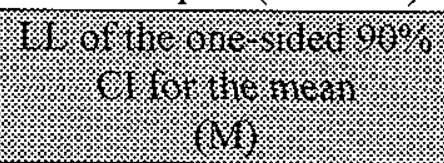 & 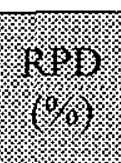 \\
\hline AY -102 & 0.018 & 0.000 & 0.018 & 0.12 \\
\hline AY-102 & 0.018 & 0.000 & 0.018 & 0.30 \\
\hline AY-102 & 0.017 & 0.000 & 0.017 & 2.45 \\
\hline AY-102 & 0.017 & 0.000 & 0.016 & 0.57 \\
\hline AY-102 & 0.017 & 0.000 & 0.017 & 0.47 \\
\hline AY-102 & 0.017 & 0.000 & 0.017 & 1.50 \\
\hline AY-102 & 0.017 & 0.000 & 0.017 & 0.40 \\
\hline $\mathrm{AZ}-101$ & 1.228 & 0.009 & 1.208 & 1.06 \\
\hline AZ-101 & 1.282 & 0.015 & 1.249 & 1.69 \\
\hline AZ-101 & 1.197 & 0.005 & 1.187 & 0.54 \\
\hline AZ-102 & 0.642 & 0.002 & 0.639 & 0.34 \\
\hline AZ-102 & 0.546 & 0.089 & 0.352 & 23.11 \\
\hline AZ-102 & 0.613 & 0.003 & 0.606 & 0.71 \\
\hline BY-103 & 0.805 & 0.014 & 0.775 & 2.43 \\
\hline BY-103 & 1.529 & 0.020 & 1.486 & 1.85 \\
\hline BY-105 & 0.578 & 0.006 & 0.565 & 1.50 \\
\hline BY-105 & 0.579 & 0.011 & 0.556 & 2.63 \\
\hline S-102 & 2.380 & 0.015 & 2.347 & 0.91 \\
\hline S-102 & 1.958 & 0.018 & 1.918 & 1.33 \\
\hline S-110 & 0.591 & 0.000 & 0.591 & 0.00 \\
\hline S-110 & 1.463 & 0.003 & 1.456 & 0.30 \\
\hline S-111 & 1.360 & 0.001 & 1.357 & 0.14 \\
\hline S-111 & 1.350 & 0.000 & 1.350 & 0.02 \\
\hline$S-111$ & 1.634 & 0.013 & 1.607 & 1.09 \\
\hline SY-102 & 0.140 & 0.001 & 0.138 & 1.16 \\
\hline SY-102 & 0.316 & 0.001 & 0.313 & 0.62 \\
\hline SY-102 & 0.336 & 0.002 & 0.331 & 0.84 \\
\hline TX-244 & 0.259 & 0.000 & 0.259 & 0.00 \\
\hline TX-244 & 0.261 & 0.003 & 0.255 & 1.41 \\
\hline $\mathrm{U}-102$ & 2.262 & 0.063 & 2.125 & 3.94 \\
\hline U-102 & 2.285 & 0.003 & 2.278 & 0.19 \\
\hline
\end{tabular}


Table B-2. OH Data - Compatibility Tank Samples (2 Sheets)

\begin{tabular}{|c|c|c|c|c|}
\hline Iran: & 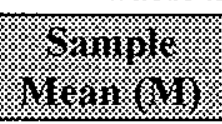 & 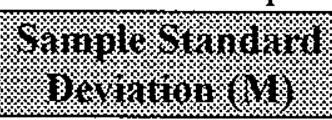 & 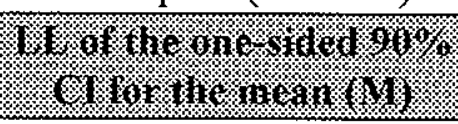 & (1) \\
\hline A-101 & 0.8379 & 0.0208 & 0.7926 & 3.51 \\
\hline A-101 & 3.2310 & 0.0125 & 3.2038 & 0.55 \\
\hline $\mathrm{A}-101$ & 3.3956 & 0.1621 & 3.0427 & 6.75 \\
\hline AP-101 & 2.8958 & 0.1123 & 2.6515 & 5.48 \\
\hline AP-101 & 2.4842 & 0.0457 & 2.3847 & 2.60 \\
\hline AP-101 & 3.1692 & 0.0166 & 3.1330 & 0.74 \\
\hline AP-101 & 2.9811 & 0.0582 & 2.8544 & 2.76 \\
\hline AP-101 & 2.9458 & 0.0166 & 2.9096 & 0.80 \\
\hline AP-101 & 2.9576 & 0.1164 & 2.7042 & 5.57 \\
\hline AP-106 & 0.1585 & 0.0112 & 0.1340 & 10.02 \\
\hline AP-106 & 1.6375 & 0.0042 & 1.6285 & 0.36 \\
\hline AP-106 & 0.3669 & 0.0141 & 0.3361 & 5.45 \\
\hline AP-108 & 0.1632 & 0.0012 & 0.1605 & 1.08 \\
\hline AP-108 & 0.1617 & 0.0050 & 0.1508 & 4.36 \\
\hline AW-105 & 0.1952 & 0.0042 & 0.1862 & 3.01 \\
\hline AW-105 & 0.1899 & 0.0033 & 0.1827 & 2.48 \\
\hline AW-105 & 0.2226 & 0.0087 & 0.2035 & 5.55 \\
\hline AW-105 & 0.1690 & 0.0021 & 0.1645 & 1.74 \\
\hline AW-105 & 0.1917 & 0.0091 & 0.1718 & 6.75 \\
\hline AW-105 & 0.3031 & 0.0021 & 0.2986 & 0.97 \\
\hline AY-102 & 0.0351 & 0.0005 & 0.0339 & 2.18 \\
\hline AY-102 & 0.0275 & 0.0017 & 0.0238 & 8.57 \\
\hline AY-102 & 0.0345 & 0.0003 & 0.0339 & 1.19 \\
\hline AY-102 & 0.0266 & 0.0014 & 0.0236 & 7.51 \\
\hline AY-102 & 0.0220 & 0.0008 & 0.0202 & 5.33 \\
\hline AY-102 & 0.0272 & 0.0010 & 0.0250 & 5.19 \\
\hline AY-102 & 0.0071 & 0.0001 & 0.0069 & 2.47 \\
\hline AY-102 & 0.0157 & 0.0002 & 0.0153 & 1.50 \\
\hline AY-102 & 0.0187 & 0.0004 & 0.0179 & 2.83 \\
\hline AY-102 & 0.1476 & 0.0033 & 0.1403 & 3.19 \\
\hline AY-102 & 0.1508 & 0.0021 & 0.1463 & 1.95 \\
\hline AY-102 & 0.1499 & 0.0042 & 0.1409 & 3.92 \\
\hline AY-102 & 0.1479 & 0.0021 & 0.1434 & 1.99 \\
\hline$A Z-101$ & 0.6556 & 0.0042 & 0.6466 & 0.90 \\
\hline AZ-101 & 0.6615 & 0.0042 & 0.6524 & 0.89 \\
\hline AZ-101 & 0.6997 & 0.0499 & 0.5911 & 10.08 \\
\hline
\end{tabular}


Table B-2. OH Data - Compatibility Tank Samples (2 Sheets)

\begin{tabular}{|c|c|c|c|c|}
\hline 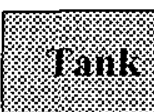 & (1.mingle & 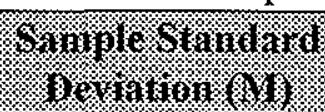 & 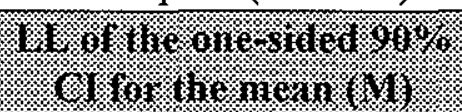 & 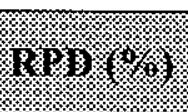 \\
\hline AZ-102 & 0.1132 & 0.0054 & 0.1014 & 6.75 \\
\hline $\mathrm{AZ}-102$ & 0.1079 & 0.0004 & 0.1070 & 0.54 \\
\hline BY-103 & 1.3729 & 0.0125 & 1.3458 & 1.28 \\
\hline BY-103 & 3.0575 & 0.0582 & 2.9308 & 2.69 \\
\hline BY-105 & 0.6909 & 0.0125 & 0.6637 & 2.55 \\
\hline BY-105 & 0.6997 & 0.0166 & 0.6635 & 3.36 \\
\hline S-102 & 2.7429 & 0.3534 & 1.9738 & 18.22 \\
\hline S-102 & 2.2726 & 0.2287 & 1.7749 & 14.23 \\
\hline S-110 & 1.9844 & 0.0208 & 1.9392 & 1.48 \\
\hline S-110 & 2.7518 & 0.0915 & 2.5527 & 4.70 \\
\hline$S-111$ & 2.3372 & 0.0707 & 2.1834 & 4.28 \\
\hline S-111 & 2.4930 & 0.0083 & 2.4749 & 0.47 \\
\hline$S-111$ & 2.2961 & 0.0624 & 2.1603 & 3.84 \\
\hline SY-102 & 0.0967 & 0.0029 & 0.0904 & 4.26 \\
\hline SY-102 & 0.4630 & 0.0087 & 0.4440 & 2.67 \\
\hline SY-102 & 0.4871 & 0.0254 & 0.4319 & 7.36 \\
\hline U-102 & 1.2583 & 0.0832 & 1.0773 & 9.35 \\
\hline U-102 & 1.4082 & 0.0374 & 1.3268 & 3.76 \\
\hline
\end{tabular}

$\mathrm{CI}=$ confidence interval 
HNF-SD-WM-DQO-001, Rev. 3

\section{Compatibility Data}

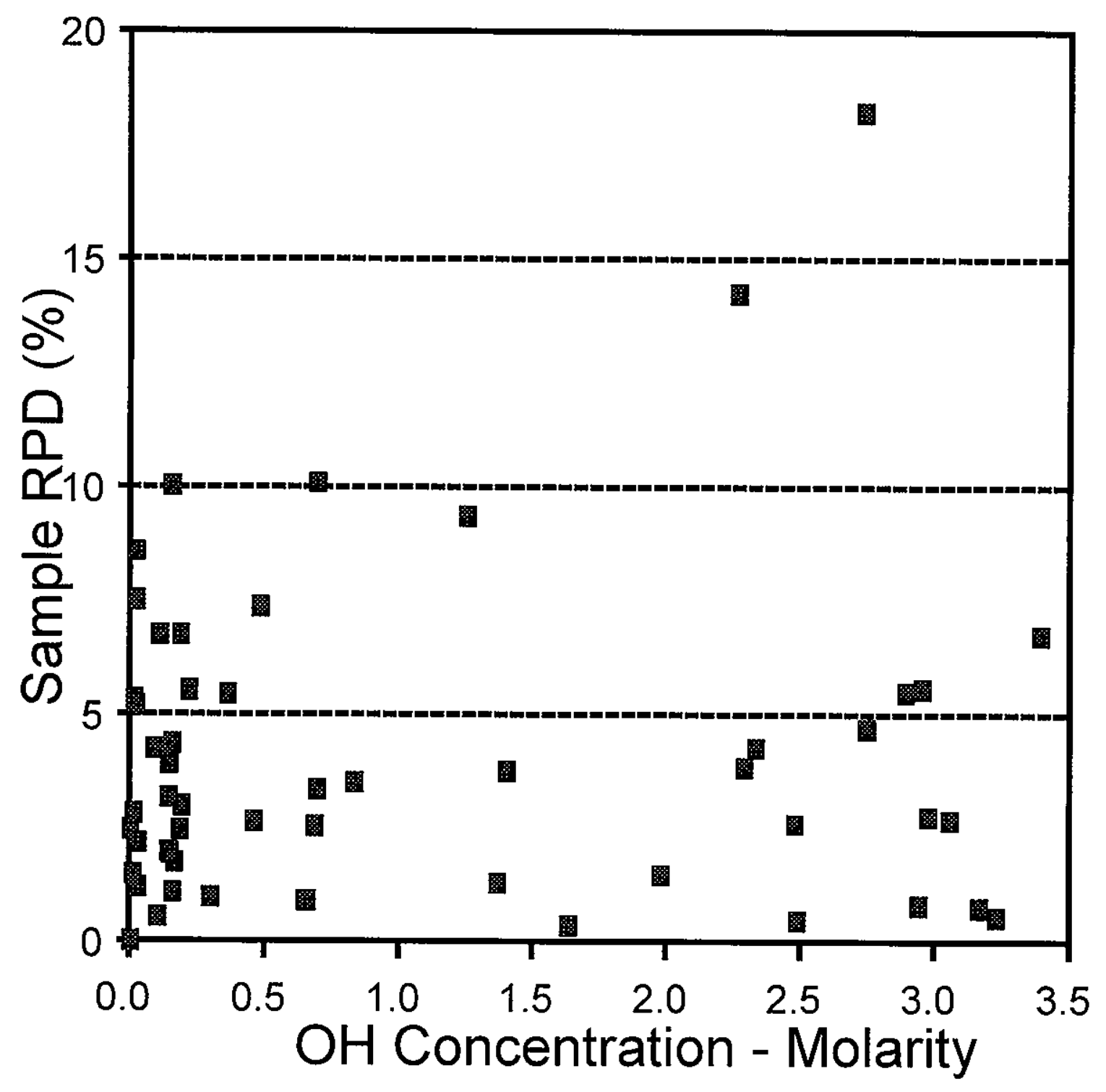




\section{Compatability Data}

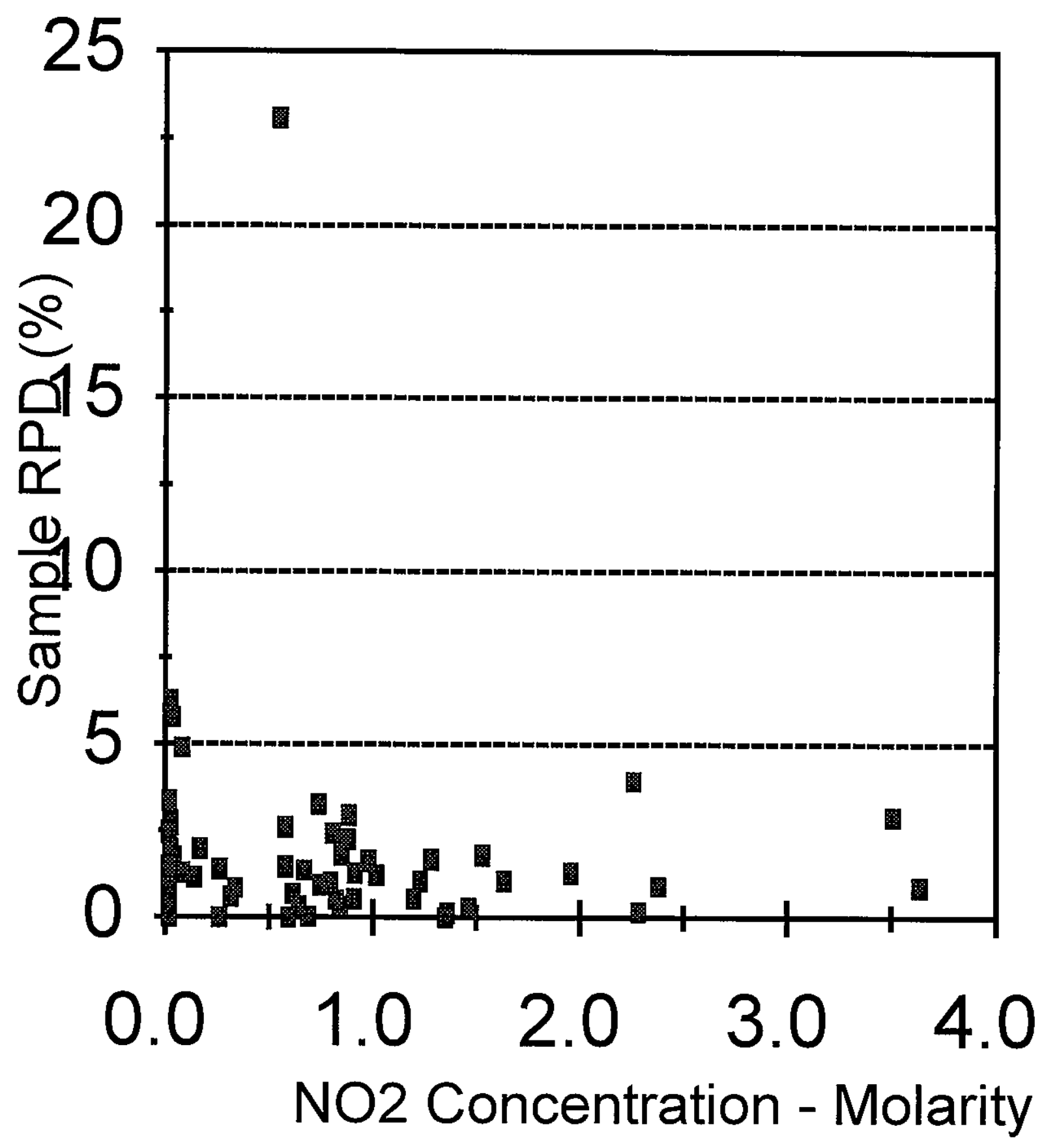


DSC Data - Waste Compatibility Samples with Exotherms

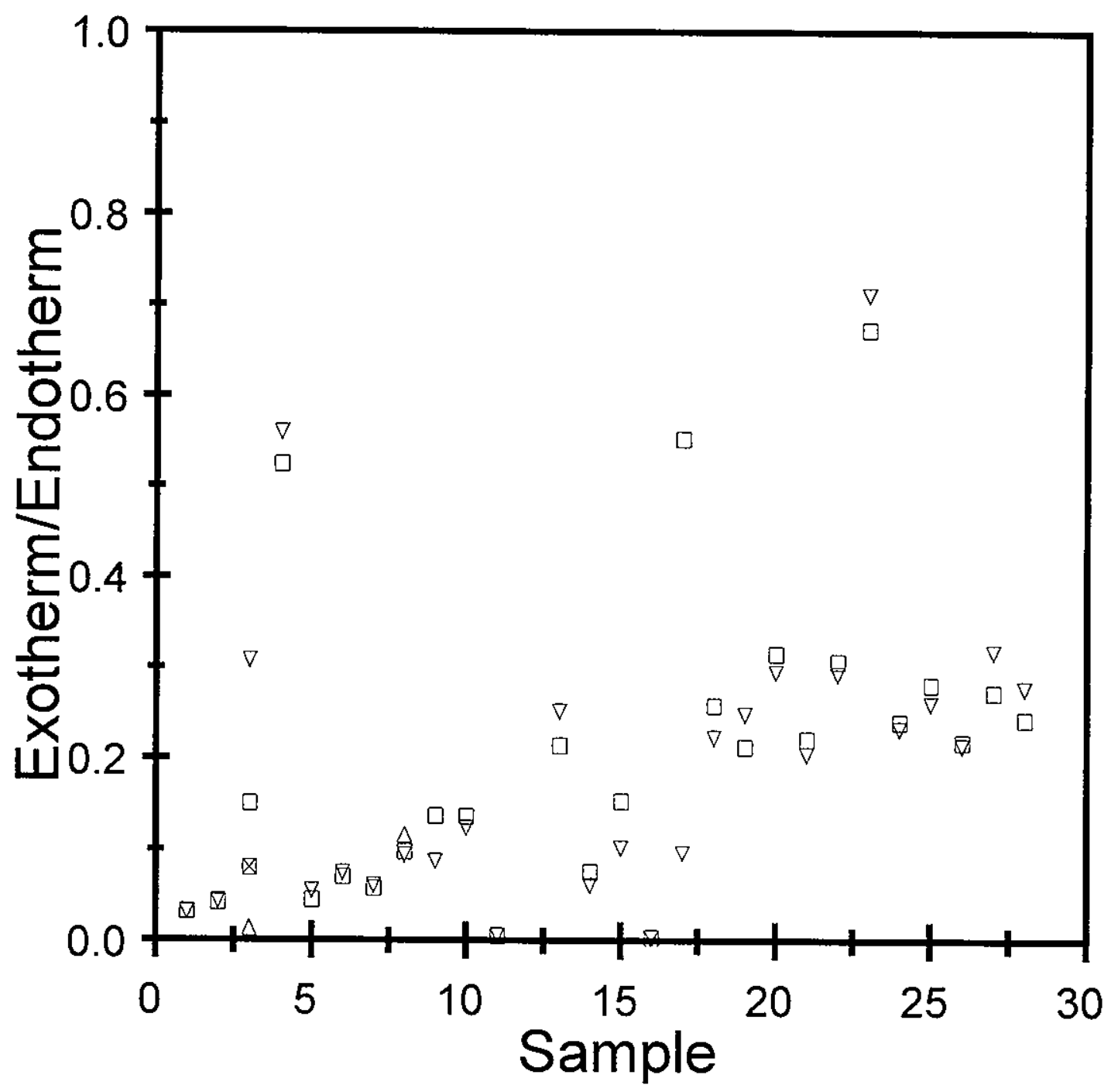

\begin{tabular}{|l|}
\hline $\mathbf{D}$ \\
Run 1 \\
$\boldsymbol{\nabla}$ \\
Run 2 \\
$\Delta$ \\
Run 3 \\
$\mathbf{m}$ \\
Run 4 \\
\hline
\end{tabular}




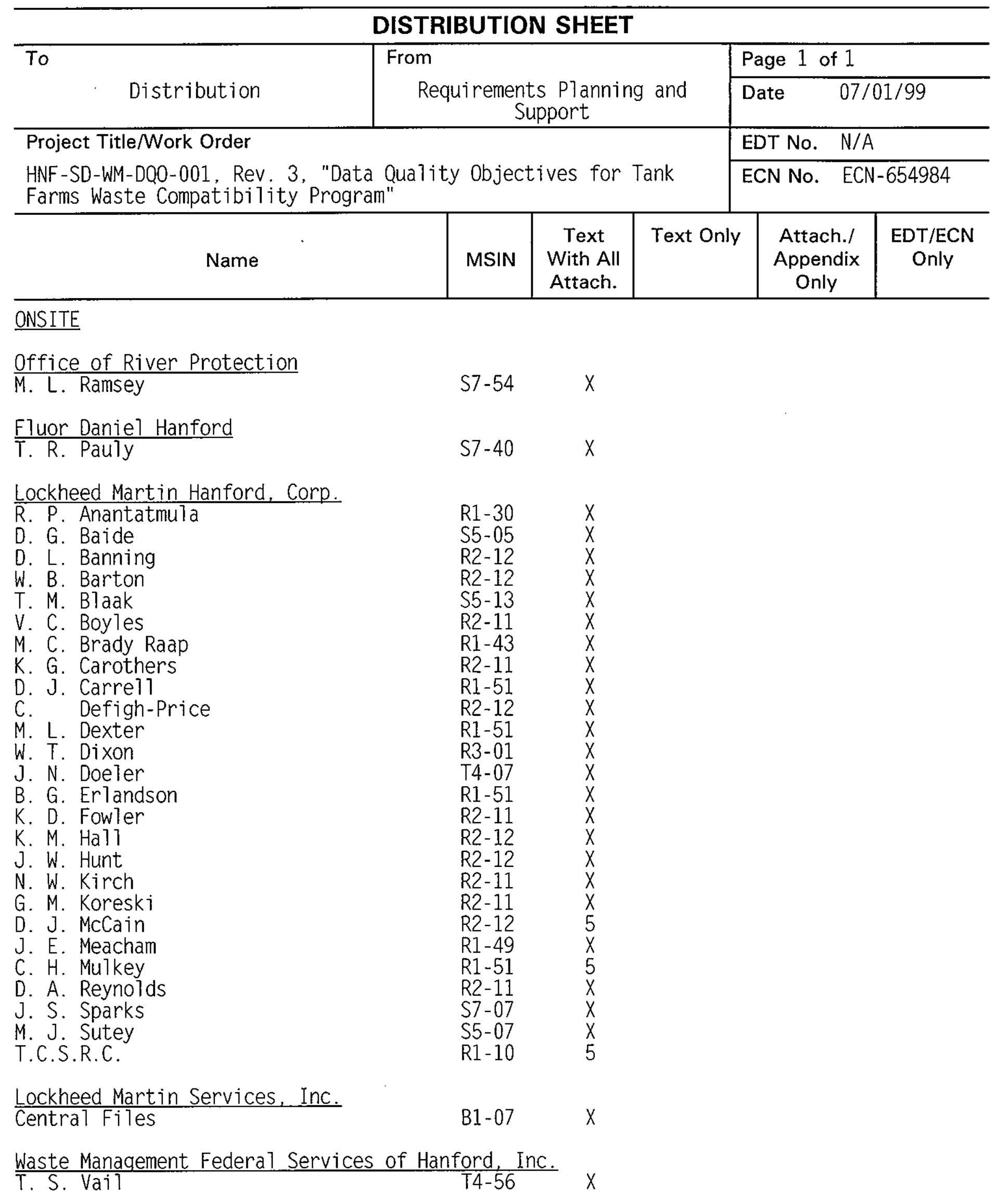

